\title{
AN INVESTIGATION OF RELATIONSHIPS BETWEEN FLOW THEORY AND MUSIC PERFORMANCE ANXIETY
}

\author{
A Dissertation \\ presented to \\ the Faculty of the Graduate School \\ at the University of Missouri Columbia \\ In Partial Fulfillment \\ of the Requirements for the \\ Degree Doctor of Philosophy \\ by \\ LI LI \\ Dr. Wendy Sims, Dissertation Advisor \\ MAY 2019
}


The undersigned, appointed by the dean of the Graduate School, have examined the dissertation entitled

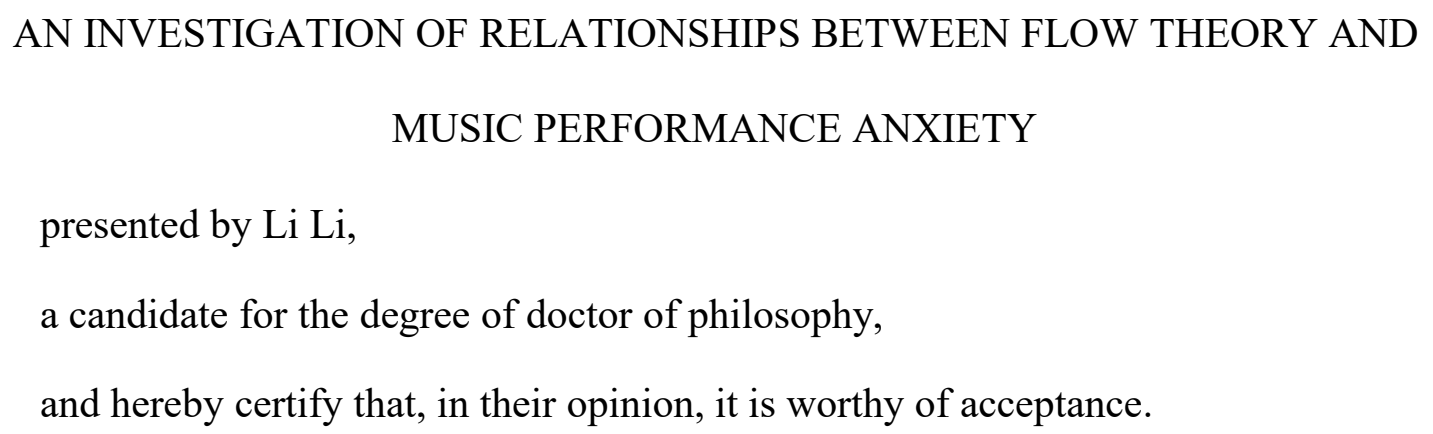

Dr. Wendy Sims

Dr. Brian Silvey

Dr. Brandon Boyd

Dr. Judith Mabary 


\section{ACKNOWLEDGEMENTS}

Thank you to my family and friends for their tireless efforts to support me. I truly appreciate each of you and would not have completed this without you.

Thank you to my advisor, Dr. Sims, for all your help, understanding, and insisting that I finish this degree. I have cherished learning from you and working with you.

Thank you to my committee and other faculty of the College of Education and the School of Music, you really inspired and pushed me. Thank you.

To Dr. Carr: thanks for your assistance, which gave me a lot of confidence in my dissertation.

Thank you to all the wonderful staff of the College of Education and the School of Music for your guidance and help. Thank you so much! 


\section{TABLE OF CONTENTS}

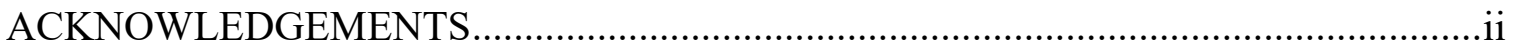

LIST OF ILLUSTRATIONS....................................................................................

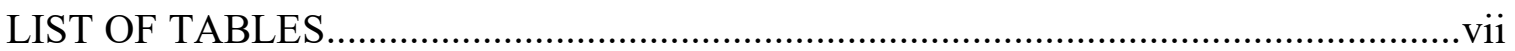

ABSTRACT

CHAPTER ONE

INTRODUCTION

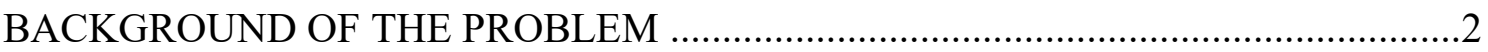

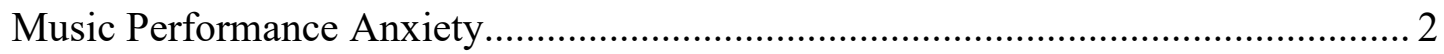

Flow, Optimal Performance, and In the Zone.........................................................

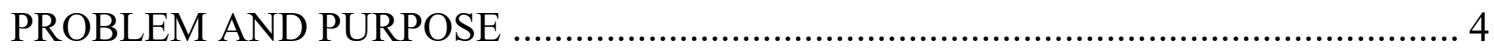

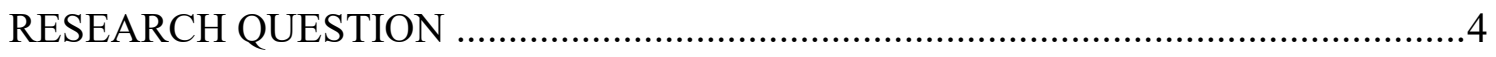

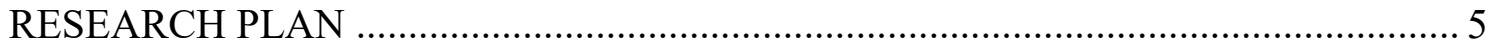

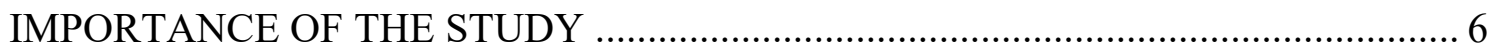

CHAPTER TWO

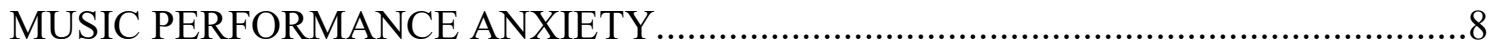

FLOW

RELATIONSHIP BETWEEN FLOW AND MPA...................................................2

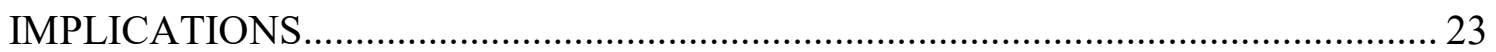

CHAPTER THREE

METHOD

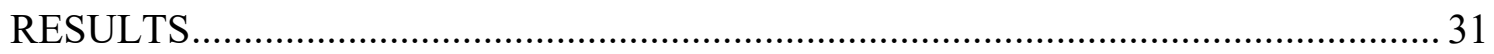

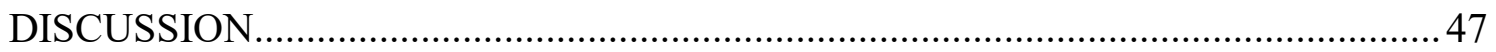




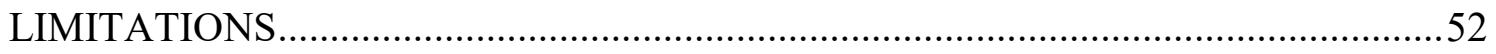

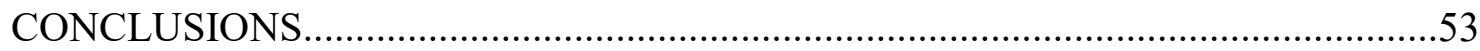

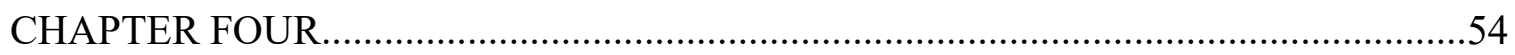

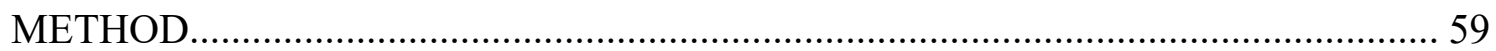

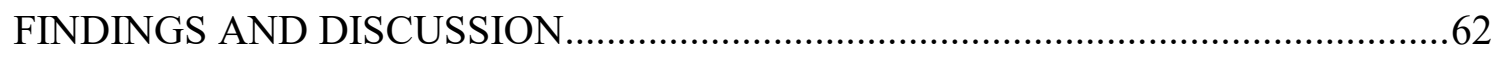

Preparation of Performers.............................................................................

Modeling by Teachers..................................................................................

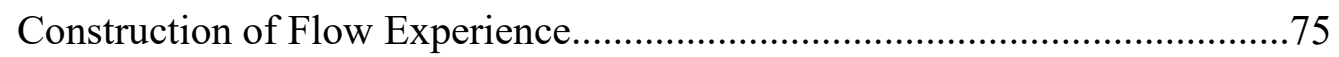

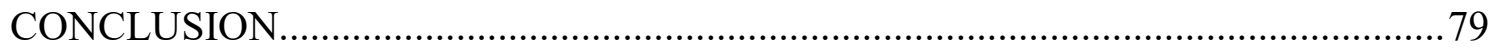

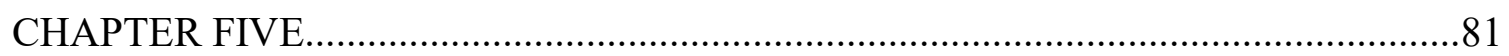

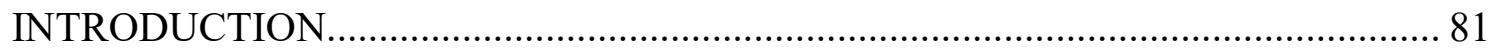

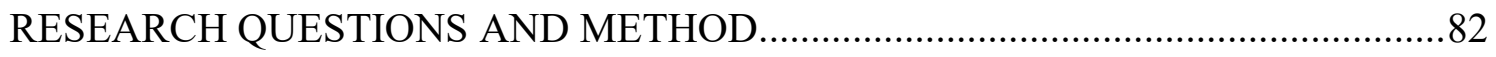

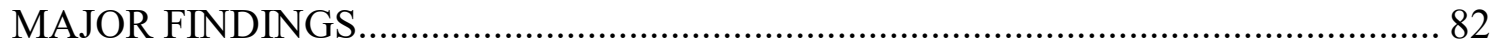

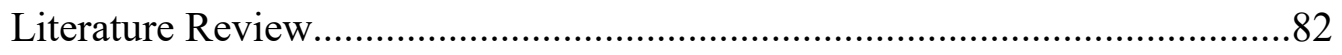

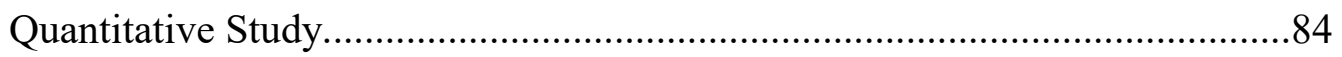

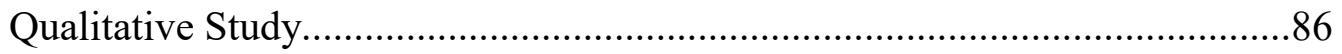

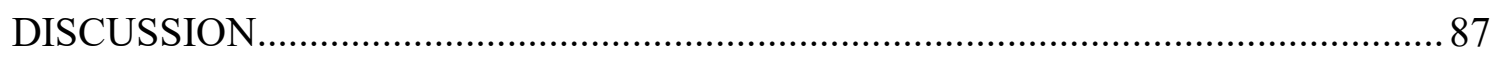

CONCLUSION

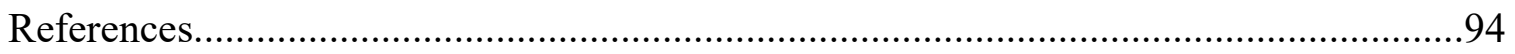

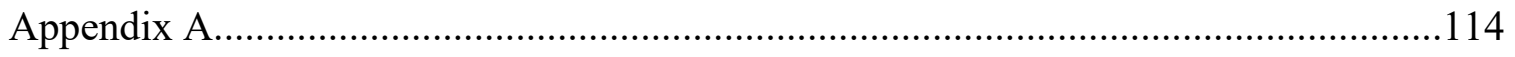

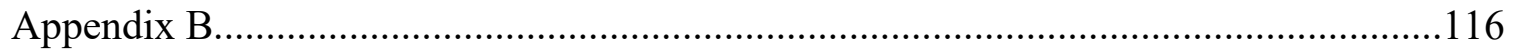

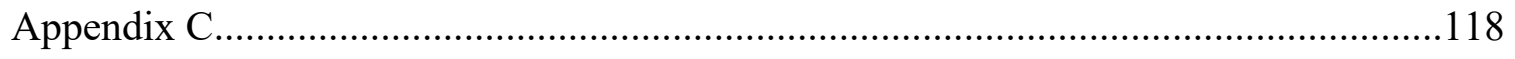

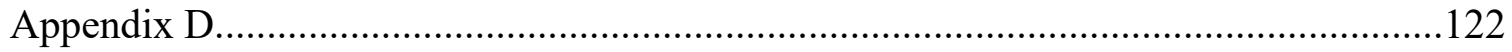




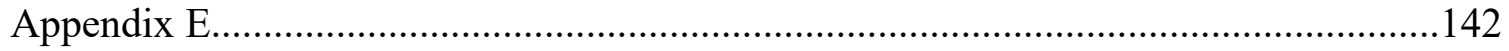

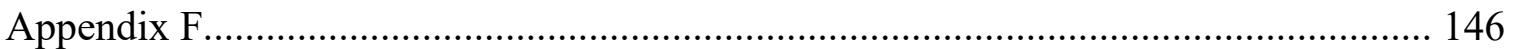

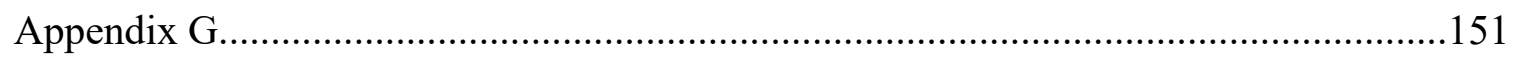

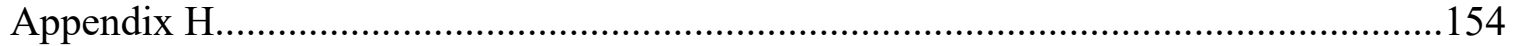

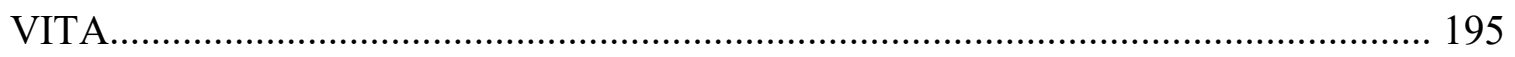




\section{LIST OF ILLUSTRATIONS}

Figures $\quad$ Page

1. Figure 1 Triple Vulnerabilities in the Development of Certain Anxiety Disorders

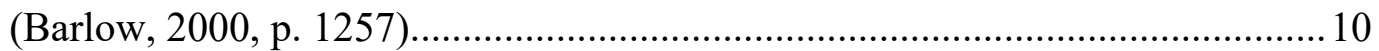

2. Figure 2 Model of the Flow State (Jackson \& Csikszentmihalyi, 1999, p. 37)...... 16

3. Figure 3 Yerkes Dodson Performance Curve (Nagel, 2017, p. 3)......................... 26

4. Figure 4 Gender and Education Ratio of the Participants .................................... 31

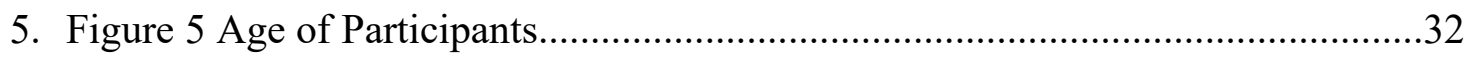

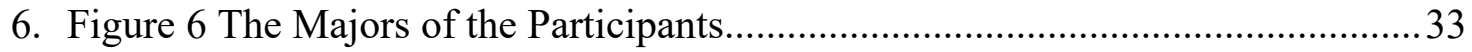

7. Figure 7 Performance Time of the Participants ................................................ 33

8. Figure 8 The Ratio of the Participants' Favorite Performing Form..........................34

9. Figure 9 The Frequency of Participants' Public Performance............................... 35

10. Figure 10 Mental State in terms of Challenge Level and Skill Level, According to Csikszentmihalyi’s Flow Model (Csikszentmihalyi, 1997, p. 31).........................68

11. Figure 11 Facilitating Flow and Reducing MPA Framework..............................71 


\section{LIST OF TABLES}

Tables

Page

12. Table 1 List of MPA Measures (Osborne \& Kenny, 2005). 13

13. Table 2 List of Flow Measures. 20

14. Table 3 Significant Canonical Correlated Coefficient between Factors of MPA and Dimensions of Flow.

15. Table 4 Significant Negative Correlations between Items of Factor One of MPA and Items of Flow.

16. Table 5 Significant Negative Correlations between Items of Factor Two of MPA and Items of Flow.

17. Table 6 Significant Negative Correlations between Items of Factor Three of MPA and Items of Flow

18. Table 7 Significant Negative Correlations between Items of Factor Four of MPA and Items of Flow

19. Table 8 Significant Negative Correlations between Items of Factor Five of MPA and Items of Flow

20. Table 9 Significant Negative Correlations between Items of Factor Six of MPA and Items of Flow

21. Table 10 Significant Negative Correlations between Items of Factor Seven of MPA and Items of Flow.

22. Table 11 Significant Negative Correlations between Items of Factor Eight of MPA and Items of Flow. 
23. Table 12 Significant Negative Correlations between Items of Factor Nine of MPA and Items of Flow.

24. Table 13 Significant Negative Correlations between Items of Factor Ten of MPA and Items of Flow.

25. Table 14 Significant Negative Correlations between Items of Factor Eleven of MPA and Items of Flow 44

26. Table 15 Significant Negative Correlations between Items of Factor Twelve of MPA and Items of Flow 44

27. Table 16 Significant Positive Correlations between Items of MPA and Items of Flow.

28. Table 17 Significant Positive Correlations between Performance Time, Performance Frequency, and Flow .46

29. Table 18 Significant Correlations between Educational Level, Performance Time,

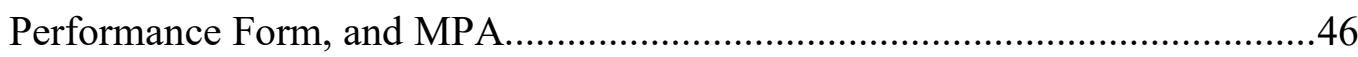

30. Table 19 Participants 60 


\title{
AN INVESTIGATION OF RELATIONSHIPS BETWEEN FLOW THEORY AND MUSIC PERFORMANCE ANXIETY
}

\section{$\mathrm{Li} \mathrm{Li}$}

Dr. Wendy Sims, Dissertation Supervisor

\begin{abstract}
This dissertation comprises three projects designed to investigate the relationship between flow and music performance anxiety and using flow to alleviate music performance anxiety. One investigation is a comprehensive literature review on flow theory and music performance anxiety. The literature review showed that flow and music performance anxiety were negatively correlated, and that facilitating flow can provide a powerful tool to reduce music performance anxiety. The second investigation is a quantitative study aimed to explore relationships between flow and music performance anxiety, which involves seventy-five participants from different music majors and education levels. Data were collected by questionnaires. Results indicated that items from four dimensions of flow (clear goals, unambiguous feedback, autotelic experience, and loss of self-consciousness) were most significantly and negatively correlated with MPA, and that strategies related to these four dimensions items may help to reduce MPA. Gender, age, education level, major, and performance form had no direct impact on flow experience, while performance time and performance frequency were significantly positively correlated with one flow dimension (unambiguous feedback). Educational level was positively correlated, and performance time and performance were negatively correlated, with MPA items. Music performers could benefit by practicing more to
\end{abstract}


prepare for their performances, especially for the soloists. The third investigation is a qualitative study aimed to provide a theoretical framework for facilitating flow and reducing music performance anxiety. Data were collected by seven interviews, and ground theory method was used in the analysis. Based on this analysis, a theoretical framework for facilitating flow and reducing music performance anxiety was generated, which included three themes: preparation of performers, modeling by teachers, and construction of flow experience. 


\section{CHAPTER ONE}

\section{Introduction}

Music performance anxiety (MPA) is the most common and the most serious problem for music performers. Salmon (1990) defined MPA as "the experience of a persisting, distressful apprehension about and/or actual impairment of, performance skills in a public context, to a degree unwarranted given the individual's musical aptitude, training, and level of preparation" (p. 3).

There is a substantial body of MPA research providing evidence that MPA is a debilitating phenomenon (Kenny, 2011). In addition, MPA has been found to be a significant factor in student musicians' experiences of burnout and in decisions not to take performing further (Fehm \& Schmidt, 2006).

A contrasting experience, and differing construct from MPA is flow, or flow theory. Flow is "a state of consciousness where one becomes totally absorbed in what one is doing, to the exclusion of all other thoughts and emotions" (Jackson \& Csikszentmihalyi, 1999, p.5). This has been described as "an optimal and positive state of mind during which individuals are highly motivated and engrossed in an enjoyable activity” (Fullagar, Knight, \& Sovern, 2013, p. 236).

Central to flow theory is that "people place value on the 'optimal experience'-a feeling of being in control of their actions, leading to a deep sense of enjoyment that is long cherished" (Hopkins, 2013, p. 70). Csikszentmihalyi (1992) outlined specific features of flow that may ensure that activities can be rewarding for participants. To achieve a state of flow, "a balance is required between the challenges perceived in a 
given situation and the skills a person brings to that situation" (Csikszentmihalyi, 1991, p. 30).

A few researchers indicated that flow and MPA were negatively correlated (Allison \& Duncan, 1988; Cohen \& Bodner, 2018a; Cohen \& Bodner, 2018b; Fullagar et al., 2013; Kirchner et al., 2008). However, the Yerkes Dodson Law (Yerkes \& Dodson, 1908) supports other existing findings that both MPA and a flow state of consciousness can exist simultaneously (Kirchner et al., 2008). Flow and MPA have been associated with motivation (Nakamura \& Csikszentmihalyi, 2002), emotion (Cohen \& Bodner, 2018a), attention/distraction (Rankin, Walsh, \& Sweeny, 2018; Izard, 1977), happiness (Marin \& Bhattacharya; 2013; Sabino, Camargo, Chagas, \& Osório, 2018), wellbeing (Fritz \& Avsec, 2007; Lamont, 2012), and Musical Emotional Contagion (MEC) (Cohen \& Bodner, 2018a). Findings suggest that flow has positive correlations, and MPA has negative correlations with these factors. Accordingly, facilitating flow may provide a powerful tool for helping to alleviate MPA.

\section{Background of the Problem}

\section{Music Performance Anxiety (MPA)}

Music performance anxiety (MPA) describes "a particular state of arousal, which regularly occurs when musicians present themselves before an audience in performance situations" (Spahn, 2015, p. 129). The incidence of MPA in different fields is quite high, including orchestral musicians (Fishbein, Middlestadt, Ottati, Straus, \& Ellis, 1988), student actors (Andrew et al., 1995), choral singers (Ryan \& Andrews, 2009), pianists (Brooker, 2018), dancers (Walker \& Nordin-Bates, 2010), and non-music majors (Roberson \& Kenny, 2017). 
There are different theories that contribute to the understanding of the

phenomenon of MPA and provide basic principles for various treatment approaches.

From the perspective of psychoanalytic theory, the symptoms of MPA arise from the background of the individual's personal history and are an expression of internal conflicts and motifs, and their related defense mechanisms. Behavioral theories of anxiety provide an important contribution for understanding MPA, particularly through the findings illuminating the development of maladaptive behaviors. Cognitive theories focus on the importance of cognition on behavioral and physical symptoms. Kenny's emotion-based model of MPA presents a current concept, which takes up Barlow's previous work on a triple vulnerability model. Physiological stress models can best explain the physical symptoms of MPA (Spahn, 2015, p. 130-131).

MPA can impair performance in three ways: "disruption of attention leading to interference with normal information processing; off-task production, incompetent or competing behaviors; and behavioral selection effects, such as reducing one's effort or choosing less competent behaviors" (Kenny, 2004, p. 4). Further, MPA is expressed in emotional and physical domains as well as the domains of thinking and behavior (Spahn, 2015). Poor concentration, rapid heart rate, tremor, sweating, and dry mouth were the most commonly reported anxiety symptoms (Wesner, Noyes, \& Davis, 1990, p. 177).

\section{Flow, Optimal Performance and In the Zone}

Researchers state that "flow is a highly coveted yet elusive state of mind that is characterized by complete absorption in a given task as well as enhanced skill performance" (Sinnamon, Moran, \& O'Connell, 2012, p. 6). Although some authors differentiate among "flow," "peak performance", and "optimal performance" (Privette, 1983), others use these terms interchangeably (MacDonald, Byrne, \& Carlton, 2006; Nijs et al., 2012). "Flow also is related closely to the concept of being 'in the zone,' a wellknown phenomenon in sports" (Bloom \& Skutnick-Henley, 2005, p. 25). 
Since Csikszentmihalyi (1975) first proposed the concept of flow, a large volume of research investigating the state of flow in a variety of life settings has occurred (Wrigley \& Emmerson, 2011, p. 294). Extensive research has examined the flow experience in sport and exercise activities, work environments, leisure, educational settings, creative works of artists and scientists, and daily life (Martin \& Jackson, 2008). In sports, although many athletes state that they have being "in the flow," many are unable to shift into this state at will (Csikszentmihalyi \& Csikszentmihalyi, 1988). There have been investigations of flow in music listening, compositions, and music performance (Cohen \& Bodner, 2018a), and this study indicates that flow theory provides positive aspects for music learning.

\section{Problem and Purpose}

There have been large bodies of research on the individual topics of "flow" and "MPA," however, much less research can be found on the combination of these two topics. Kenny (2005) reviewed the treatments of MPA and concluded that "the literature on treatment approaches for MPA was fragmented, inconsistent, and methodologically weak" (p. 206). Accordingly, several studies have suggested that generating a flow state would appear to be one effective way to reduce performance anxiety (Fullagar et al., 2013; Kirchner et al., 2008). However, these studies didn’t give specific strategies on facilitating flow and reducing MPA. Accordingly, the purpose of this dissertation was to explore the relationship between flow and MPA more systematically and to provide a theoretical framework for using flow to alleviate MPA.

\section{Research Question}

The following primary research questions guided my work: What is the 
relationship between flow and MPA? How can we use flow to reduce MPA? I also wished to explore the effects of age, gender, education, major, performance time, performance forms (solo or ensemble) and performance frequency on flow and MPA, respectively. These are variables that have been found to affect one or the other in previous studies.

\section{Research Plan}

In order to answer these research questions, I surveyed the existing literature related to flow, MPA, and the relationship between the two. By synthesizing definitions, causes, effects, measures, and the relationship between these two constructs, I could determine if flow is negatively correlated with MPA and how can we use flow to alleviate MPA. Then, in two separate empirical studies, I explored the relationship between flow and MPA and the strategies for facilitating flow and reducing MPA.

The first investigation is a literature review on the relationship between flow and MPA, which includes MPA (definition, incidence, effects, causes, treatments, and measures), flow (definition, components, conditions, facilitators, inhibitors, challenge/skill balance (CSB), flow in music, flow in young children, effects, and measures), and the relationship between flow and MPA (flow and anxiety, flow and MPA, $\mathrm{CSB}$, and other factors). From the review of the literature, I determined that flow was negatively correlated with MPA while the effects of age, gender, educational level, performance experience, performance forms (solo/ensemble), and performance frequency on flow and MPA needed further investigation.

The second investigation is a quantitative study utilizing assessments for both MPA and flow and determining relationships based on responses from students 
representing different music majors of varying educational levels. The Kenny Music Performance Anxiety Inventory-Revised (K-MPAI-R) (Kenny, 2009) and Activity Flow State Scale (AFSS) (Payne, Jackson, Noh \& Stine-Morrow, 2011) were used to collect data. In addition, the questionnaire asked participants to provide basic demographic information (age, gender, education, performance experience and favorite performance forms). SPSS software was used for statistical analysis of the data. The purpose of this investigation was to confirm the relationship between flow and MPA and determine other variables that may influence flow and MPA.

The third investigation is a qualitative study involving graduate music education students, with data collection by interviews. Grounded theory methodology was used in analyzing and coding data. The purpose of this investigation was to provide a theoretical framework for facilitating flow and alleviating MPA.

The final chapter of this dissertation provides a summary and synthesis of findings and implications for music performance, music teachers and music students. Results and findings make an important contribution to the theory of a relationship between flow and MPA and how to use flow to reduce MPA.

\section{Importance of the Study}

I designed this dissertation to investigate the relationship between flow and MPA in an effort to identify possible ways to use flow to alleviate MPA. It was my goal to be able to provide implications for music performers, teachers, and students, including strategies for alleviating MPA. Accordingly, this dissertation has theoretical and practical meaning for the fields of musical performance and music education. 


\section{CHAPTER TWO}

\section{A Literature Review on Flow and Music Performance Anxiety}

The incidence of Music Performance Anxiety (MPA) in different fields is quite high, and "MPA can affect musicians at any stage of their career: professional performers, amateurs, student musicians, adolescents, and even young elementary school children" (Cohen \& Bodner, 2018a, p. 422). MPA not only can impair the quality of performance but can also affect the music performers' personal life and professional career aspirations (Steptoe, 2001). Therefore, it is necessary to provide more ways to overcome MPA. In recent years, there has been a growing interest in the concept of "flow," the subjective psychological state often associated with "optimal functioning" (Csikszentmihalyi, 1975). Flow is an antidote to uncertainty-related distress (Rankin, Walsh, \& Sweeny, 2018). It starts with simple absorbing moments at one end of a continuum and the defining moments of optimal experience at the other end (Jackson \& Csikszentmihalyi, 1999, p. 13). Both types of experiences may help music performers become more involved in their performance opportunities and may increase joy and satisfaction with the performing experience. In addition, flow is a path to achieve personal growth by developing greater skills in several areas. Flow involves developing physical, psychological, and cognitive skills; taking on increasingly greater challenges; and constantly moving the performer upward in proficiency (Jackson \& Csikszentmihalyi, 1999). Thus, maintaining flow in musical performance may impact music performers' skill development in a variety of domains, which can lead to higher levels of music performance and an enjoyable life experience. 
There have been investigations of flow in music listening, composition, and music performance (Cohen \& Bodner, 2018a), and most of them have indicated that flow theory is positive for different aspects of music learning, such as motivation (Sloboda, 1991), creativity (MacDonald, Byrne, \& Carlton, 2006), selecting high-quality repertoire (Hopkins, 2013), music performance skills and achievement (O'Neill, 1999), and wellbeing (Fritz \& Avsec, 2007). A few studies have indicated that flow is significantly and negatively correlated with MPA and facilitating flow may provide a helpful approach for alleviating MPA (Cohen \& Bodner, 2018a; Cohen \& Bodner, 2018b; Fullagar et al., 2013; Kirchner, Bloom, \& Skutnick-Henley, 2008; Lamont, 2012; Wilson \& Roland, 2002). Accordingly, the purpose of this literature review was to further explore the relationship between flow and MPA respectively through definitions, causes, effects, and measurements and to provide a theoretical basis for using flow to reduce MPA. The following questions guided my exploration: What is MPA? What are MPA's incidence rate, effects, attributions, treatments, and measures? What is flow? What are flow's components, conditions, facilitators, inhibitors, effects, and measures? What is the relationship between flow and MPA?

\section{Music Performance Anxiety}

Music performance anxiety (MPA) is defined as "the experience of a persisting, distressful apprehension about and/or actual impairment of, performance skills in a public context, to a degree unwarranted given the individual's musical aptitude, training, and level of preparation" (Salmon, 1990, p. 3).

The incidence of MPA in different fields is quite high. In professional orchestral musicians, MPA has been shown to be the leading cause of severe medical problems 
(Fishbein, Middlestadt, Ottati, Straus, \& Ellis, 1988). Andrew et al. (1995) studied the impact of stage fright on student actors (178 senior full-time drama students), with "9.6 percent reporting stage fright to be a severe problem, and 36.7 percent considering stage fright to be a moderate problem" (p. 27). A study on choral singers' experience of stage performance anxiety indicated that performance anxiety was a common experience for choral singers: over 50 percent of choral singers reported experiencing anxiety in at least one-half of their performances (Ryan \& Andrews, 2009). In another study, only 4\% of the 195 participants (vocalists, $n=23$; brass players, $n=37$; woodwind players, $n=16$; string players, $n=59$; pianists, $n=40$; miscellaneous, $n=15$ ) rated stage fright as being no problem $(0=$ no problem, $4=$ major problem $)$, whereas levels $1,2,3$ of stage fright were indicated by $25 \%, 40 \%$ and $19 \%$ of participants, respectively, and $12 \%$ indicated that stage fright was a major problem (Level 4) (Studer, Gomez, Hildebrandt, Arial, \& Danuser, 2011, p. 765).

As indicated, MPA can affect musicians at any stage of their career, even young elementary school children (Ryan, 2004; Ryan, 2005). MPA has been reported to have a negative impact on musicians and students' well-being and health (Owen, 2009; Steptoe, 2001). "Psychological and physical symptoms such as shaking, memory slips, insecurity despite excellent preparation, fear of ridicule by an audience that leads to embarrassment and shame, and the worry that 'something must be wrong with me,' has the potential to undermine the best-prepared performer" (Nagel, 2017, p. 1). In addition, it not only can impair the quality of performance (Brotons, 1994; Craske \& Craig, 1984; Fredrikson \& Gunnarsson 1992; Wesner et al., 1990; Yoshie, Kudo, Murakoshi, \& Ohtsuki, 2009), but can lead to avoidance or interruption of performance (Kaspersen \& Gotestam, 2002; 
Wesner et al., 1990) and, thereby, can affect the musicians or students' personal life and professional career (Owen, 2009; Steptoe, 2001; van Kemenade \& van Son, 1995;

Wesner et al., 1990). Therefore, the effect of MPA is serious and it is necessary to provide more ways to overcome MPA.

Barlow's model of anxiety (see Figure 1) explains the probable origins of anxiety and the reasons for its persistence throughout the different stages of a person's life (Barlow, 2000). "This model specifies an integrated set of triple vulnerabilities: a generalized biological vulnerability (genetic contributions), a generalized psychological vulnerability (a diminished sense of control), and a more specific psychological vulnerability (learning what is dangerous)" (p. 1247). Thus, genetic contributions, a diminished sense of control and early learning experiences seem to contribute to feelings of anxiety.

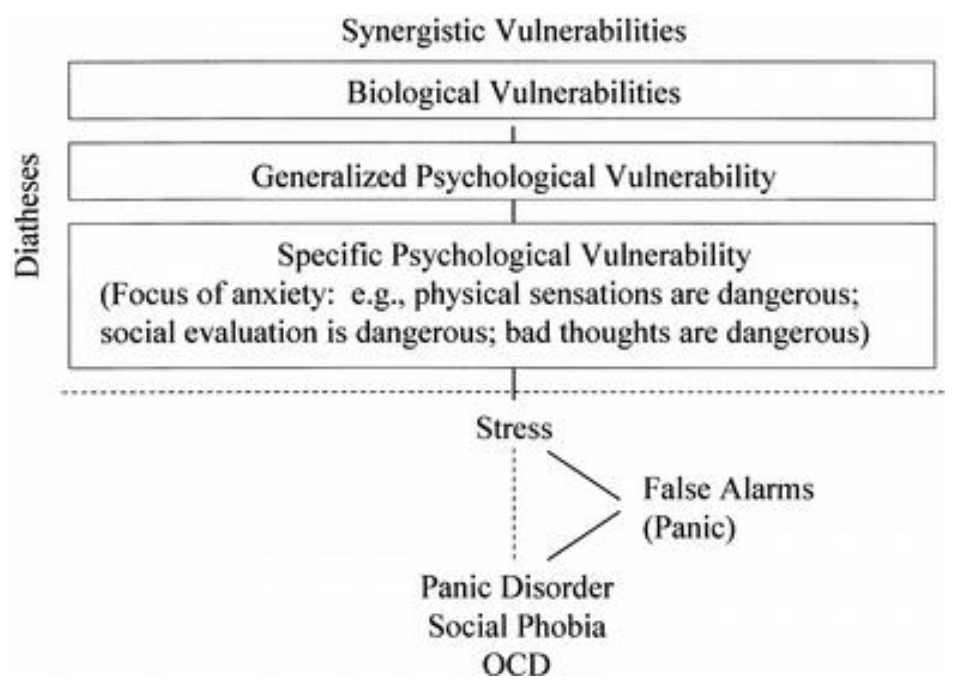

Figure 1. Triple vulnerabilities in the development of certain anxiety disorders (Barlow, 2000, p. 1257)

The factors found to influence MPA in previous studies were either internal or external. Internal attributions include genetics (Kenny, 2006), neuroticism and self- 
statements (Steptoe \& Helen, 1987), gender and extraversion (Andrew et al., 1995), individual differences and personality factors (Hallam, 2002), metacognitive skills, age, expectancy and achievement attributions (Papageorgi, Hallam, \& Welch, 2007), selfefficacy (Eğilmez, 2015; Topoglu, 2014), and perfectionism (Diaz, 2018; Kenny, 2006; Mor, Day, and Flett, 1995). External attributions include life history, previous experiences (Kenny, 2006), family and peers (Hallam, 2002), musical training, occupational stress, preparation, learning approach, pedagogy, task difficulty, audience reactions, performance conditions, conductors (Ryan \& Andrews, 2009), performing experience (Osborne, Kenny, \& Holsomback, 2005), and the situation (Harris, 1986; Michiko, Kazutoshi, Takayuki, \& Tatsuyuki, 2009; Papageorgi et al., 2007; Salmon, Schrodt, \& Wright, 1989).

There are three main kinds of approaches to relieve MPA: behavioral, psychological, and cognitive. Behavioral approaches include progressive muscle relaxation (Grishman,1989; Kim, 2008; Lehrer, 1987; Mansberger, 1988), insight relaxation and systematic desensitization techniques (Wardle, 1969), awareness and breathing techniques (Deen, 1999; Robertson \& Eisensmith, 2010), pre-performance routines, anxiety hierarchy, supportive lifestyle habits (Parncutt \& McPherson, 2002), some aspects of the Alexander Technique (AT) ${ }^{1}$ (Valentine, Fitzgerald, Gorton, Hudson, \& Symonds, 1995), drugs (Wills \& Cooper, 1988), yoga (Jensen \& Kenny, 2004), and Tai Chi (Lehrer, 1987). Psychological approaches mainly include self-hypnosis (Lehrer, 1987), imagery treatment (Kim, 2008), and exposure therapy (Spahn, 2011). Cognitive approaches include attention training, "Stress Inoculation Training" (SIT), which refers to

\footnotetext{
${ }^{1}$ Alexander Technique (AT) is characterized as a form of kinesthetic reeducation that uses a mixture of verbal instructions and hands-on demonstration to correct postural misuse (Parncutt \& McPherson, 2002, p. 54-55).
} 
a set of procedures to help people under stress become aware of the source of the stress, develop effective coping skills, and put those skills into daily practice (Salmon \& Meyer, 1992); mindfulness (Diaz, 2018), rehearsal behavior, viewing anxiety as positive (Hanton \& Jones, 1999; Roland, 1992), positive self-talk (Seligman, 1995), mental rehearsal and imagery (Murphy \& Jowdy, 1992), and goal setting (Burton, 1992).

Some Chinese researchers posited that performers could reduce their MPA through their environment, themselves, and their skills. Environmental aspects included creating an easy environment, rehearsal, adaptive training, public practice, and clothing preparation (advance preparation); performer aspects included self-confidence, selection of appropriate works, strengthening artistic accomplishment, inner visual imaging, accumulated stage experience, using hints, self-regulation, and hard work; skills aspects included using correct methods of practice, understanding the connotation of the work, improving basic skills, re-recognizing and re-memorizing notation before going on stage (Li, 2015).

"A review of the English-language literature using PsycINFO and MUSE databases identified twenty MPA self-report measures published in peer-reviewed journals" (Osborne \& Kenny, 2005, p. 727). The total list is shown in Table 1. 
Table 1

List of MPA Measures in Chronological Order of Publication

\begin{tabular}{lll}
\hline Abbreviation & \multicolumn{1}{c}{ Measure } & \multicolumn{1}{c}{ Citation } \\
\hline PRCP & Personal Report of Confidence as a Performer & Appel (1976) \\
PASSS & Performance Anxiety Self-statement Scale & Kendrick, Craig, Lawson, and \\
& Davidson (1982) \\
AATS & Achievement Anxiety Test Scale & Sweeney and Horan (1982) \\
AD & Anxiety Differential & Sweeney and Horan (1982) \\
PPAS & Piano Performance Anxiety Scale & Sweeney and Horan (1982) \\
SFRS & Stage Fright Rating Scale & Neftel et al. (1982) \\
SES & Self-efficacy Scale & Craske and Craig (1984) \\
SSQ & Self-statement Questionnaire & Steptoe and Fidler (1987) \\
MQ & Musician's Questionnaire & Wills and Cooper (1988) \\
PAI & Performance Anxiety Inventory & Nagle, Himle, and Papsdorf (1989) \\
MPAS & Music Performance Anxiety Scale & Wolfe (1989) \\
AAS-MAS & Adaptive-Maladaptive Anxiety Scale & Wolfe (1989) \\
MPAQ & Music Performance Anxiety Questionnaire & Lehrer, Goldman, and Strommen \\
TAS & Trait Anxiety Scale & (1990) \\
PAQ-CK & Performance Anxiety Questionnaire-CK & Wolfe (1990) \\
MPSS & Music Performance Stress Survey & Brodsky, Sloboda, and Waterman \\
& & (1994) \\
PAQ-WND & Performance Anxiety Questionnaire-WND & Brodsky et al. (1994); Wesner er al. \\
PI & Performance Inventory & (1990) \\
SEQ & State Emotion Questionnaire & Kubzansky and Stewart (1999) \\
K-MPAI & Kenny-Music Performance Anxiety Inventory & Kubzansky and Stewart (1999) \\
K-MPAI-R & Kenny-Music Performance Anxiety Inventor- & Kenny (2009) \\
\hline
\end{tabular}

Only the Kenny-Music Performance Anxiety Inventory (K-MPAI), Personal Report of Confidence as a Performer (PRCP) and Performance Anxiety Inventory (PAI) assess all three components — cognitive, behavioral and physiological—that are now commonly believed to comprise MPA and other anxiety disorders (Osborne \& Kenny, 2005, p. 727). The K-MPAI was developed to assess the relevance to MPA in the emotion-based theory of anxiety proposed by Barlow (2000). Thus, items for the inventory were either specially constructed or selected from other scales to address each of Barlow's theoretical components, including evocation of anxious propositions, 
attentional shift, physiological arousal and memory bias (Kenny \& Osborne, 2006, p.

104-105). In 2009, Kenny revised this inventory using a sample $(\mathrm{n}=151)$ of music and dance students. The new scale (K-MPAI-R) consists of 40 items that assess the factor structure of the revised and expanded K-MPAI.

Principal component analysis of the K-MPAI-R revealed three latent factors and 12 underlying factors, as follows: early relationship context comprising generational transmission of anxiety and parental empathy; psychological vulnerability comprising controllability, depression, hopelessness, and trust; and proximal performance concerns comprising somatic anxiety, pre- and post-performance rumination, self/other scrutiny, performance outcome concerns, memory reliability, and commitment to performance. (Kenny, 2009, p. 37).

A few authors have used physiological measures to test MPA. LeBlanc, Jin, Obert, and Siivola (1997) used two Polar Vantage XL heart-rate monitors with high school band students to record each participant's heart rate during music performance as a way of testing their MPA. They found that female participants had significantly higher heartrates during performance than did the males. Tartalone (1992) studied the physiological arousal and perceived state anxiety of 39 college music majors who were preparing for brass jury recitals. "Blood pressure, heart rate, and respiration rate all showed a distinct rise at the time of dress rehearsal and at the jury performance" (LeBlanc et al., 1997, p. 482).

\section{Flow}

Flow is a state of profound task-absorption, cognitive efficiency, and intrinsic enjoyment that makes a person feel one with the activity in which she/he is involved (Moneta, 2004, p. 115). Csikszentmihalyi has identified nine dimensions of flow, including: challenge/skill balance (CSB), merging of action-awareness, clear goals, 
unambiguous feedback, concentration on the task at hand, sense of control, loss of selfconsciousness, autotelic experience, and time transformation (Csikszentmihalyi, 1994).

Achieving flow requires several conditions: the presence of perceived challenges, or opportunities for action that stretch (without overextending) existing skills, and clear, proximal goals coupled with immediate feedback on one's progress (Nakamura \& Csikszentmihalyi, 2002, p. 90). Jackson (1992) provided some ways to facilitate flow based on these dimensions: "positive mental attitude, positive pre-competitive and competitive affect, maintaining appropriate focus, physical readiness and for some pairesldance skaters, unity with partner" (p. 161).

Barriers to achieving flow are primarily physical and mental. Physical barriers include time, money, commitment/responsibility, and illness/disease/health problems. Mental barriers include feelings of inadequacy, fear of others, fear of failure, comparison to others, and negative beliefs (Flow State Philosophy, 2017). Two impediments of flow that concern the subject construction of experience include preference for relaxation versus flow and attitudes towards work and play (Nakamura \& Csikszentmihalyi, 2014, p. 97-98).

A critical characteristic of flow can be described as the challenge/skill balance (CSB). CSB involves a perceived high level of skill, ability to act, or capacity to meet challenges (Flett, 2015).

The "flow" quadrant (in Figure 2) illustrates CSB, and it is under this optimal condition that the experience of flow typically occurs. The top left quadrant is called "anxiety", which describes the feeling one tends to have when challenges are perceived to be higher than one's skill. "Boredom" in the bottom right, is the result of high skills and low challenges. People are likely to experience "apathy" in situations where neither skills nor challenges are present to a significant level, creating a feeling of low energy, boredom, and a lack of attention (Jackson \& Csikszentmihalyi, 1999, p. 36). 


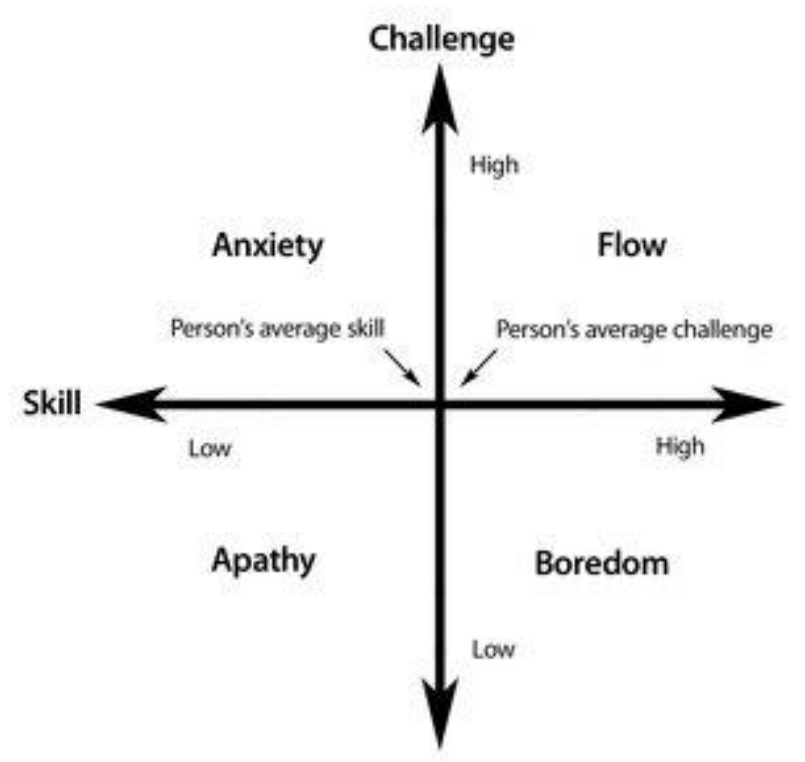

Figure 2. Model of the flow state (Jackson \& Csikszentmihalyi, 1999, p. 37)

In recent years, investigations of flow in the domain of music have become more frequent. Carter, River, and Sachs's study (2012) indicated that music and flow have a positive relationship on performance, with asynchronous motivational music correlated to higher flow states within study participants. The key finding of Sinnamon, Moran, and O'Connell (2012) was that the way in which flow was experienced by musicians did not differ from the experience of flow in athletes. "It may well be that many of the highly formalized approaches to training and self-control devised by sports psychologists with highly specific physical activities in mind, turn out to be partially applicable to the performance of music" (p. 21). This study also indicated that the Dispositional Flow Scale-2 (DFS-2) (Jackson and Eklund, 2002) was a generally reliable and factoriallysound measure of flow, but the results also raised questions about the validity of certain subscales of this test (e.g., merging of action and awareness and loss of selfconsciousness) (p. 6). 
Young children's flow experience was examined in four naturally-occurring music learning environments: infants and two-year-olds in childcare settings, and schoolage children in Suzuki violin and Dalcroze classes (Custodero, 2005, p. 185). Key findings include "an age-related increase in observed self-assignment, which declined in children of school age" (p. 185). Also, "the accessibility and responses to musical structure for infants and toddlers, the role of gesture in helping children focus, the salience of adult awareness and the changing roles of peers across development" (p. 185). Custodero (2002) suggested that teachers should be careful observers of cues from the children, stating that, "Children actively seek musical challenges and in doing so guide teachers in designing appropriate strategies to assist in the acquisition of musical skill" ( $p$. 8).

The peak experience of flow was examined among 178 music teachers and 605 students from 16 different music schools, from the results, researchers determined that flow may cross over from teachers to their students (Bakker, 2005). Bloom and SkutnickHenley (2005) identified five key predictors of flow proneness among ninety adult classical instrumental musicians:

Self-confidence and self-trust while playing; desire to experience and express feelings through music; having experience goals; ability to maintain focus on the music; ability to play without self-criticism. Interestingly, this study also indicated that flow experiences tended to occur more often in small ensemble situations than when playing alone while gender, age, experience, and proficiency levels showed no direct impact on flow proneness (p. 26).

In addition, another study of elite and amateur students indicated that experiences of flow were very common among the musician participants, $95 \%$ of the elite students ("following a number of years of learning an instrument, were studying music performance on a full-time basis, with the aim of pursuing a professional career in music") 
(Sinnamon et al., 2012, p. 10) and 87\% of amateur students ("studying music in their spare time, were still at school, were not aiming to become professional musicians, engaged in a number of musical activities in the conservatory, and were between Grades 1 and 8 of official music examination standards") (p. 10) reported experiencing flow frequently.

Some studies have indicated that flow theory is positive for music learning. Sloboda (1991) found that adults who described having had peak experiences with music before the age of about ten were more likely to pursue involvement with music later in life. MacDonald et al. (2006) investigated the relationship between flow and creativity in musical composition and found positive relationships: increased levels of flow were related to increased levels of creativity (p. 300). Hopkins (2013) did a study on selecting high-quality repertoire that matched the musical and technical levels of ensembles based on Vygotsky's Zone of Proximal Development (ZPD) and Csikszentmihalyi's CSB. Vygotsky (1978) described ZPD as "the distance between the actual developmental level as determined by independent problem solving and the level of potential development as determined through problem solving under adult guidance, or in collaboration with more capable peers" (p. 38). Hopkins (2013) provided seven strategies for choosing the right pieces based on flow theory:

1) Establish the musical achievement level of the individual students in your ensemble, 2) familiarize yourself with the grading systems used by different organizations, 3 ) create a folder with a selection of graded literature ranging from very, very easy to difficult and have sight-reading days, 4) don't perform every piece that you sight-read, 5) divide rehearsal into a skill development portion and a repertoire rehearsal portion, 6) ask yourself these "reality check" questions (e.g., will my ensemble be able to perform the piece at the tempo indicated in the score?), and 7) do an assessment and reflection after the performance (p.72-73). 
In addition, O'Neill (1999) used flow theory to examine motivational and social factors associated with young musicians' development of musical performance skills concurrent with, and in the context of, their everyday life experiences. The results indicated that "high achievers at a music school and students at a non-specialist school reported more 'flow' experience when practicing than the moderate achievers at the music school' (p. 129). Through studying eighty-four students at the Academy of Music of Ljubljana, Fritz and Avsec (2007) concluded that "experiencing flow is more related to emotional than to cognitive aspects of subjective well-being" (p. 5).

Several self-report tools have been fashioned to study flow, including interviews, questionnaires, and the Experience Sampling Method (ESM) (Nakamura \& Csikszentmihalyi, 2014). The semi-structured interview was a "critical tool in initially identifying and delineating dimensions and dynamics of flow experience" (Nakamura \& Csikszentmihalyi, 2014, p. 93). Questionnaires have been used "when the goal is to measure dimensions of flow experience and/or differences in its occurrence across contexts or individuals" (Nakamura \& Csikszentmihalyi, 2014, p. 93).

The ESM is an attempt to provide a valid instrument to describe variations in self-reports of mental processes, which can be used to obtain empirical data on three types of variables: frequency and patterning of daily activity, social interaction, and changes in location; frequency, intensity, and patterning of psychological states, i.e., emotional, cognitive, and conative dimensions of experience; and frequency and patterning of thoughts, including quality and intensity of thought disturbance (Csikszentmihalyi \& Larson, 2014, p. 35).

The nine most used scales of flow in the current literature are shown in Table 2. 
Table 2

List of Flow Measures in Chronological Order

\begin{tabular}{lll}
\hline Abbreviation & \multicolumn{1}{c}{ Measure } & \multicolumn{1}{c}{ Citation } \\
\hline FSS & Flow State Scale & Jackson and Marsh (1996) \\
DFS & Dispositional Flow Scale & Jackson and Marsh (1996) \\
WOLF & WOrk-reLated Flow inventory & Bakker (2001) \\
FSS-2 & Flow State Scale-2 & Jackson and Eklund (2002) \\
DFS-2 & Dispositional Flow Scale-2 & Jackson and Eklund (2002) \\
SF & Short Flow & Martin and Jackson (2008) \\
CF & Core Flow & Martin and Jackson (2008) \\
SFPQ & Swedish Flow Proneness Questionnaire & Ullén et al. (2012) \\
AFSS & Activity Flow State Scale & Payne et al. (2011) \\
\hline
\end{tabular}

These measures have been developed and validated largely in physical activity and elite sports settings but have not been used widely in other performance domains (Sinnamon et al., 2012). Jackson and Marsh (1996) devised two complementary instruments - the Flow State Scale (FSS) and the Dispositional Flow Scale (DFS) known together as the Flow Scales (Jackson \& Eklund, 2002).

"The FSS was designed to be answered after a specific event to assess the experience of flow in that event, and the DFS was designed to assess the frequency with which respondents report experiencing flow, in general, during participation in their main activity" (Horn, 2008, p. 395).

To develop multidimensional measures that would reflect all nine flow dimensions rather than focusing primarily on the challenge-skill balance (CSB) ratio, Jackson and Eklund (2002) revised the FSS and DFS scales and gave them new titles (FSS-2 and DFS-2). The FSS-2 and DFS-2 demonstrated acceptable factorial validity for assessing dispositional and state flow, respectively.

The WOrk-reLated Flow scale (WOLF) (Bakker, 2001) was used to measure flow of music teachers and students. "The WOLF includes 13 items measuring absorption (4 items), work enjoyment (4 items) and intrinsic work motivation (5 items)" (Bakker, 2005, 
p. 32). The Swedish Flow Proneness Questionnaire (SFPQ) (Ullén et al., 2012) consists of three subscales: work (if the participant worked), leisure, and maintenance, and was used in the study of music practice (Butkovic, Ullén, \& Mosing, 2015, p. 135).

To expand current approaches to assessing task absorption and subjective experience, Martin and Jackson (2008) tested two brief measures of flow across the diverse performance domains of work, sports, music, and school in relation to motivation and engagement correlates through assessing "short" flow and "core" flow. "Short" flow reflects an aggregate or global measure drawn from the "long" multi-item multi-factor flow instrument and "core" flow captures the central subjective flow experience (p. 141).

In 2011, Payne, Jackson, Noh, and Stine-Morrow tested the validity of another flow scale, the Activity Flow State Scale (AFSS), for use in assessing the flow state across different activities and within a population of older adults. The AFSS contained 26 items representing each of the nine dimensions of flow. "The majority of items were adapted from Jackson's FSS. Items that did not translate well from the domain of physical activities to general activities were removed or replaced with items adapted from other flow measures" (Payne et al., 2011, p. 3).

\section{Relationship between Flow and Music Performance Anxiety}

Previous researchers have indicated that flow and anxiety are negatively correlated. Anxiety is an important component of the antiflow state, which is the experience of either boredom or anxiety (Allison \& Duncan, 1988). Thus, felt anxiety during performance of a task may suppress the experience of flow (Fullagar et al., 2013, p. 240). Physiologically, the state of extreme arousal generated by anxiety has been found to be associated with "disintegrated" attention rather than the focused attention that is 
characteristic of flow (Izard, 1977). A study of flow and anxiety in athletes (John \& Nicola, 2016) found a greater increase in mindfulness from baseline to post-test and was associated with increased flow and decreased pessimism. Also, "increases in flow were associated with decreases in somatic anxiety and pessimism" (John \& Nicola, 2016, p. 99).

Flow proneness was found to be significantly and negatively correlated with MPA (Kirchner et al., 2008, p. 59). MPA provides a relevant, task-appropriate construct for examining the relationship between anxiety and flow in the current research. When flow was highest, MPA was lowest, and vice versa (Fullagar et al., 2013, p. 236). Cohen and Bodner (2018a) found that there was a strong negative relationship between flow and MPA and concluded that facilitating flow may provide a helpful approach for alleviating MPA. In addition, flow may predict long-term motivation and achievement in music performing, while MPA has been related to negative elements of music performing. MPA symptoms are created by the autonomic nervous system's response to perceived threat and include physiological symptoms like increased heart rate/pounding chest, excessive sweating, dry mouth, nausea, trembling hands, and cognitive symptoms such as loss of concentration and negative thoughts about the performance (Lamont, 2012, p. 576).

Wilson and Roland's study (2002) showed that flow has occasionally been referred to as a desirable state that may help reduce MPA.

Both flow and MPA were associated with challenge/skill balance (CSB) (Fullagar et al., 2013). Two techniques can quantify flow experiences; the first, and most established method, is based on the four-channel model (Csikszentmihalyi, 1988). This approach splits each of the ratings into two levels (e.g., high and low). The perceived 
challenges match the perceived skills is flow; On the other hand, anxiety is experienced when challenge far exceed skills (Fullagar et al, 2013, p. 237).

Flow and MPA have been associated with motivation (Nakamura \& Csikszentmihalyi, 2002), emotion (Cohen \& Bodner, 2018a), attention/distraction (Izard, 1977; Rankin, Walsh, \& Sweeny, 2018), happiness (Marin \& Bhattacharya, 2013; Sabino, Camargo, Chagas, \& Osório, 2018), wellbeing (Fritz \& Avsec, 2007; Lamont, 2012), and Musical Emotional Contagion (MEC) (Cohen \& Bodner, 2018a). Findings suggest that flow has positive correlations and MPA has negative correlations with these factors. Accordingly, facilitating flow may provide a powerful tool for helping to alleviate MPA.

\section{Implications}

Flow may cross over from teachers to their students: teachers' flow experience partly correlate with those of the students (Bakker, 2005, p. 35). This suggests that music teachers who are positive, motivated, and cheerful in their music teaching play an important role in demonstrating and modeling and can also play an important role by selecting suitable music for their students to address CSB and provide scaffolding opportunities (Bakker, 2005). In addition, music teachers can share their own flow experience with their students and explain how they personally facilitate flow in their performing.

To thoroughly connect flow and MPA, their interrelationships must be clearly elucidated through continued theory refinement (e.g., CSB, ZPD). Several factors related to flow and MPA deserve further study, such as motivation, attention, and confidence. Flow experience has high levels of motivation, attention, and confidence, while MPA has low levels of these factors, thus, studying these factors can help to provide more specific 
strategies on using flow to reduce MPA. Additionally, while the nine components of flow referenced earlier can lead to positive flow results, these effects on MPA need further study.

Based on this review of the literature, it should be evident that flow and MPA present as two opposite experiences, yet facilitating flow may help to reduce MPA. However, the current body of literature does not provide specific strategies for using flow to reduce MPA. Thus, future studies are needed in this regard.

Finally, various research methods should be applied in future studies on the relationship between flow and MPA. For example, mixed methods or qualitative studies could provide multiple types of data on this topic. Previous research has focused on quantitative methodology. 


\section{CHAPTER THREE}

\section{Examining the Relationship between Flow and Music Performance Anxiety}

Results of previous research have indicated that flow and anxiety are negatively correlated. Anxiety is an important component of the antiflow state (Allison \& Duncan, 1988). Physiologically, the state of extreme arousal generated by anxiety has been found to be associated with "disintegrated" attention rather than the focused attention that is also a characteristic of flow (Izard, 1977). A study of flow and anxiety in athletes also showed greater increase in mindfulness from baseline to post-test and an association with increased flow and decreased pessimism. Increases in flow were associated with decreases in somatic anxiety and pessimism (John \& Nicola, 2016).

Flow proneness was found to be significantly and negatively correlated with music performance anxiety (MPA) (Kirchner, Bloom, \& Skutnick-Henley, 2008). MPA provides a relevant, task-appropriate construct for examining the relationship between anxiety and flow in current research. When flow was highest, music performance anxiety was lowest and vice versa (Fullagar, Knight, \& Sovern, 2013, p. 236). Cohen and Bodner (2018a) found that flow may predict long-term motivation and achievement in music performing, while MPA has been associated with negative elements of music performing. Findings from Wilson and Roland's study (2002) showed that flow has occasionally been referred to as a desirable state that may help reduce music performance anxiety.

Both flow and MPA were associated with challenge/skill balance (CSB) (Fullagar et al., 2013). The four-channel model of flow in Chapter 2, Figure 2 (Csikszentmihalyi, 1988) is often simplified to disregard apathy, boredom, and anxiety and present flow as a

dichotomous outcome: in or out of flow (Fleet, 2015). Csikszentmihalyi's theory of flow 
has several implications for predicting task-specific performance anxiety and its effect on flow. Flow and task-specific anxiety (including MPA) are incompatible states corroborated by recent research on the physiology of flow (Ullén, de Manzano, Theorell, \& Harmat, 2010).

The Yerkes Dodson Law (Figure 3) illustrates a relationship between arousal/anxiety and performance level (Yerkes \& Dodson, 1908).

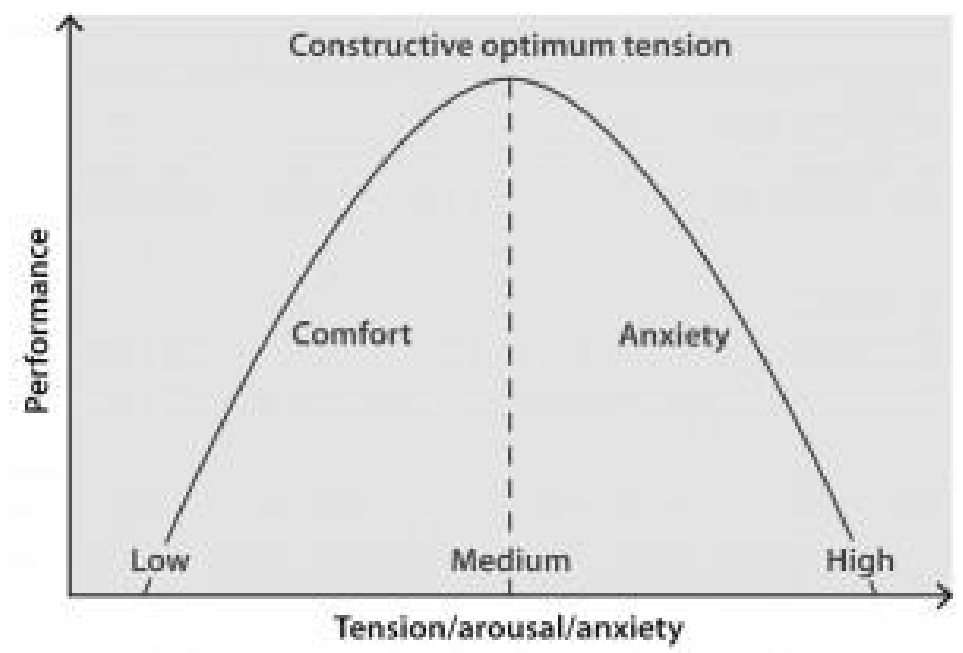

Figure 3. Yerkes Dodson performance curve (Nagel, 2017, p. 7)

The inverted $U$ shape indicates how performance is enhanced (optimal performance) - to a certain point - when there is some increased physical or psychological arousal (anxiety). It also indicates that performers who have too much anxiety or too little anxiety may demonstrate a decrease in their performance quality (Nagel, 2017, p. 7).

This is consistent with existing findings that both MPA and a flow state of consciousness can exist simultaneously (Kirchner et al., 2008).

Flow and MPA also are associated with motivation (Nakamura \& Csikszentmihalyi, 2002), emotion (Cohen \& Bodner, 2018a), attention/distraction (Izard, 1977; Rankin, Walsh, \& Sweeny, 2018), happiness (Marin \& Bhattacharya, 2013; Sabino, Camargo, Chagas, \& Osório, 2018), well-being (Fritz \& Avsec, 2007; Lamont, 2012), 
and Musical Emotional Contagion (MEC) (Cohen \& Bodner, 2018a). Findings suggest that flow has positive correlations and MPA has negative correlations with these factors.

These findings suggest that flow and MPA are negatively correlated and can exist simultaneously; flow and MPA are associated with the CSB; flow and MPA are also associated with some other factors, like motivation, emotion, attention, happiness, wellbeing, and MEC. Due to the absence of studies examining the flow experiences of different music majors, there is a need to gather data on the experiences of flow from this diverse group to examine the relationship between flow and MPA.

Accordingly, the purpose of this study was to explore the relationship between flow experience and MPA. The following two research questions guided my exploration: 1) What is the relationship between flow and MPA based on rating scale responses? and 2) Do age, gender, educational level, major, performance time, performance form, and performance frequency have effects on rating scale measures of flow and music performance anxiety?

\section{Method}

\section{Participants}

A purposeful sampling method was used in this study to maintain a balance among gender, educational level, and music majors. A sufficient number of participants was needed to provide rich information about participant flow and anxiety experiences during their music performance. Data were collected, in person, from different classes of different levels (music history class, $n=11$; vocal class, $n=36$; guitar class, $n=3$;

percussion studio, $n=12$; band rehearsal clinic, $n=8$; and music education class, $n=5$ ) that resulted in a $100 \%$ questionnaire recovery rate. 
This study involved seventy-five participants, including vocal and instrumental music majors, and non-music majors enrolled in music classes. There were both undergraduate and graduate students included, with a wide range of ages and performance experience represented. Specific demographic characteristics of the sample will be provided in the results section.

\section{Procedure}

The questionnaires were designed based on the literature and the researcher's previous studies and included three components (see Appendix C). The first component was demographic information, including participants' gender, age, education level, major, performance experience, favorite performing form (solo/ensemble), and frequency of public performance. The second component was the administration of the Activity Flow State Scale (AFSS) (Payne, Jackson, Noh, \& Stine-Morrow, 2011), and the third component was the administration of the Kenny Music Performance Anxiety InventoryRevised (K-MPAI-R) (Kenny, 2009). The permissions for using these two scales are included in Appendix B. The IRB-approved informed consent forms are also provided in Appendix A.

The AFSS (Payne et al., 2011) is a 26-item inventory with items representing nine dimensions of flow:1) Merging actions and awareness; 2) Clear goals; 3) Concentration on task at hand; 4) Unambiguous feedback; 5) Challenge/skill balance; 6) Transformation of time; 7) Sense of control; 8) Loss of self-consciousness; and 9) Autotelic experience. Participants rated items on a Likert scale ranging from (1) Strongly Disagree to (5) Strongly Agree. Instructions for this flow measure are as follows: 
Think about a musical performance that you performed before, particularly one that you enjoyed and /or found satisfying. Try to remember how you experienced that activity as you read each statement below. Provide a rating for each statement to indicate how well it describes your performance by circling the appropriate number(p. 3).

The K-MPAI-R (2009) is a 40-item version of an earlier inventory. It was developed to assess the emotion-based theory of anxiety proposed by Barlow (2000) as it applies to anxiety in the context of music performance (Kenny \& Ackermann, 2015). Questions were answered on a 7-point Likert scale, utilizing reverse scoring [0 $=$ Strongly disagree to $6=$ Strongly agree or $6=$ Strongly disagree to $0=$ Strongly agree $]$. Higher scores indicate greater anxiety and psychological distress. Instructions for this scale were as follows:

Below are some statements about how you feel generally and how you feel before or during a performance. Please circle one number to indicate how much you agree or disagree with each statement (Kenny, 2009).

Principal axis factoring of the K-MPAI-R revealed twelve underlying factors: 1) Depression/hopelessness; 2) Worry/dread; 3) Proximal somatic anxiety; 4) Parental empathy; 5) Memory; 6) Pre- and post-performance rumination;7) Generational transmission of anxiety; 8) Self/other scrutiny; 9) Controllability; 10) Opportunity cost; 11) Trust; and 12) Pervasive anxiety (Kenny, 2009, p. 41).

\section{Reliability and Validity Properties for Both Scales}

In a study by Payne et al. (2011), confirmatory factor analysis (CFA) was used to test factorial validity in the AFSS. The following fit indices were used to evaluate the adequacy of the model: "the comparative fit index (CFI), non-normed fit index (NNFI), and root mean square error approximation (RMSEA)" (p. 4). "Overall, the nine-factor model showed a good fit to the data $(\chi 2=479.39, \mathrm{df}=266, \mathrm{NNFI} / \mathrm{TFI}=.90, \mathrm{CFI}=.92$, 
RMSEA $=.06,90 \% \mathrm{CI}=.05, .07)$. These findings suggest that AFSS adequately captures the nine components of flow in various activities" (p. 4). This study also indicates good scale reliability and intercorrelations among the nine factors of AFSS (Cronbach's alpha for the nine factors are all above .71).

The K-MPAI-R (Kenny, 2009) demonstrated excellent internal reliability $($ Cronbach's alpha $=0.94)$ and a stable factor structure across professional and student classical musicians (Kenny, 2011). An appropriate Kaiser-Meyer Olkin measure of sampling adequacy (KMO) and a statistically significant Bartlett's test of sphericity were obtained, $\mathrm{KMO}=.929, \chi^{2}(586)=6352.896, p<.001$ (Kenny, 2018, p. 338). Factor analysis for this scale, which used professional orchestral musicians in the original study, revealed six robust factors (proximal somatic anxiety and worry about performance, worry/dread, depression/hopelessness, parental empathy, concerns with memory, generational transmission of anxiety; Cronbach's alpha for the six factors are all above .72), one weaker factor-anxious apprehension, and one item for biological vulnerability² (Kenny, Driscoll, \& Ackermann, 2014).

Both the K-MPAI-R and the AFSS inventory have demonstrated stable psychometric properties, and, given that the literature findings indicated strong negative correlations between the two constructs, canonical correlation was selected to provide an overall comparison of the two scales. Canonical correlation is considered a descriptive technique or a screening procedure and is primarily utilized in exploratory studies rather than a hypothesis-testing procedure (Tabachnick \& Fidell, 1989). Thus, the canonical

\footnotetext{
${ }^{2}$ The factors of MPA in professional musicians were: 1) Proximal somatic anxiety and worry about performance, 2) Worry/dread (Negative cognitions/ ruminations) focused on self/other scrutiny, 3) Depression/ hopelessness (Psycho logical vulnerability), 4) Parental empathy, 5) Memory, 6) Generational transmission of anxiety, 7) Anxious apprehension, and 8) Biological vulnerability (Kenny, 2018).
} 
correlation test (MANOVA) was used to identify and measure the association among these two sets of variables (26 items of AFSS and 40 items of K-MPAI-R) in this study.

Canonical correlation was also utilized to find possible associations between the factors in both scales. Post-hoc exploratory correlational analyses between specific items were numerous, thus, utilizing a $\mathrm{p}$ value of .01 was selected to minimize possible Type I and Type II errors in all analyses (Knudson \& Lindsey, 2014).

\section{Results}

\section{Descriptive Statistics of Sample Data}

Gender and education ratio of the participants. Participants in this study included 40 undergraduates (female, $n=30$; male, $n=10$ ) and 35 graduates (female, $n=$ 14; male, $n=21$ ), as shown below in Figure 4.

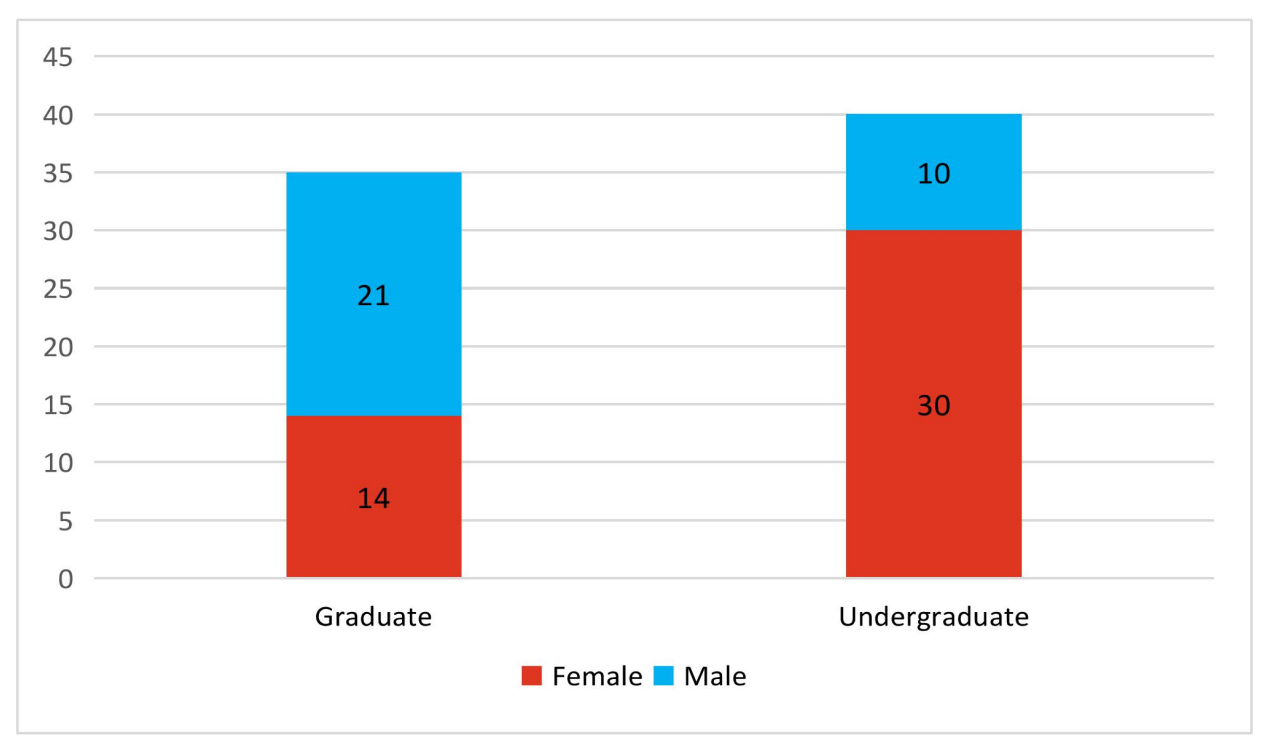

Figure 4. Gender and education ratio of the participants

The age of participants. The ages of participants ranged from 18-47 years $(\mathrm{M}=$ $24, \mathrm{SD}=5.83$ ), as shown in Figure 5. 


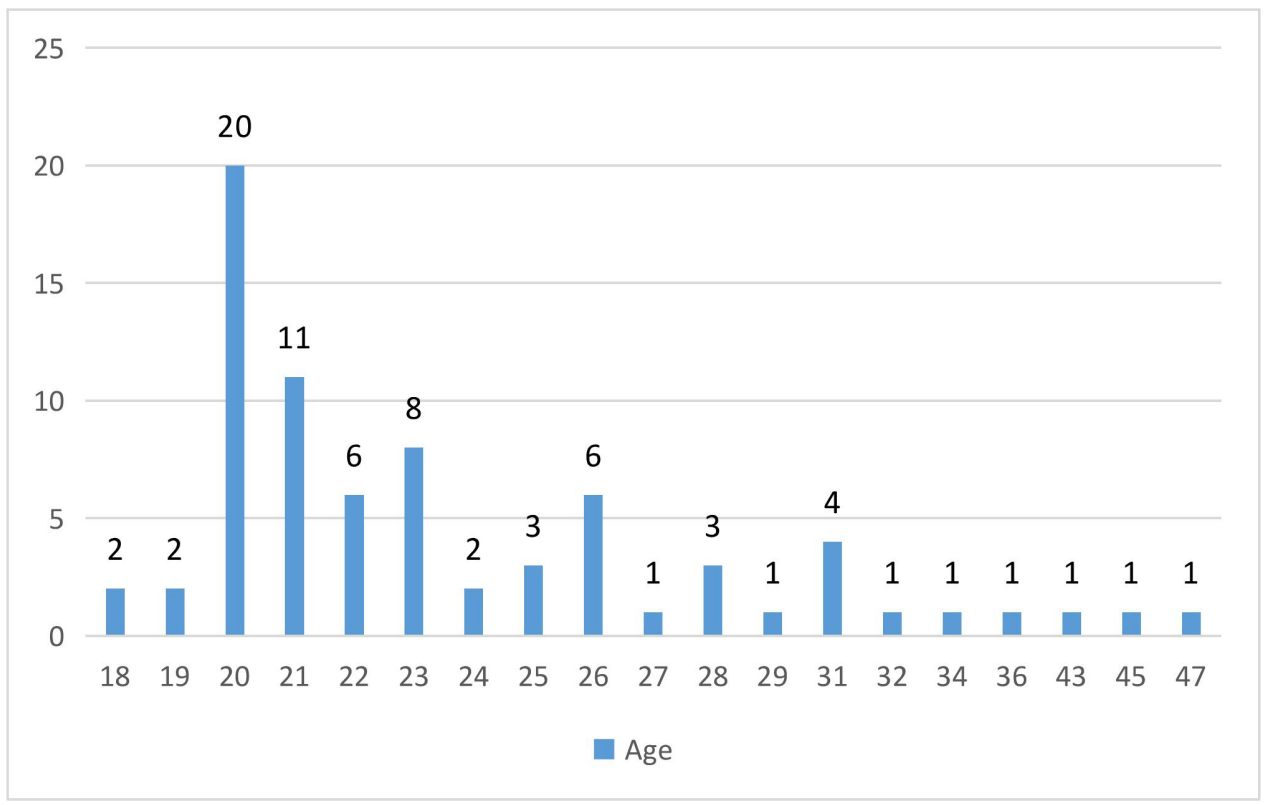

Figure 5. Age of participants

Major area of study. The majors of participants included vocal $(n=25)$ and instrumental ( $n=39)$ - percussion, $n=12$; piano, $n=7$; violin, $n=1$, viola, $n=1$, clarinet, $n=5$; guitar, $n=1$; flute, $n=4$; trumpet, $n=6$; trombone, $n=1$; pipa - a Chinese instrument, $n=1$. Non-majors (NA) numbered 11 . The counts of these majors are shown in Figure 6. 


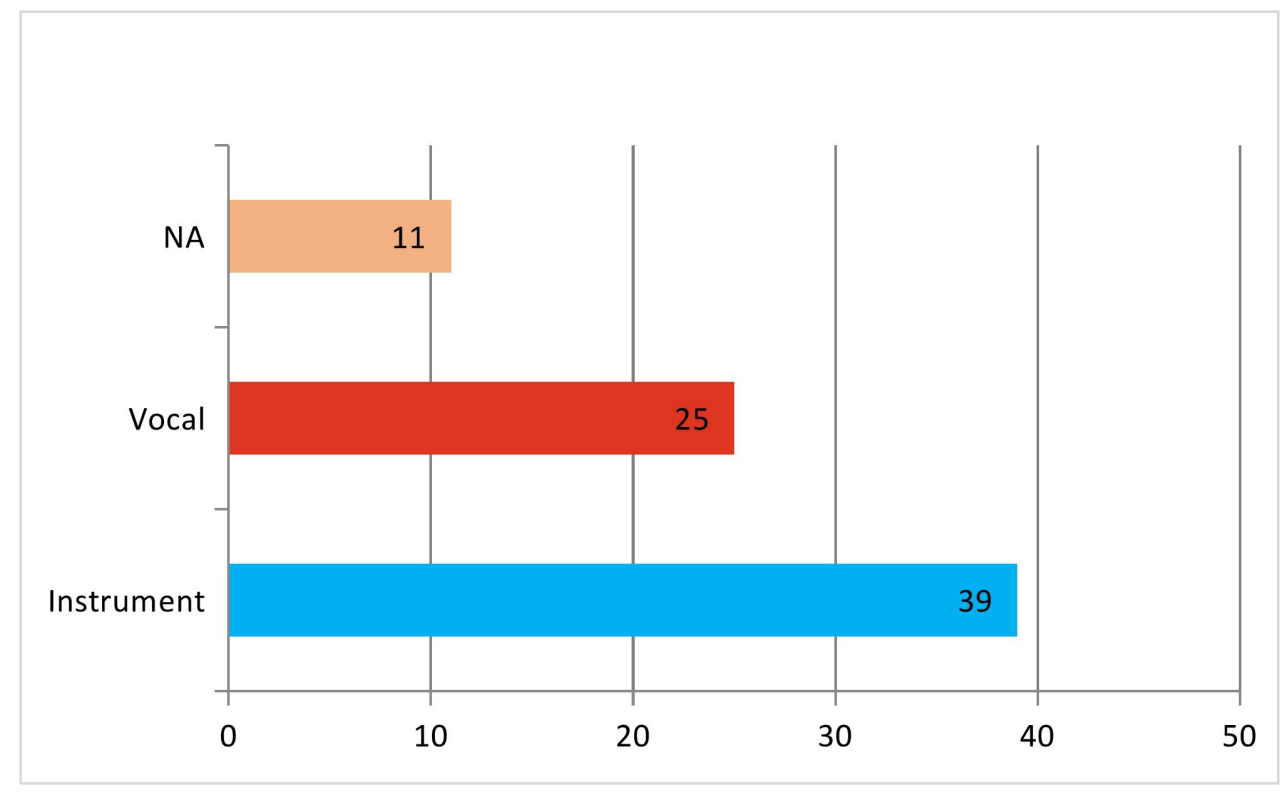

Figure 6. The majors of the participants

The years of participants' music performance. Participants had 0-37 years of performance experience $(\mathrm{M}=12, \mathrm{SD}=7.65)$, as shown in Figure 7 .

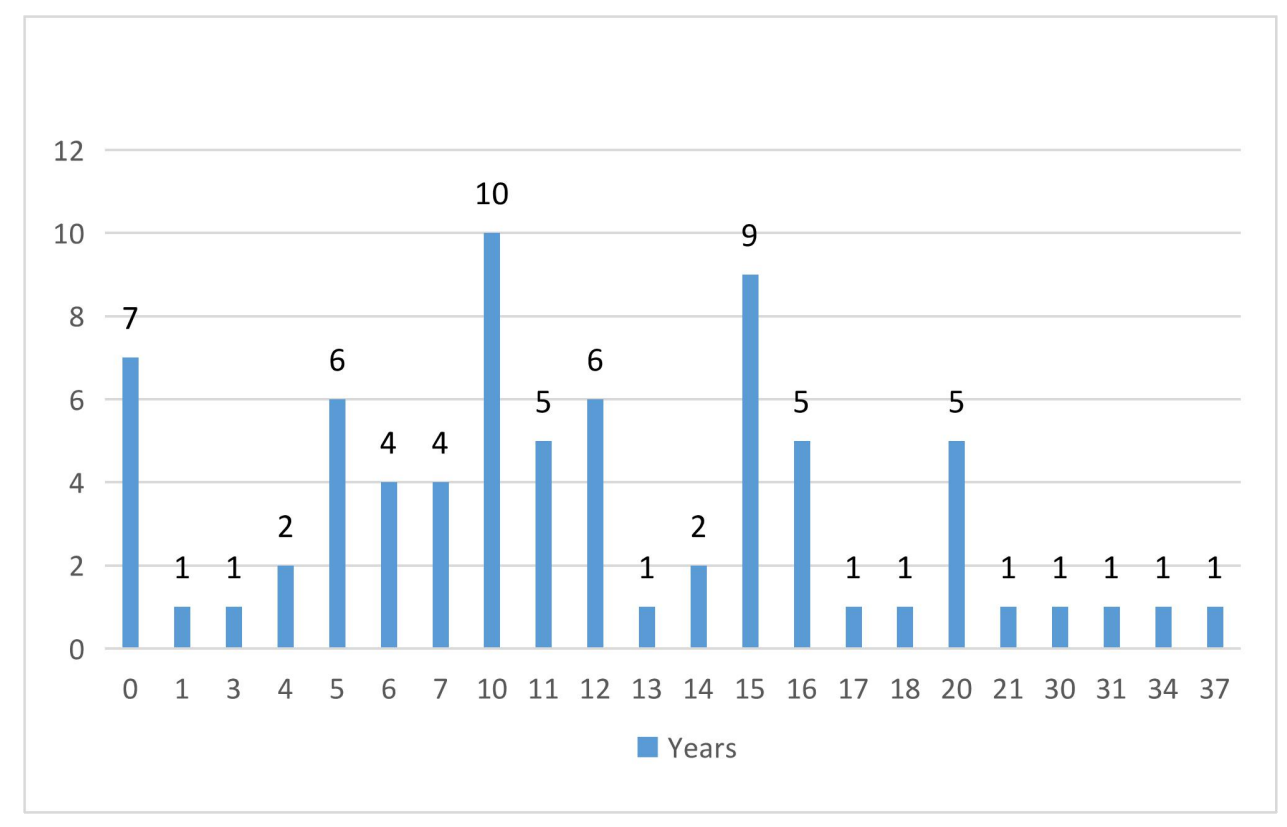

Figure 7. Performance time of the participants

The ratio of favorite performing form. When asked to report their preference, there were 60 participants who indicated that they preferred to perform with others 
(ensemble) and 15 participants who preferred solo performance. The ratio of their favorite performing form is shown in Figure 8 .

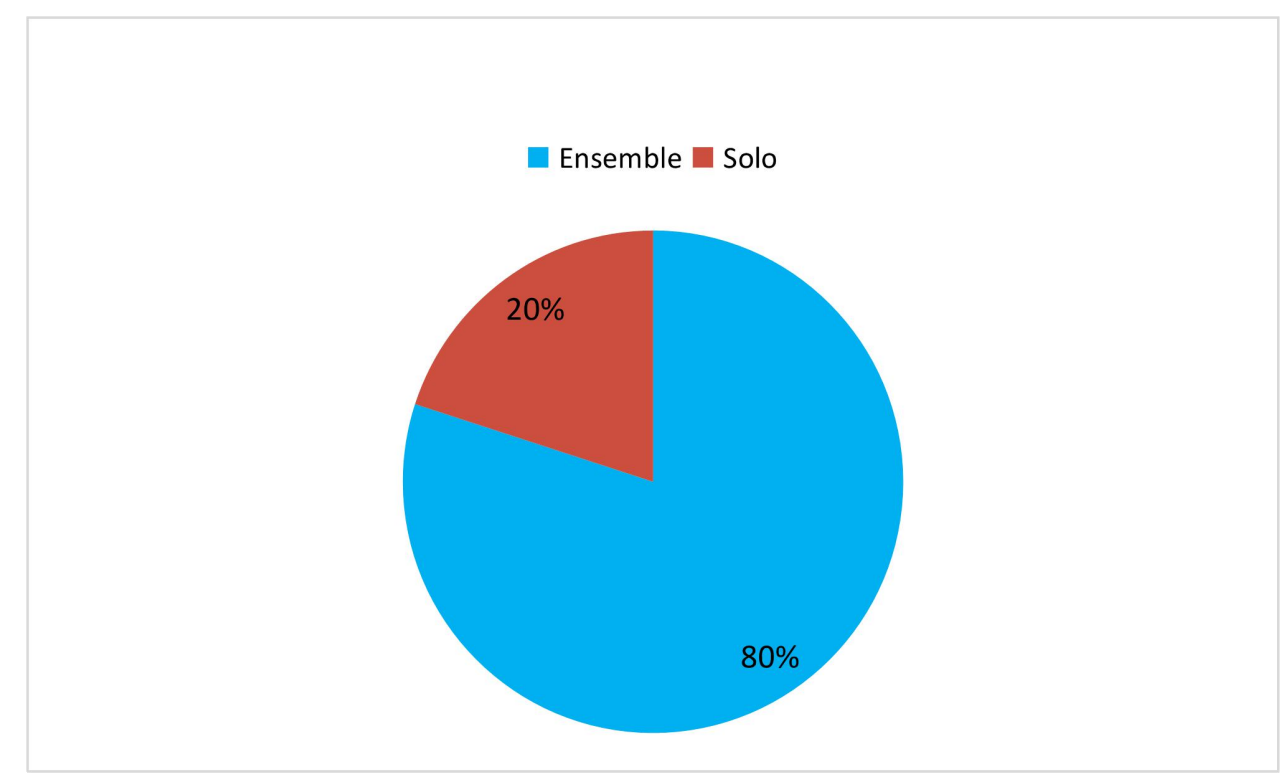

Figure 8. The ratio of participants' favorite performing form

The frequency of public performance. A Likert-type scale was used in this portion of the questionnaire, which included five different levels: Never, Rarely, Sometimes, Usually, and Always. As shown in Figure 9, there were 5 participants who never performed music in public, 15 participants who rarely performed music in public, 16 participants who sometimes performed music in public, 30 participants who usually performed music in public, and 9 participants who always performed music in public. 


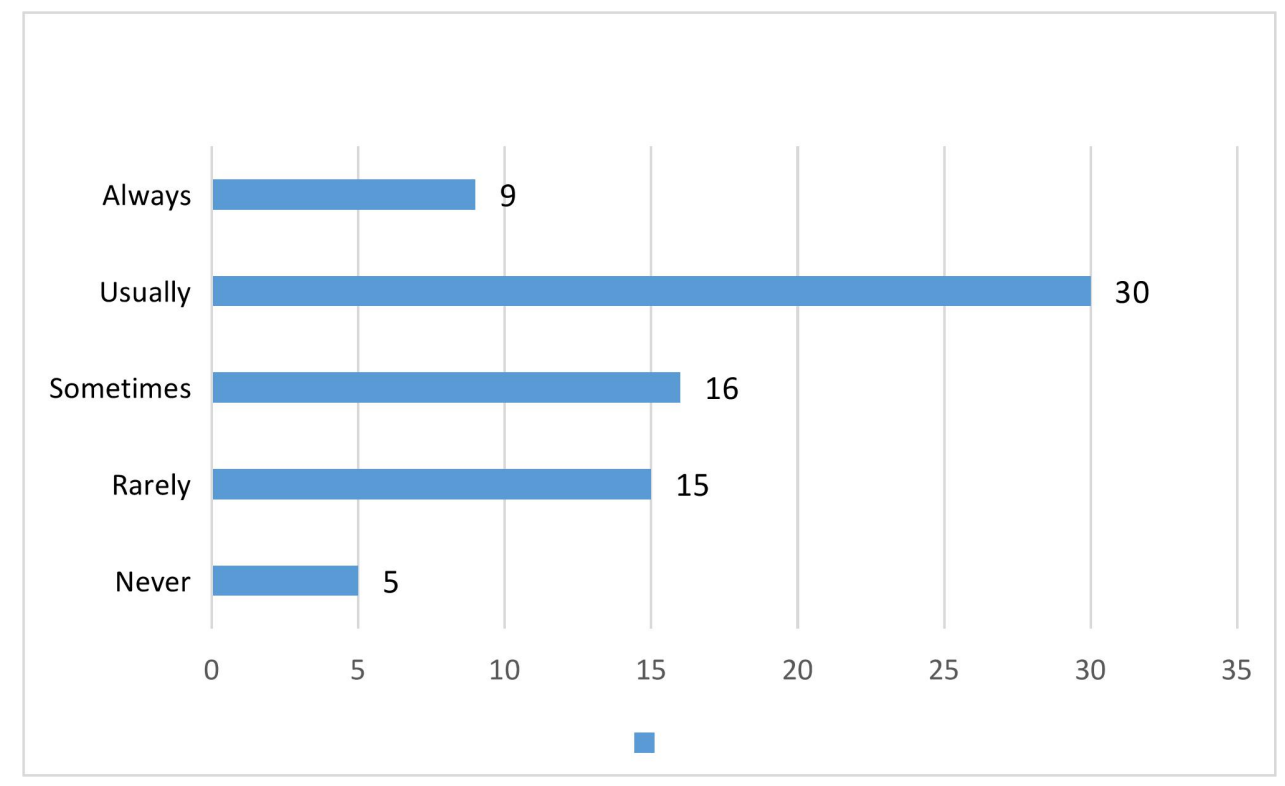

Figure 9. The frequency of public performance

\section{Correlation between Flow and Music Performance Anxiety}

The results of the first canonical correlation test showed that flow was not significantly associated with MPA, Wilks' $\lambda=.000, \mathrm{p}=.119>.05, \rho=.989, \rho^{2}=.978$. Although a value of zero is ideal, rejection of the null hypotheses must also include a small p-value. Small sample sizes can be used in canonical correlation analyses of multiple dependent variables provided the relationship between the scales is strong. However, relationships that are not statistically significant should not be interpreted in a canonical correlation test (Tabachnick \& Fidell, 1989).

An additional exploratory canonical correlation test was run to explore the correlations between the twelve factors of MPA and the nine flow dimensions. Results indicated four dimensions of flow (clear goals, unambiguous feedback, autotelic experience, and sense of control) were significantly associated with MPA factors compared with other dimensions (Table 3). (Because multiple analyses were used, the level of rejection was set at .01 in an attempt to mitigate against Type I errors.) 
Table 3

Significant Canonical Correlated Coefficient between Factors of MPA and Dimensions of Flow

\begin{tabular}{|c|c|c|}
\hline Factors of MPA & Dimensions of flow & Canonical correlated coefficient \\
\hline Factor 1 & Dimension 2 & Wilks' $\lambda=.497, p=.010, \rho=.582, \rho^{2}=.339$ \\
\hline $\begin{array}{l}\text { Depression/hopelessnes } \\
\mathrm{s}\end{array}$ & Clear goals & \\
\hline Factor 2 & Dimension 4 & Wilks' $\lambda=.622, p=.001, \rho=.526, \rho^{2}=.277$ \\
\hline Worry/dread & Unambiguous feedback & \\
\hline Factor 3 & Dimension 9 & Wilks' $\lambda=.505, p=.001, \rho=.623, \rho^{2}=.388$ \\
\hline $\begin{array}{l}\text { Proximal somatic } \\
\text { anxiety }\end{array}$ & Autotelic experience & \\
\hline Factor 6 & Dimension 7 & Wilks' $\lambda=.823, p=.008, \rho=.364, \rho^{2}=.132$ \\
\hline $\begin{array}{l}\text { Pre-and post- } \\
\text { performance } \\
\text { rumination }\end{array}$ & Sense of control & \\
\hline Factor 7 & Dimension2 & Wilks' $\lambda=.724, p=.007, \rho=.476, \rho^{2}=.227$ \\
\hline $\begin{array}{l}\text { Generational } \\
\text { transmission of anxiety }\end{array}$ & Clear goals & \\
\hline $\begin{array}{l}\text { Factor } 9 \\
\text { Controllability }\end{array}$ & $\begin{array}{l}\text { Dimension } 4 \\
\text { Unambiguous feedback }\end{array}$ & Wilks' $\lambda=.720, p=.000, \rho=.527, \rho^{2}=.278$ \\
\hline
\end{tabular}

The Pearson correlation tests showed a total of eighty-eight significant negative correlations $(\mathrm{p}<.01)$ between items of the K-MPAI-R and items of the AFSS (see Appendix D). In these eighty-eight significant negative correlations, four aspects of flow were most significantly and negatively correlated with MPA items of twelve factors: FQ4, FQ5, FQ6 (clear goals), FQ24, FQ25, FQ26 (autotelic experience), FQ21, FQ22, FQ23 (loss of self-consciousness), FQ11 and FQ12 (unambiguous feedback).

Items of clear goals of flow (FQ4 - "I had a strong sense of what I wanted to accomplish"; FQ5 - "I knew what I want to achieve"; and FQ6 - "My goals were clearly defined") were significantly negatively correlated with items of depression/hopelessness and generational transmission of anxiety of MPA (Table 4 and Table 10).

Items of unambiguous feedback of flow (FQ11 - "It was really clear to me how my performance was going"; and FQ12 - "I had a good idea while I was performing 
about how well I was doing") were significantly negatively correlated with items of worry/dread and controllability of MPA (Table 5 and Table 12).

Items of autotelic experience of flow (FQ24 - "I really enjoyed the experience"; FQ25 - "The experience left me feeling great"; and FQ26 - "The experience was extremely rewarding") were significantly negatively correlated with items of proximal somatic anxiety of MPA (Table 6).

Items of loss of self-consciousness of flow (FQ21 - "I was not concerned with how others might be evaluating me"; FQ22 - "I was not concerned with how I was presenting myself"; and FQ23 - "I was not worried about what others might be thinking of me") were significantly negatively correlated with items of Pre- and post-performance rumination of MPA (Table 9).

The K-MPAI-R twelve factor analyses resulted in negative correlations between different factors of MPA and items of AFSS.

Among the items of factor one of K-MPAI-R (Depression/hopelessness) and items of AFSS, there were 18 significant negative correlations (Table 4). 


\section{Table 4}

\section{Significant Negative Correlations between Items of Factor One of MPA and Items of}

\section{Flow}

\begin{tabular}{|c|c|c|}
\hline $\begin{array}{l}\text { Items of factor one of the } \\
\text { K-MPAI-R } \\
\text { (Depression/hopelessness) }\end{array}$ & AFSS Items & $\begin{array}{l}\text { Pearson correlation } \\
\text { coefficient }\end{array}$ \\
\hline \multirow[t]{2}{*}{$\begin{array}{l}\text { Q13 I often feel that I am } \\
\text { not worth much as a person }\end{array}$} & $\begin{array}{l}\text { Q4 I had a strong sense of what I wanted to } \\
\text { accomplish }\end{array}$ & $\mathrm{r}=-.354, \mathrm{p}=.002$ \\
\hline & Q6 My goals were clearly defined & $r=-.356, p=.002$ \\
\hline $\begin{array}{l}\text { Q3 Sometimes I feel } \\
\text { depressed without knowing } \\
\text { why }\end{array}$ & $\begin{array}{l}\text { Q13 I was challenged, but I believe my skills } \\
\text { will allow me to meet the challenge }\end{array}$ & $\mathrm{r}=-.299, \mathrm{p}=.009$ \\
\hline \multirow{4}{*}{$\begin{array}{l}\text { Q31 I often feel that I have } \\
\text { nothing to look forward to }\end{array}$} & Q6 My goals were clearly defined & $\mathrm{r}=-.323, \mathrm{p}=.005$ \\
\hline & $\begin{array}{l}\text { Q7 My attention was focused entirely on what I } \\
\text { was doing }\end{array}$ & $\mathrm{r}=-.305, \mathrm{p}=.008$ \\
\hline & Q24 I really enjoyed the performance & $r=-.318, p=.006$ \\
\hline & Q25 The performance left me feeling great & $\mathrm{r}=-.383, \mathrm{p}=.001$ \\
\hline \multirow[t]{3}{*}{$\begin{array}{l}\text { Q6 I often feel that life has } \\
\text { not much to offer me }\end{array}$} & $\begin{array}{l}\text { Q4 I had a strong sense of what I wanted to } \\
\text { accomplish }\end{array}$ & $\mathrm{r}=-.476, \mathrm{p}=.000$ \\
\hline & Q5 I knew what I want to achieve & $\mathrm{r}=-.380, \mathrm{p}=.001$ \\
\hline & Q6 My goals were clearly defined & $r=-.346, p=.002$ \\
\hline \multirow{7}{*}{$\begin{array}{l}\text { Q21 I worry that one bad } \\
\text { performance may ruin my } \\
\text { career }\end{array}$} & $\begin{array}{l}\text { Q4 I had a strong sense of what I wanted to } \\
\text { accomplish }\end{array}$ & $r=-, 320, p=.005$ \\
\hline & Q5 I knew what I want to achieve & $r=-.316, p=.006$ \\
\hline & Q6 My goals were clearly defined & $\mathrm{r}=-.317, \mathrm{p}=.006$ \\
\hline & $\begin{array}{l}\text { Q11 It was really clear to me how my } \\
\text { performance was going }\end{array}$ & $\mathrm{r}=-.310, \mathrm{p}=.007$ \\
\hline & Q24 I really enjoyed the performance & $\mathrm{r}=-.350, \mathrm{p}=.002$ \\
\hline & Q25 The performance left me feeling great & $\mathrm{r}=-.397, \mathrm{p}=000$ \\
\hline & Q26 The performance was extremely rewarding & $r=-, 362, p=.001$ \\
\hline $\begin{array}{l}\text { Q18 I am often concerned } \\
\text { about a negative reaction } \\
\text { from the audience }\end{array}$ & $\begin{array}{l}\text { Q23 I was not worried about what others might } \\
\text { be thinking of me }\end{array}$ & $\mathrm{r}=-.339, \mathrm{p}=.003$ \\
\hline
\end{tabular}

Among factor two of MPA (Worry/dread) and items of flow, there were 18 significant negative correlations (Table 5). 


\section{Table 5}

\section{Significant Negative Correlations between Items of Factor Two of MPA and Items of}

\section{Flow}

$\begin{array}{ccc}\text { Items of factor two of the } & \text { AFSS Items } & \begin{array}{c}\text { Pearson correlation } \\ \text { K-MPAI-R }\end{array} \\ \text { coefficient }\end{array}$

(Worry/dread)

\begin{tabular}{|c|c|c|}
\hline $\begin{array}{l}\text { Q15 Thinking about the } \\
\text { evaluation I may get }\end{array}$ & $\begin{array}{l}\text { Q21 I was not concerned with how others might } \\
\text { be evaluating me }\end{array}$ & $\mathrm{r}=-.406, \mathrm{p}=.000$ \\
\hline interferes with my & Q24 I really enjoyed the performance & $\mathrm{r}=-.299, \mathrm{p}=.009$ \\
\hline performance & $\begin{array}{l}\text { Q25 The performance left me feeling great } \\
\text { Q26 The performance was extremely rewarding }\end{array}$ & $\begin{array}{l}\mathrm{r}=-.359, \mathrm{p}=.002 \\
\mathrm{r}=-.316, \mathrm{p}=.006\end{array}$ \\
\hline $\begin{array}{l}\text { Q14 During a } \\
\text { performance I find myself }\end{array}$ & $\begin{array}{l}\text { Q11 It was really clear to me how my } \\
\text { performance was going }\end{array}$ & $\mathrm{r}=-.382, \mathrm{p}=.001$ \\
\hline $\begin{array}{l}\text { thinking about whether } \\
\text { I'll even get through it }\end{array}$ & $\begin{array}{l}\text { Q12 I had a good idea while I was performing } \\
\text { about how well I was doing }\end{array}$ & $\mathrm{r}=-.316, \mathrm{p}=.006$ \\
\hline $\begin{array}{l}\text { Q28 I often prepare for a } \\
\text { concert with a sense of }\end{array}$ & $\begin{array}{l}\text { Q25 The performance left me feeling great } \\
\text { Q4 I had a strong sense of what I wanted to } \\
\text { accomplish }\end{array}$ & $\begin{array}{l}\mathrm{r}=-.345, \mathrm{p}=.002 \\
\mathrm{r}=-.377, \mathrm{p}=.001\end{array}$ \\
\hline dread and impending & Q5 I knew what I want to achieve & $\mathrm{r}=-.350, \mathrm{p}=.002$ \\
\hline disaster & $\begin{array}{l}\text { Q6 My goals were clearly defined } \\
\text { Q25 The performance left me feeling great }\end{array}$ & $\begin{array}{l}\mathrm{r}=-.300, \mathrm{p}=.009 \\
\mathrm{r}=-.356, \mathrm{p}=.002\end{array}$ \\
\hline $\begin{array}{l}\text { Q26 My worry and } \\
\text { nervousness about my } \\
\text { performance interferes }\end{array}$ & $\begin{array}{l}\text { Q2 Things just seemed to happen automatically } \\
\text { Q11 It was really clear to me how my } \\
\text { performance was going }\end{array}$ & $\begin{array}{l}\mathrm{r}=-.442, \mathrm{p}=.000 \\
\mathrm{r}=-.312, \mathrm{p}=.006\end{array}$ \\
\hline $\begin{array}{l}\text { with my focus and } \\
\text { concentration }\end{array}$ & $\begin{array}{l}\text { Q19 I felt as though I had everything under } \\
\text { control }\end{array}$ & $\mathrm{r}=-.307, \mathrm{p}=.007$ \\
\hline $\begin{array}{l}\text { Q7 Even if I work hard in } \\
\text { preparation for a } \\
\text { performance, I am likely }\end{array}$ & $\begin{array}{l}\text { Q2 Things just seemed to happen automatically } \\
\text { Q21 I was not concerned with how others might } \\
\text { be evaluating me }\end{array}$ & $\begin{array}{l}\mathrm{r}=-.322, \mathrm{p}=.005 \\
\mathrm{r}=-.321, \mathrm{p}=.005\end{array}$ \\
\hline to make mistakes & $\begin{array}{l}\text { Q22 I was not concerned with how I was } \\
\text { presenting myself }\end{array}$ & $\mathrm{r}=-.335, \mathrm{p}=.003$ \\
\hline
\end{tabular}

Among factor three of MPA (Proximal somatic anxiety) and items of flow, there

were 10 significant negative correlations (Table 6). 
Table 6

Significant Negative Correlations between Items of Factor Three of MPA and Items of

Flow

\begin{tabular}{|c|c|c|}
\hline $\begin{array}{l}\text { Items of factor three of } \\
\text { the K-MPAI-R } \\
\text { (Proximal somatic } \\
\text { anxiety) }\end{array}$ & AFSS Items & $\begin{array}{l}\text { Pearson correlation } \\
\text { coefficient }\end{array}$ \\
\hline $\begin{array}{l}\text { Q36 Prior to, or during a } \\
\text { performance, I experience }\end{array}$ & $\begin{array}{l}\text { Q12 I had a good idea while I was performing } \\
\text { about how well I was doing }\end{array}$ & $\mathrm{r}=-.298, \mathrm{p}=.009$ \\
\hline $\begin{array}{l}\text { shaking or trembling or } \\
\text { tremor }\end{array}$ & Q24 I really enjoyed the performance & $\mathrm{r}=-.305, \mathrm{p}=.008$ \\
\hline Q16 Prior to, or during a & Q24 I really enjoyed the performance & $\mathrm{r}=-.352, \mathrm{p}=.002$ \\
\hline $\begin{array}{l}\text { performance, I feel sick } \\
\text { or faint or have a } \\
\text { churning in my stomach }\end{array}$ & Q25 The performance left me feeling great & $\mathrm{r}=-.315, \mathrm{p}=.006$ \\
\hline $\begin{array}{l}\text { Q10 Prior to, or during a } \\
\text { performance, I get }\end{array}$ & $\begin{array}{l}\text { Q12 I had a good idea while I was performing } \\
\text { about how well I was doing }\end{array}$ & $\mathrm{r}=-.316, \mathrm{p}=.006$ \\
\hline feelings akin to panic & Q24 I really enjoyed the performance & $\mathrm{r}=-.366, \mathrm{p}=.001$ \\
\hline \multirow{3}{*}{$\begin{array}{l}\text { Q30 Prior to, or during a } \\
\text { performance, I have } \\
\text { increased muscle tension }\end{array}$} & Q9 I had total concentration & $\mathrm{r}=-.308, \mathrm{p}=.007$ \\
\hline & $\begin{array}{l}\text { Q19 I felt as though I had everything under } \\
\text { control }\end{array}$ & $\mathrm{r}=-.297, \mathrm{p}=.010$ \\
\hline & $\begin{array}{l}\text { Q21 I was not concerned with how others might } \\
\text { be evaluating me }\end{array}$ & $\mathrm{r}=-.303, \mathrm{p}=.008$ \\
\hline $\begin{array}{l}\text { Q12 Prior to, or during a } \\
\text { performance, I experience } \\
\text { dry mouth }\end{array}$ & $\begin{array}{l}\text { Q11 It was really clear to me how my } \\
\text { performance was going }\end{array}$ & $\mathrm{r}=-.296, \mathrm{p}=.010$ \\
\hline
\end{tabular}

Between factor four of MPA (Parental empathy) and items of flow, there was one significant negative correlation (Table 7).

\section{Table 7}

Significant Negative Correlations between Items of Factor Four of MPA and Items of

Flow

\begin{tabular}{lcc}
\hline $\begin{array}{l}\text { Items of factor four of the } \\
\text { K-MPAI-R (Parental } \\
\text { empathy) }\end{array}$ & AFSS Items & $\begin{array}{c}\text { Pearson correlation } \\
\text { coefficient }\end{array}$ \\
\hline $\begin{array}{l}\text { Q33 My parents } \\
\text { encouraged me to try new } \\
\text { things }\end{array}$ & Q6 My goals were clearly defined & $\mathrm{r}=-.397, \mathrm{p}=.000$ \\
\hline
\end{tabular}


For factor five of MPA (Memory) and items of flow, there were 5 significant negative correlations (Table 8).

Table 8

Significant Negative Correlations between Items of Factor Five of MPA and Items of

Flow

\begin{tabular}{lll}
\hline $\begin{array}{l}\text { Items of factor five of the } \\
\text { K-MPAI-R (Memory) }\end{array}$ & \multicolumn{1}{c}{ AFSS Items } & $\begin{array}{c}\text { Pearson correlation } \\
\text { coefficient }\end{array}$ \\
\hline $\begin{array}{l}\text { Q35 When performing } \\
\text { without music, my }\end{array}$ & $\begin{array}{l}\text { Q8 It was no effort to keep my mind on what was } \\
\text { happening }\end{array}$ & $\mathrm{r}=-.369, \mathrm{p}=.001$ \\
memory is reliable & $\begin{array}{l}\text { Q9 I had total concentration } \\
\text { Q24 I really enjoyed the performance }\end{array}$ & $\mathrm{r}=-.359, \mathrm{p}=.002$ \\
Q37 I am confident & $\begin{array}{l}\mathrm{r}=-.355, \mathrm{p}=.002 \\
\text { playing from memory } \\
\text { happening no effort to keep my mind on what was }\end{array}$ & $\mathrm{r}=-.318, \mathrm{p}=.005$ \\
& $\begin{array}{l}\text { Q12 I had a good idea while I was performing } \\
\text { about how well I was doing }\end{array}$ & $\mathrm{r}=-.331, \mathrm{p}=.004$ \\
\hline
\end{tabular}

Within factor six of MPA (Pre-and post-performance rumination) and items of flow, there were 6 significant negative correlations (Table 9).

Table 9

Significant Negative Correlations between Items of Factor Six of MPA and Items of Flow

\begin{tabular}{|c|c|c|}
\hline $\begin{array}{l}\text { Items of factor six of the } \\
\text { K-MPAI-R (Pre- and } \\
\text { post-performance } \\
\text { rumination) }\end{array}$ & AFSS Items & $\begin{array}{l}\text { Pearson correlation } \\
\text { coefficient }\end{array}$ \\
\hline \multirow{2}{*}{$\begin{array}{l}\text { Q32 After the } \\
\text { performance, I replay it in } \\
\text { my mind over and over }\end{array}$} & $\begin{array}{l}\text { Q21 I was not concerned with how others might } \\
\text { be evaluating me }\end{array}$ & $\mathrm{r}=-.315, \mathrm{p}=.006$ \\
\hline & $\begin{array}{l}\text { Q22 I was not concerned with how I was } \\
\text { presenting myself }\end{array}$ & $\mathrm{r}=-.301, \mathrm{p}=.009$ \\
\hline \multirow{4}{*}{$\begin{array}{l}\text { Q34 I worry so much } \\
\text { before a performance, I } \\
\text { cannot sleep }\end{array}$} & $\begin{array}{l}\text { Q11 It was really clear to me how my } \\
\text { performance was going }\end{array}$ & $\mathrm{r}=-.345, \mathrm{p}=.002$ \\
\hline & $\begin{array}{l}\text { Q12 I had a good idea while I was performing } \\
\text { about how well I was doing }\end{array}$ & $r=-.366, p=.001$ \\
\hline & $\begin{array}{l}\text { Q13 I was challenged, but I believe my skills will } \\
\text { allow me to meet that challenge }\end{array}$ & $\mathrm{r}=-.306, \mathrm{p}=.008$ \\
\hline & Q15 I felt just the right amount of challenge & $\mathrm{r}=-.302, \mathrm{p}=.008$ \\
\hline
\end{tabular}

Among the factor seven of MPA (Generational transmission of anxiety) and items of flow, there were 12 significant negative correlations (Table 10). 
Table 10

Significant Negative Correlations between Items of Factor Seven of MPA and Items of

Flow

\begin{tabular}{|c|c|c|}
\hline \\
\hline $\begin{array}{l}\text { Items of factor seven of } \\
\text { K-MPAI-R (General } \\
\text { transmission of anxiety) }\end{array}$ & AFSS items & $\begin{array}{l}\text { Pearson correlation } \\
\text { coefficient }\end{array}$ \\
\hline \multirow{3}{*}{$\begin{array}{l}\text { Q29 One or both of my } \\
\text { parents were overly } \\
\text { anxious }\end{array}$} & $\begin{array}{l}\text { Q21 I was not concerned with how others might } \\
\text { be evaluating me }\end{array}$ & $\mathrm{r}=-.319, \mathrm{p}=.005$ \\
\hline & $\begin{array}{l}\text { Q22 I was not concerned with how I was } \\
\text { presenting myself }\end{array}$ & $\mathrm{r}=-.363, \mathrm{p}=.001$ \\
\hline & $\begin{array}{l}\text { Q23 I was not worried about what others might } \\
\text { be thinking of me }\end{array}$ & $\mathrm{r}=-.323, \mathrm{p}=.005$ \\
\hline \multirow{3}{*}{$\begin{array}{l}\text { Q5 Excessive worrying is } \\
\text { a characteristic of my } \\
\text { family }\end{array}$} & Q2 Things just seemed to happen automatically & $\mathrm{r}=-.344, \mathrm{p}=.002$ \\
\hline & $\begin{array}{l}\text { Q19 I felt as though I had everything under } \\
\text { control }\end{array}$ & $\mathrm{r}=-.308, \mathrm{p}=.007$ \\
\hline & Q20 I felt that I had everything under control & $\mathrm{r}=-.348, \mathrm{p}=.002$ \\
\hline \multirow[t]{6}{*}{$\begin{array}{l}\text { Q27 As a child, I often } \\
\text { felt sad }\end{array}$} & $\begin{array}{l}\text { Q4 I had a strong sense of what I wanted to } \\
\text { accomplish }\end{array}$ & $\mathrm{r}=-.342, \mathrm{p}=.003$ \\
\hline & Q5 I knew what I want to achieve & $\mathrm{r}=-.319, \mathrm{p}=.005$ \\
\hline & Q6 My goals were clearly defined & $\mathrm{r}=-.434, \mathrm{p}=.000$ \\
\hline & $\begin{array}{l}\text { Q11 It was really clear to me how my } \\
\text { performance was going }\end{array}$ & $\mathrm{r}=-.351, \mathrm{p}=.002$ \\
\hline & Q25 The performance left me feeling great & $\mathrm{r}=-.370 . \mathrm{p}=.001$ \\
\hline & Q26 The performance was extremely rewarding & $r=-.324, p=.005$ \\
\hline
\end{tabular}

For factor eight of MPA (Self/other scrutiny) and items of flow, there were 2 significant negative correlations (Table 11).

Table 11

Significant Negative Correlations between Items of Factor Eight of MPA and Items of Flow

\begin{tabular}{clc}
\hline $\begin{array}{c}\text { Items of factor eight of K- } \\
\text { MPAI-R (Self/other } \\
\text { scrutiny) }\end{array}$ & \multicolumn{1}{c}{ AFSS items } & $\begin{array}{c}\text { Pearson correlation } \\
\text { coefficient }\end{array}$ \\
\hline $\begin{array}{l}\text { Q38 I am concerned about } \\
\text { being scrutinized by others }\end{array}$ & $\begin{array}{l}\text { Q21 I was not concerned with how others might } \\
\text { be evaluating me } \\
\text { Q22 I was not concerned with how I was } \\
\text { presenting myself }\end{array}$ & $\mathrm{r}=-.361, \mathrm{p}=.001$ \\
\hline
\end{tabular}


Among factor nine of MPA (Controllability) and items of flow, there were 7

significant negative correlations (Table 12).

Table 12

Significant Negative Correlations between Items of Factor Nine of MPA and Items of

Flow

\begin{tabular}{lll}
\hline $\begin{array}{l}\text { Items of factor nine of K- } \\
\text { MPAI-R (Controllability) }\end{array}$ & \multicolumn{1}{c}{ AFSS items } & $\begin{array}{c}\text { Pearson correlation } \\
\text { coefficient }\end{array}$ \\
\hline $\begin{array}{l}\text { Q1 I generally feel in } \\
\text { control of my life }\end{array}$ & $\begin{array}{l}\text { Q4 I had a strong sense of what I wanted to } \\
\text { accomplish }\end{array}$ & $\mathrm{r}=-.319, \mathrm{p}=.002$ \\
& $\begin{array}{l}\text { Q5 I knew what I want to achieve } \\
\text { Q6 My goals were clearly defined }\end{array}$ & $\mathrm{r}=-.343, \mathrm{p}=.003$ \\
$\begin{array}{l}\text { Q11 I never know before a }=-.316, \mathrm{p}=.006 \\
\text { concert whether I will } \\
\text { perform well }\end{array}$ & $\begin{array}{l}\text { Q2 Things just seemed to happen automatically } \\
\text { Q11 It was really clear to me how my }\end{array}$ & $\begin{array}{c}\mathrm{r}=-.319, \mathrm{p}=.005 \\
\text { performance was going }\end{array}$ \\
& $\begin{array}{l}\text { Q12 I had a good idea while I was performing } \\
\text { about how well I was doing }\end{array}$ & $\mathrm{r}=-.415, \mathrm{p}=.000$ \\
& $\begin{array}{l}\text { Q14 The challenge and my skills were at an } \\
\text { equally high level }\end{array}$ & $\mathrm{r}=-.336, \mathrm{p}=.000$ \\
& & \\
\hline
\end{tabular}

Among factor ten of MPA (Opportunity cost) and items of flow, there were 6

significant negative correlations (Table 13).

Table 13

Significant Negative Correlations between Items of Factor Ten of MPA and Items of

Flow

\begin{tabular}{lll}
\hline $\begin{array}{c}\text { Items of factor ten of K- } \\
\text { MPAI-R (Opportunity } \\
\text { cost })\end{array}$ & \multicolumn{1}{c}{ AFSS items } & $\begin{array}{c}\text { Pearson correlation } \\
\text { coefficient }\end{array}$ \\
\hline $\begin{array}{l}\text { Q24 I give up worthwhile } \\
\text { performance opportunities } \\
\text { due to anxiety }\end{array}$ & Q5 I knew what I want to achieve & $\mathrm{r}=-.344, \mathrm{p}=.002$ \\
& Q6 My goals were clearly defined & $\mathrm{r}=-.341, \mathrm{p}=.003$ \\
& $\begin{array}{l}\text { Q19 I felt as though I had everything under } \\
\text { control }\end{array}$ & $\mathrm{r}=-.435, \mathrm{p}=.000$ \\
& Q20 I felt that I had everything under control & $\mathrm{r}=-.324, \mathrm{p}=.005$ \\
& Q24 I really enjoyed the performance & $\mathrm{r}=-.377, \mathrm{p}=.001$ \\
& Q25 The performance left me feeling great & $\mathrm{r}=-.328, \mathrm{p}=.004$ \\
\hline
\end{tabular}

Among factor eleven of MPA (Trust) and items of flow, there was one significant negative correlation (Table 14). 
Table 14

Significant Negative Correlations between Items of Factor Eleven of MPA and Items of flow

\begin{tabular}{lcc}
\hline $\begin{array}{c}\text { Item of factor eleven of } \\
\text { K-MPAI-R (Trust) }\end{array}$ & AFSS item & $\begin{array}{c}\text { Pearson correlation } \\
\text { coefficient }\end{array}$ \\
\hline $\begin{array}{l}\text { Q8 I find it difficult to } \\
\text { depend on others }\end{array}$ & Q6 My goals were clearly defined & $\mathrm{r}=-.303, \mathrm{p}=.008$ \\
\hline
\end{tabular}

For factor twelve of MPA (Pervasive anxiety) and items of flow, there were 2 significant negative correlations (Table 15).

Table 15

Significant Negative Correlations between Items of Factor Twelve of MPA and Items of Flow

\begin{tabular}{lll}
\hline \begin{tabular}{c} 
Items of factor twelve of \\
K-MPAI-R (Pervasive \\
\multicolumn{1}{c}{ anxiety) }
\end{tabular} & \multicolumn{1}{c}{ AFSS items } & $\begin{array}{c}\text { Pearson correlation } \\
\text { coefficient }\end{array}$ \\
\hline $\begin{array}{l}\text { Q20 From early in my } \\
\text { music studies, I remember } \\
\text { being anxious about }\end{array}$ & $\begin{array}{l}\text { Q21 I was not concerned with how others might } \\
\text { performing }\end{array}$ & $\begin{array}{l}\mathrm{r}=-.328, \mathrm{p}=.004 \\
\text { Q22 I was not concerned with how I was }\end{array}$ \\
\hline
\end{tabular}

Positive correlations were found in two pairs of items between the K-MPAI-R and AFSS (Table 16). This result may be explained by considering that the more you trust others, the more you will not be concerned with how you will present yourself, and the clearer your goals are, the more you will remain committed to performing even though it has caused you great anxiety. 
Table 16

Significant Positive Correlations between Items of MPA and Items of Flow

\begin{tabular}{llll}
\hline \multicolumn{1}{c}{$\begin{array}{c}\text { Factors of } \\
\text { MPA }\end{array}$} & Items of K-MPAI-R & \multicolumn{1}{c}{ AFSS items } & $\begin{array}{c}\text { Pearson correlation } \\
\text { coefficient }\end{array}$ \\
\hline $\begin{array}{l}\text { Factor 1 } \\
\begin{array}{l}\text { Depression/hop } \\
\text { elessness }\end{array}\end{array}$ & $\begin{array}{l}\text { Q2I find it easy to } \\
\text { trust others }\end{array}$ & $\begin{array}{l}\text { Q22 I was not concerned with how I } \\
\text { was presenting myself }\end{array}$ & $\mathrm{r}=.321, \mathrm{p}=.005$ \\
$\begin{array}{l}\text { Factor 3 } \\
\begin{array}{l}\text { Proximal } \\
\text { somatic anxiety }\end{array}\end{array}$ & $\begin{array}{l}\text { Q40 I remain } \\
\text { committed to } \\
\text { performing even } \\
\text { though it causes me } \\
\text { great anxiety }\end{array}$ & Q6 My goals were clearly defined & $\mathrm{r}=.373, \mathrm{p}=.001$ \\
& & \\
\hline
\end{tabular}

To summarize, Tables 4-15 reflect the negative correlations between MPA and flow based on twelve MPA factors. Once music performers identify their own MPA factors, they can find corresponding negative flow items to help to reduce their specific MPA factor/factors.

\section{Effects of Gender, Age, Education, Major, Performance Time, Performance Form, and Performance Frequency on Flow and MPA}

Pearson's correlation tests (see Appendix E) showed no significant correlations between gender and flow, age and flow, education and flow, major and flow, and performance form and flow. Performance time and performance frequency were positively correlated with five items of AFSS (Table 17), which indicated that the more years participants had performed, the clearer their feedback was considered to be. Also, the more performance, the better attention and controllability. 
Table 17

Significant Positive Correlations between Performance Time, Performance Frequency, and Flow

\begin{tabular}{lll}
\hline \multicolumn{1}{c}{ Variables } & \multicolumn{1}{c}{ AFSS items } & \multicolumn{1}{c}{$\begin{array}{c}\text { Pearson correlation } \\
\text { coefficient }\end{array}$} \\
\hline $\begin{array}{l}\text { Performance time } \\
\text { (years) }\end{array}$ & $\begin{array}{l}\text { Q11 It was really clear to me how my performance } \\
\text { was going }\end{array}$ & $\mathrm{r}=.300, \mathrm{p}=.009$ \\
& $\begin{array}{l}\text { Q12 I had a good idea while I was performing } \\
\text { about how well I was doing }\end{array}$ & $\mathrm{r}=.371, \mathrm{p}=.001$ \\
Performance & $\begin{array}{l}\text { Q10 I had no difficulty concentrating } \\
\text { frequency }\end{array}$ & $\mathrm{r}=.314, \mathrm{p}=.006$ \\
& Q19 I felt as though I had everything under control & $\mathrm{r}=.315, \mathrm{p}=.006$ \\
Q20I felt that I had everything under control & $\mathrm{r}=.310, \mathrm{p}=.007$ \\
\hline
\end{tabular}

Pearson's correlation tests (see Appendix F) showed no significant correlations between gender and MPA, age and MPA, major and MPA, and performance frequency and MPA. Education level was positively correlated with two items of the K-MPAI-R, which indicated that the more educated one was, the more likely the individual would be to trust others, and the more often they felt sad as a child. Performance time and performance form were negatively correlated with one item of the K-MPAI-R, indicating that the more years the participants performed, the less they remembered being anxious about performing. Also, music performers had the "dry mouth" symptom more frequently in solo performance than in ensembles (Table 18).

Table 18

Significant Correlations between Educational Level, Performance Time, Performance

Form, and MPA

\begin{tabular}{lll}
\hline \multicolumn{1}{c}{ Variables } & \multicolumn{1}{c}{ Items of K-MPAI-R } & \multicolumn{1}{c}{ Pearson correlation coefficient } \\
\hline Educational level & Q2 I find it easy to trust others & $\mathrm{r}=.309, \mathrm{p}=.007$ \\
& Q27 As a child, I often felt sad & $\mathrm{r}=.299, \mathrm{p}=.009$ \\
$\begin{array}{l}\text { Performance time } \\
\text { (years) }\end{array}$ & $\begin{array}{l}\text { Q20 From early in my music studies, I } \\
\text { remember being anxious about performing }\end{array}$ & $\mathrm{r}=-.297, \mathrm{p}=.010$ \\
$\begin{array}{l}\text { (erformance form } \\
\text { (solo/ensemble) }\end{array}$ & $\begin{array}{l}\text { Q12 Prior to, or during a performance, I } \\
\text { experience dry mouth }\end{array}$ & $\mathrm{r}=-.298, \mathrm{p}=.009$ \\
\hline
\end{tabular}




\section{Discussion}

The purpose of this study was to explore the relationship between flow experience and MPA. The research questions of this study addressed the relationships between flow and MPA and the effects of various demographic variables on flow and MPA, as measured by rating scale responses.

Canonical correlation tests between flow and MPA indicated that flow was not generally associated with MPA, based on the probability value obtained. Possible explanations for this lack of significance may include the small sample used in this study (insufficient power) or that these scales do measure different constructs and their association is not strong overall (Cohen, 1988). To explore this further, analyses were utilized to ascertain whether there were components of these scales that could be used to determine the relationship between flow and MPA.

Some of these additional exploratory tests did yield significant outcomes. The canonical correlation test between flow dimensions and MPA factors indicated that four dimensions of flow (clear goals, unambiguous feedback, autotelic experience, and sense of control) may help performers to reduce MPA factors. These findings suggest that setting clear goals may help performers reduce their depression, hopelessness, and general transmissions of anxiety. Unambiguous feedback may help performers to reduce their worry and dread and improve their controllability. Using autotelic experience strategies, perhaps thinking positive thoughts about enjoying performing, may help performers to reduce their proximal somatic anxiety. Working to develop a sense of control may help performers to reduce their pre- and post-performance rumination. 
Pearson correlation tests showed that there were a total of eighty-eight negative correlations between items of K-MPAI-R and items of AFSS (see Appendix D), which supports the results of previous studies that reported that flow was negatively correlated with MPA, and that facilitating flow may provide a powerful tool to reduce MPA (Cohen \& Bonder, 2018a; Fullager et al., 2013; Kirchner et al., 2008; Lamont, 2012; Wrigley \& Emerson, 2011). Items analyses indicated that items of four dimensions of flow (clear goals, unambiguous feedback, autotelic experience, and loss of self-consciousness) were most significantly and negatively correlated with MPA items. Three of these are the same as the results of the canonical correlations. The different item, loss of self-consciousness, seems related to the sense of control dimension found in the previous analysis, as both address personal mind-sets regarding performance. Thus, using the items from these dimensions can provide helpful strategies to reduce MPA.

For example, the more one enjoys the performance and feels great and rewarded during music performance, the less feelings of panic may be experienced. Similarly, the less performers are concerned with others' evaluations, or how they are presenting themselves and what others might be thinking of them, the less they will replay the music in their mind over and over after the performance. Finally, the better the music performers know how their performance is going and how well they are doing, the less they will think about whether they will even get through the performance, and whether they will perform well.

Specifically, the clear goals dimension of flow indicated that music performers should have a strong sense of what they want to accomplish, they should know what they want to achieve, and their goals should be clearly defined (Payne et al., 2011). Thus, 
music performers should have clear goals toward both learning and performanceknowing what they want to learn from their study and what they want to express through their music performance. If they establish challenging goals, such goals could be divided into smaller goals, and they could work to achieve these smaller goals step by step. In addition, performers may benefit by sharing their goals with their teachers and peers and asking for suggestions and/or help.

The unambiguous feedback dimension of flow can help music performers reduce MPA, indicating that music performers should strive to know how their performance is going and have a good idea while they are performing about how well they are doing (Payne et al., 2011). Thus, music performers should get immediate feedback before, during, and after their own performance. This feedback may come from themselves and others (teachers, audiences and peers). In their practice before the performance, they should receive immediate feedback from themselves and teachers on their preparation for performing and whether they are ready to perform music in public. During their performance, they should know where they are in the music and be aware of feedback from audiences' responses.

The autotelic experience dimension of flow indicates that music performers can help reduce MPA by learning how to enjoy the performance, feel good about it, and be rewarded by it (Payne et al., 2011). One strategy might be for music performers to first select their favorite pieces for performance. If they like the pieces, that may help them enjoy their practice and performance. Autotelic experience may also be related to performers' motivation, therefore, music educators need to consider different ways of fostering the motivation of their music students. 
Music performers may use strategies related to the loss of self-consciousness dimension of flow to alleviate MPA, including not paying attention to how others might be evaluating them, how they were presenting themselves, and what others might be thinking of them (Payne et al., 2011). Thus, they may use focused attention strategies, like meditation and mindfulness, to quiet their negative thoughts and focus their attention on the music to reduce self-consciousness in their performance.

Assessing themselves based on the twelve factors of MPA may help music performers identify their own MPA and find corresponding strategies from flow items to reduce their anxiety. For example, the factor MQ18 (I am often concerned about a negative reaction from the audience) was significantly correlated with FQ 23 (I was not worried about what others might be thinking of me). Accordingly, we can use this negative correlation to find some ways to reduce attention on negative reactions from the audience, such as focused attention strategies on the performance itself.

Two positive correlations between items of the K-MPAI-R and the AFSS indicated that the more people trust others, the less they will be concerned with how they will present themselves. Also, clear goals can result in a performer remaining committed to performing, even though it has caused great anxiety. Thus, music performers should work to establish trust with others and generate clear performance goals, which can help them focus their attention and keep them on their music track.

Gender, age, education level, major, and performance form were shown to have no direct impact on flow experience, which is consistent with some previous research. Bloom and Skutnick-Henley's (2005) study showed that gender and age had no correlation with flow proneness. Cohen and Bodner (2018a) found that there were no 
significant correlations between gender and flow. Wrigley and Emmerson (2011) found that flow did not vary substantially according to instrument type, year level, or gender. Gender, age, major, and performance frequency also had no direct impact on MPA. This assertion is supported by van Kemenade and van Son's (1995) findings that there was no difference for MPA between women and men, but differs from the study of Wesner, Noyes, and Davis (1990), who reported that women more frequently reported distress and impairment due to performance anxiety than men. Also, these findings differ from the results obtained by Zarza-Alzugaray, Orejudo, Casanova, and Aparicio-Moreno (2018), who found a significant relationship between the age of musical training onset and the individual's currently perceived level of MPA.

Performance time and performance frequency were significantly positively correlated with five items of three flow dimensions (unambiguous feedback, concentration on task at hand, sense of control) indicating that more experienced performers may get more unambiguous feedback and the better attention and controllability from the performance. Although this finding differs from the results of Bloom and Skutnick-Henley's study (2005), which indicated that experience and proficiency levels showed no direct impact on flow proneness, it is possible that increasing practice and performing hours, and taking an active part in various performances, may help music performers to facilitate their flow experience.

Education level was positively correlated with two items of the K-MPAI-R, which indicated that the more educated one was, the more likely the individual would be to trust others, and the more often they felt sad as a child, but the later finding has little practical application. Performance time and performance form were negatively correlated with one 
item of the K-MPAI-R, indicating that more years of performing were associated with less remembrance of being anxious about performing. Also, the participants reported experiencing "dry mouth" symptoms more often with solo performance than in ensembles. These results support those of Biasutti and Concina (2014), in that MPA can be explained by experience and hours of practice per week, and the study of Li (2017), who found that students in solo performance had a higher level of MPA than those in an ensemble. Thus, music performers might be advised to perform as frequently as possible and extend their practice time, especially for solo performances.

\section{Limitations}

A possible limitation of this study may have been using the two scales without any revisions, which perhaps confused some participants and, at the same time, created more difficulties for the researcher in analyzing the data. This was especially true in the K-MPAI-R, where for some of the questions, the answer range was 0-6, while for some other answers, the scale ranged from 6-0. However, explaining this to the participants and analyzing the data carefully helped to solve this problem successfully. Researchers should consider this potential problem in future quantitative studies.

The result of the first canonical correlation test between two sets of items of KMPAI-R and AFSS was not significant. This may be because of the small sample size and the large number of independent and dependent variables. In order to arrive at reliable estimates of canonical factor loadings (for interpretation), Stevens (1986) recommends that there should be at least 20 times as many cases as variables in the analysis, if one wants to interpret the most significant canonical root only. To arrive at reliable estimates for two canonical roots, Barcikowski and Stevens (1975) recommend to 
include 40 to 60 times as many cases as variables. Thus, future studies should consider these factors and increase sample numbers accordingly or select shortened scales for this topic.

\section{Conclusions}

Given the inverse relationship found between many of the scale items representing MPA and flow, it seems reasonable to conclude that participants may benefit from using various aspects of flow to assist them in reducing MPA. A first step may be understanding the factor/factors leading to an individual's MPA and then developing corresponding methods to address those factors. The more strategies that are available to assist musicians who suffer from MPA, the greater the chance that individual might find strategies that work for them in providing relief from the detrimental effects of music performance anxiety may cause. Hopefully, this will assist the performers by making preparation for performing, as well as the performance itself, a more enjoyable and rewarding musical experience. 


\section{CHAPTER FOUR}

\section{Facilitating Flow and Alleviating Music Performance Anxiety}

Flow is "a state of deep absorption in an activity that is intrinsically enjoyable, as when artists or athletes are focused on their play or performance" (Csikszentmihalyi, 2014, p.477). Being "in flow" is the way that someone describe the subjective experience of engaging just-manageable by tackling a series of goals, continuously processing feedback about progress, and adjusting action based on this feedback (Nakamura \& Csikszentmihalyi, 2014, p. 90). Such optimal experiences have been reported in a wide variety of domains, including leisure (Csikszentmihalyi \& Csikszentmihalyi, 1988), sports (Jackson \& Marsh, 1996), work activities (Demerouti, 2006), and music listening (Diaz, 2011), composition (MacDonald, Byrne, \& Carlton, 2006) and music performance (O'Neill, 1999).

Music performance anxiety (MPA) has been defined as "a constant, continuously distressful feeling that may impair performance in a public context and affect an individual's musical aptitude training and overall level of performance" (Valentine, 2002, p. 167). The incidence of MPA in different fields is quite high (Studer, Gomez, Hildebrandt, Arial, \& Danuser, 2011) and MPA has been reported to have a negative impact on musicians' and students' well-being and health (Owen, 2009; Steptoe, 2001). Authors of several studies have suggested that generating a flow state could be one effective way to reduce performance anxiety (Allison \& Duncan, 1988; Cohen \& Bodner, 2018a; Cohen \& Bodner, 2018b; Fullagar, Knight, \& Sovern, 2013; Kirchner, Bloom, \& Skutnick-Henley, 2008), but specific strategies were not provided.

Accordingly, the current study is focused on the experiences of flow and MPA. 
My goal was to provide a specific theoretical framework for facilitating flow and reducing MPA. Thus, the following research questions guided my exploration: What is the relationship between flow and MPA experiences? How can we use flow to reduce MPA?

Flow

Csikszentmihalyi has identified nine dimensions and three conditions of flow (Csikszentmihalyi, 1994), including challenge-skill balance, action-awareness merging, clear goals, unambiguous feedback, concentration on the task at hand, sense of control, loss of self-consciousness, autotelic experience, and time transformation. The three conditions for achieving flow include: 1) the challenge/skill balance; 2) clear goals; and, 3) immediate feedback (Nakamura \& Csikszentmihalyi, 2002).

Several additional factors have been identified as facilitators of flow. Csikszentmihalyi (2017) provides two detailed strategies for attaining flow more frequently: providing "space" in one's psyche (keeping an open mind, meditation, putting the mind at rest), and internal representations (mental visualizations and self-suggestion). Additional facilitators of flow include an autotelic personality and autotelic families (Nakamura \& Csikszentmihalyi, 2014). Autotelic personality means a person who tends to enjoy life or "generally does things for their own sake, rather than in order to achieve some later external goal" (Csikszentmihalyi, 1997, p. 117). Autotelic family means a complex family environment that simultaneously provides support and challenge. Students from complex families spend significantly more time in high-challenge, highskill situations and less time in low-challenge, low-skill situations than did the students from other types of families (e.g., ones that provided support or challenge alone) 
(Nakamura \& Csikszentmihalyi, 2014, p. 99). In sports, specific factors identified as influencing flow include: focus, preparation, motivation, arousal, thoughts and emotions, confidence, environmental and situational conditions, feedback, performance, and team play and interaction (Swann, Keegan, Piggott, \& Crust, 2012, p. 813). Accordingly, flow facilitators include appropriate focus, effective preparation, optimal motivation, optimal arousal, positive thoughts and emotions, high levels of confidence, optimal environmental and situational conditions, positive feedback, starting well, and positive team play and interaction (Jackson, 1992; Jackson, 1995).

Barriers to achieving flow are found in both physical and psychological aspects. Physical barriers include time, money, commitment/responsibility, and illness/disease/health problems. Psychological barriers include feeling of inadequacy, fear of others, fear of failure, comparison, and negative beliefs (Flow State Philosophy, 2017). Moreover, two impediments of flow that concern the subjective construction of experience include preference for relaxation and attitudes towards work and play (Nakamura \& Csikszentmihalyi, 2014).

\section{Music Performance Anxiety (MPA)}

In music performance, one experience contrary to flow is music performance anxiety (MPA). MPA is defined as "the experience of persisting, distressful apprehension about, and/or actual impairment of, performance skills in a public context, to a degree unwarranted given the individual's musical aptitude, training, and level of preparation" (Salmon, 1990, p. 3). The incidence of MPA in different fields is quite high and MPA can negatively affect musicians at any stage of their career (Cohen \& Bodner, 2018a). 
Factors found in previous studies that influenced MPA were either internal or external. Internal attributions include genetics (Kenny, 2006), neuroticism and negative self-statements (Steptoe \& Helen, 1987), gender and extroversion (Andrew et al., 1995), individual differences and personality factors (Hallam, 2002), metacognitive skills, age, expectancy and achievement attributions (Papageorgi, Hallam, \& Welch, 2007), selfefficacy (Topoglu, 2014), and perfectionistic tendencies (Kenny, 2006; Mor, Day, and Flett, 1995). External attributions include life history, previous experiences (Kenny, 2006), family and peers (Hallam, 2002), musical training, occupational stress, preparation, learning approach, pedagogy, task difficulty, audience, performance conditions, conductors (Ryan \& Andrews, 2009), performing experience (Osborne, Kenny, \& Holsomback, 2005), and the situation (Harris, 1986; Michiko, Kazutoshi, Takayuki, \& Tatsuyuki, 2009; Papageorgi et al., 2007; Salmon, Schrodt, \& Wright, 1989).

There are three main kinds of approaches to relieve MPA: behavioral, psychological, and cognitive. Behavioral approaches include progressive muscle relaxation (Grishman, 1989; Kim, 2008; Lehrer, 1987; Mansberger, 1988), insight relaxation and systematic desensitization techniques (Wardle, 1969), awareness and breathing techniques (Deen, 1999; Robertson \& Eisensmith, 2010), pre-performance routines, anxiety hierarchy, supportive lifestyle habits (Parncutt \& McPherson, 2002), some aspects of the Feldenkrais and Alexander methods, drugs, yoga, and Tai Chi (Lehrer, 1987). Psychological approaches mainly include self-hypnosis (Lehrer, 1987), imagery treatment (Kim, 2008), and exposure therapy (Garner, 2014; Spahn, 2011). Cognitive approaches include attention training, e.g., "Stress Inoculation Training" (SIT), which refers to a set of procedures to help people under stress become aware of the 
source of the stress, develop effective coping skills, and put these skills into daily practice (Salmon \& Meyer, 1992); behavior rehearsal, viewing anxiety as positive (Hanton \& Jones, 1999; Meichenbaum, 1985; Roland, 1992), positive self-talk (Seligman, 1995), mental rehearsal and imagery (Murphy \& Jowdy, 1992; Roland, 1992), and goal setting (Burton, 1992).

However, there are few well-conducted studies that have assessed the effectiveness of these treatments (Fullagar et al., 2013). Kenny (2005) reviewed the treatments of MPA and concluded that "the literature on treatment approaches for MPA is fragmented, inconsistent, and methodologically weak" (p. 206). Accordingly, several studies suggest that generating a flow state is one effective way to reduce MPA (Allison \& Duncan, 1988; Cohen \& Bodner, 2018a; Cohen \& Bodner, 2018b; Fullagar et al., 2013; Kirchner et al., 2008).

\section{Relationship between Flow and MPA}

A few researchers have studied the relationship between flow and MPA and indicated that the two are negatively correlated and that fostering techniques for facilitating flow may provide a useful tool for helping to reduce MPA and facilitate optimal performance (Allison \& Duncan, 1988; Cohen \& Bodner, 2018a; Cohen \& Bodner, 2018b; Fullagar et al., 2013; Kirchner et al., 2008). However, these studies failed to provide specific strategies on how to facilitate flow to reduce MPA.

Four videos on YouTube provide some strategies on using flow to reduce MPA. Manvelyan (2018) provides an online course that includes three ways to reach the state of flow and overcome stage fright: control negative thoughts and the body's stress response, be confident and motivated, and focus. Anderson's video (2013a) provides two ways for 
musicians to reduce performance anxiety that comprise visualization and breathing techniques. Her second video (Anderson, 2013b) contains two additional ways: controlling tempo practice and knowing a piece very well. Gudde's TED talk (2014) provides strategies of how a performer can relax in music performance using flow power, listening, closing eyes, using relaxing tempos, and quieting thoughts.

The purpose of this study was to contribute to the literature regarding the relationships between flow and MPA and provide a theoretical framework on facilitating flow and reducing MPA. I sought to confirm the relationship between them, and provide a theoretical framework on facilitating flow to alleviate or overcome MPA.

\section{Method}

A grounded theory approach (Strauss \& Corbin, 1998) was selected because of the lack of knowledge regarding the relationship between flow, MPA, and strategies on facilitating flow to reduce MPA. This approach was also used to develop a theoretical framework for facilitating flow and reducing MPA.

\section{Participants}

Purposeful sampling methods (Creswell, 2013) were used in this study, primarily criterion sampling. Criterion sampling refers to choosing samples that meet some prespecified criterion (Harley et al., 2009). Criteria for this study's participants were graduate music students having sufficient music performance experience (defined as performing music for more than 20 years) and familiarity with the topic based on completion of a two music education courses where material on both flow and MPA were presented. Accordingly, I emailed ten class members of which seven graduate music education students responded and participated in this study. Six were Ph.D. candidates in 
music education, and one was a master's student who had recently finished her studies and now is an elementary music teacher. They all had taken the courses "Psychology of Music Instruction and Performance" and "Current Issues in Music Education" during their degree study, in which flow and MPA were covered systematically. Participants stated their music performance media, when they began their study, and what type of performance experience they had, as shown in Table 19.

Table 19

Participants

\begin{tabular}{|c|c|c|c|c|}
\hline Name* & Gender & Performance Media & Starting Age & $\begin{array}{l}\text { Performance } \\
\text { Experiences }\end{array}$ \\
\hline Rebecca & Female & Piano & $\begin{array}{l}\text { From five years } \\
\text { old }\end{array}$ & $\begin{array}{l}\text { Informal } \\
\text { performance until } \\
\text { high school }\end{array}$ \\
\hline David & Male & Piano & $\begin{array}{l}\text { When he was just } \\
\text { a child }\end{array}$ & $\begin{array}{l}\text { Informal } \\
\text { performance until } \\
\text { college }\end{array}$ \\
\hline Joe & Male & Vocal & From young & $\begin{array}{l}\text { Performed a lot at } \\
\text { church, school, } \\
\text { singing festivals }\end{array}$ \\
\hline Andrea & Female & Piano & From ten years old & $\begin{array}{l}\text { Informal } \\
\text { performance until } \\
\text { college }\end{array}$ \\
\hline Maggie & Female & Piano and French Horn & From six years old & $\begin{array}{l}\text { Many performance } \\
\text { opportunities }\end{array}$ \\
\hline Jennifer & Female & Vocal and Piano & $\begin{array}{l}\text { From seven years } \\
\text { old }\end{array}$ & $\begin{array}{l}\text { Mainly performed } \\
\text { in church }\end{array}$ \\
\hline Victoria & Female & Pipa & $\begin{array}{l}\text { From five years } \\
\text { old }\end{array}$ & $\begin{array}{l}\text { Informal } \\
\text { performance until } \\
\text { college, ensemble } \\
\text { every Monday in } \\
\text { college }\end{array}$ \\
\hline
\end{tabular}

*Note: All names are pseudonyms.

\section{Data Collection}

Data were collected by in-depth interviews. Before the interviews began, the purpose of the study was explained to the participants. They signed an informed consent form in which they were notified that they would not suffer any ill effects from this research, their participation was voluntary, they could say "no" to any question they did 
not feel comfortable answering, and finally, they could stop the interview at any time, in accordance with IRB approval of the study (see Appendix A).

The questions asked in the interviews referenced participants' music study background, MPA experience, flow experience, the relationship between flow and MPA, whether and how flow can be used to reduce MPA, and feedback on this research project. Six interviews were completed in person, and one interview was completed through email. A digital recording was used for transcriptions in six of the interviews, with the permission of participants, and the e-mail was used as the written transcript for the participant responding in that format. After transcribing the recordings, transcripts of interviews were shared individually with the seven participants through e-mail with a request for feedback and clarification in order to enhance the trustworthiness of the data (Creswell \& Miller, 2000).

\section{Data Analysis}

The basic principles of grounded theory data analysis (Strauss \& Corbin, 1998) guided this study. Microanalysis was used for all interviews to ensure that no important ideas were overlooked. The process of coding included categories, key points, and themes. The categories derived from the interview data include: learning background, MPA experience, flow experience, relationship between flow and MPA, strategies on using flow to reduce MPA, and feedback. Finally, a theoretical framework, the final product of the study, explains the central themes of the data.

\section{Reliability and Credibility}

"Reliability can be enhanced if the researcher obtains detailed field notes by employing a good quality recorder and by transcribing the recording to a written format" 
(Creswell, 2013, p. 253). Accordingly, a digital recording pen was used for recording interviews and generating material for transcribing. Recording tests were performed before all interviews to ensure that the recording pen worked properly. After the interviews, I listened to the recordings repeatedly to ensure the reliability of the transcripts.

Member checking was also used to enhance the credibility of the data in this study. In member checking, the researcher solicits participants' views on the credibility of the findings and interpretations (Erlandson et al., 1993). This technique is considered by Guba and Lincoln (2005) to be "the most critical technique for establishing credibility" (p. 314), this approach involves taking data, analyses, interpretations, and conclusions back to the participants so they can judge the accuracy and credibility of the account (Creswell, 2013 , p. 252). Thus, interviewees were invited to provide feedback on interview questions and to offer personal suggestions for this study. They also were invited to check the transcripts of their corresponding interviews and provide suggestions on coding results through an e-mail inquiry after interviews were completed. Lastly, after study completion, participants were invited to read the findings and interpretations of this inquiry and provide their suggestions. Because the participants were all well informed advanced graduate students, their feedback also served in the role of peer debriefing.

\section{Findings and Discussion}

The findings will be presented in six sections. The transcripts of interviews were divided into five categories: 1) the learning background of participants, 2) the experience of MPA, 3) the experience of flow, 4) the relationship between flow and MPA, 5) strategies on using flow to reduce MPA, and 6) feedback on this study. 


\section{The Learning Background}

The participants in this study began to learn music from 5 to 10 years of age and performed in four types of places: church, school, festivals, and competitions.

Participants included three piano majors, one voice major, one voice major and piano minor, one piano major and French horn minor, and one pipa major (Chinese stringed instrument). Performances during their childhood were primarily informal until high school or college.

\section{The Experiences of MPA}

The MPA experiences of participants were characterized by levels, causes, strategies, and effects.

Level. Participants had different levels of MPA, but none reached a level of "fear" that was debilitating. Rebecca and Andrea described similar anxiety experiences, which were the most negative MPA experiences of those interviewed. Rebecca reported that:

Growing up I didn't have a lot of anxiety, but once I got into college and played more serious, confusing, and complex music definitely I had some anxiety. I don't have some specific experience where I was like super nervous, but usually I was generally nervous and kind of just worked through it in the performance. But there was one time when I was playing in a student recital and my memory just completely left me, like right before starting to play. It was just gone, so that was probably the worst anxiety moment I ever had.

Andrea stated:

I had serious anxiety in most of my performances, but they didn't interrupt my performance except during one rehearsal. In the rehearsal, I was too nervous to remember my score, I couldn't find the key of my score, and I replayed and repeated until I couldn't remember anything of it, and finally, I gave up on that rehearsal. But it was a good thing for my performance later because, after that, I tried to prepare myself as much as possible to overcome my anxiety of performance, and I have never given up in any performance after that. 
Causes. Participants had different anxiety levels because of different causes. For David, the better sense of performance cues, the less anxiety he had, and the more responses from the audience, the less anxiety he had. Jennifer explained that when music was difficult for her, and when she played music in front of people she didn't know, she started having anxiety. Also, memorization was another cause of her MPA. Rebecca reported that if she had a lot of time to prepare or if she had a relaxing day, she would be less nervous. For Victoria, external pressure led to her MPA, including competitors and interviews. She also had higher anxiety in solo performance than in ensembles. Andrea thought that the causes of her MPA were poor concentration, poor practice and high expectation of herself. Maggie was most nervous in her hour-and-a-half long diploma recital with challenging material, and she thought her MPA mostly came from her family, who all had a strong background in music. In the case of Joe, anxiety mainly came from "the desire to do well," "labels", and "high expectations." Thus, attribution of their MPA included internal (memory, preparation, poor concentration, high expectation, and not enough practice) and external (difficulty of the piece, family approval, combination of things, audiences, environment, labels, competitors, and interviewers).

Strategies. Participants had individual strategies for overcoming their MPA, and their strategies could be divided into three kinds: behavioral (good preparation, segmented practice, playing long warm ups, breathing exercises, slowing their pace, talking with others before performance, and relaxing themselves), psychological (performance cues, meditation, mindfulness, confidence, recalling the piece before the 
performance), and cognitive (memory strategies, collecting yourself) strategies. For

example, David described his practice strategy and performance strategy separately, explaining:

For memorization, I use a segmented strategy. On piano, I learn one hand at a time: right hand first for a little ways, then the left hand, and then put them together. Then I play the music over and over and go right hand only, then left hand only, and together until I can play the music absolutely perfectly without thinking about it. Then I go on to the next four measures, right hand only, left hand only, right hand only, left hand only, and then put them together. That's how I do it, with the segmented strategy, and one hand at a time.

For a live performance, the main thing is to feel good inside and to feel confident about your ability to perform. You have to feel good about yourself. You can't go out there feeling like you will not be performing well. You have to think positively. That's my performance strategy. Another thing you need to do is collect yourself. Slow down and relax. Don't rush things. Maintain a real positive attitude, relax, and don't rush the performance. If you rush, music performance goes too fast. You have to slow down and take it easy.

Effects. Four participants thought MPA was positive to their performance.

The reasons provided were "how much I practice is related to how nervous I get, "I love performing," "MPA helped me focus," and "if somebody taught you some strategies to overcome MPA, then you will feel more confident to fix it." Andrea thought MPA was negative for her performance. She said she doesn't like MPA at all, that it's the biggest obstacle to her music performance. David thought that MPA was positive in practice but was negative in formal performance. Victoria thought that MPA was neither positive nor negative for her music performance because it is just a normal psychological and physical reaction.

\section{The Experiences of Flow}

The flow experiences of participants were characterized by levels, causes, and effects. 
Level and causes. Participants all experienced flow at different levels because of different situations. For example, Rebecca experienced flow in longer performances, David experienced flow when he thought about his technique and the artistic expression in his performing, Andrea experienced flow mostly in practice with a favorite piece, and Victoria experienced flow in the middle or end of her performances.

Effects. As a whole, participants had consistent and positive opinions on the effects of flow in music. For example, Joe stated,

Extremely positive. It's like a good workout. I'm very tired afterwards, but in a good way. Those moments have garnered more praise from those listening than normal because they have seen me give myself completely over to the music and experience.

David claimed that,

Flow is the ultimate goal in a performance. You are able to create an artistic interpretation of the music when you are in the "flow." You can shape the music and create an artistic expression if you want. You can be a creative and artistic musician. It allows you to be artistic.

\section{The Relationship between Flow and MPA}

After sharing their flow and MPA experiences, participants were asked a question on the relationship between flow and MPA. Overall, the participants in this study thought that the relationship between flow and MPA was negative, which means that if a performer is really anxious, it's harder to experience flow, and, if the performer is in the flow, there is no anxiety. But Rebecca also stated that if someone is just normally anxious, it's a pretty typical experience, then, after getting over that, the person can experience flow too. David expressed a different perspective, however: 
I think flow and anxiety are like yin and yang. You can't have one without the other. They are connected like night and day. You need both, I guess, but not too much anxiety. Too much can be debilitating. A little anxiety can encourage you to practice when you don't want to and that's it. When you get on stage you shouldn't feel any anxiety unless you're getting off track. You should be feeling confident and happy about performing and anticipating a "flow" experience where you are free to create an artistic experience for your audience to enjoy. You shouldn't feel anxiety on stage.

The nine components of flow $(\mathrm{MAA}=$ merging actions and awareness; $\mathrm{CG}=$ clear goals; $\mathrm{CO}=$ concentration on task at hand; $\mathrm{UF}=$ unambiguous feedback; $\mathrm{CS}=$ challenge/skill balance; $\mathrm{TT}=$ transformation of time; $\mathrm{CN}=$ sense of control; $\mathrm{SC}=1$ loss of self-consciousness; $\mathrm{AE}=$ autotelic experience) were provided for participants to consider whether they related to flow and MPA and to also apply these components in their deliberation about the relationship between flow and MPA. Five participants believed that all of these components could lead to flow and lower anxiety. Rebecca thought that "sense of control" and "transformation of time" were definitely related to anxiety-if she has gets over the anxiousness and enter into the flow, time seems to pass much faster than normal and she feels more in control. Victoria thought that if goals were too demanding, it might increase anxiety.

Csikszentmihalyi's flow model (Csikszentmihalyi, 1997) was used in interviews to help participants think about the relationship between flow and MPA based on the challenge/skill balance (CSB) (see Figure 10). 


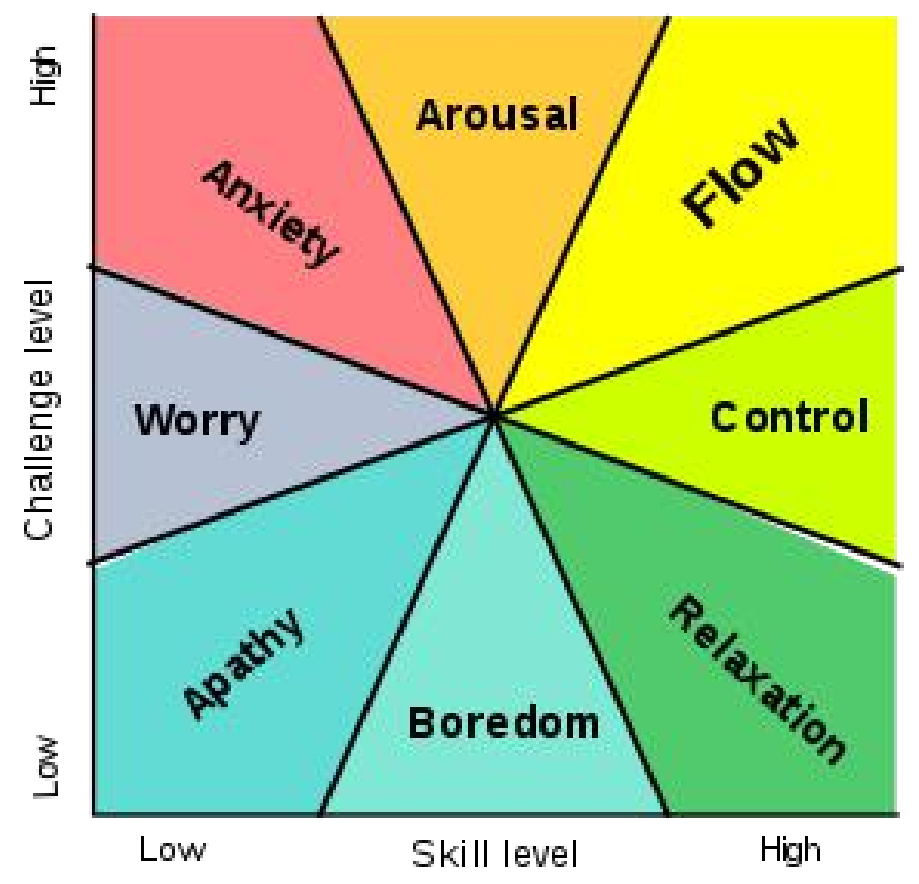

Figure 10. Mental state in terms of challenge level and skill level, according to Csikszentmihalyi's flow model (Csikszentmihalyi, 1997, p. 31)

Participants all agreed with this model, which depicted the CSB. Two participants gave different thoughts on portions of this model. Rebecca thought that anxiety should include medium or high skill levels. She thought it was still possible to be anxious with a high level of skill. Victoria expressed that when you have high skill but the task is not very challenging, you can still experience flow.

\section{Strategies on Using Flow to Alleviate MPA}

The next question posed was about strategies on using flow to alleviate MPA.

Rebecca thought that making flow as a goal and teaching herself to get into flow could help to overcome anxiety.

I think kind of making flow as a goal can help you overcome anxiety. I am not sure, how you would do that, how you would teach yourself to experience flow. When I experience it, it's kind of just automatic. It happens sometimes, it doesn't happen other times. But I think if I could teach myself to get in the flow more often, I think I would be less anxious. 
David proposed that musicians can use flow in practice as a signal of readiness to perform in public.

I think that when you know you are ready to perform in public, when you know you can just walk into a practice room and play your music, and detach yourself and think freely, and shape the music, I think you're in the flow and you know you are ready to perform. So, you can use "flow" in practice as a signal that you are ready to perform in public. Anxiety should naturally go away when you play in "flow."

Joe thought that by examining the steps to flow, perhaps some performers would achieve this state more often, but that would take specific strategies of overcoming MPA — just knowing about flow won't help. Andrea thought that music education coursework should cover these two concepts and provide specific steps for facilitating flow and reducing MPA. Maggie discussed her perspectives as a performer and teacher:

I think the first thing we should know is what causes music performance anxiety and assess it individually. And then figure out what we can do to manage those anxieties and then possibly try to set up a flow experience. So, for me, the breath, meditation, could help, just focus on the task at hand, quiet the voice like "don't forget the measure", I think you are allowing yourself those flow opportunities.

I think it is tough to describe how to introduce flow to our students but we can describe the steps you can take to set yourself up to this experience, make students prepare for the performance. So, I think the first step is letting your students know it's possible from there to go further. Like I said, make sure your students prepare and prepare correct ways. Maybe we identify anxiety earlier, teaching them and showing performance with that.

Jennifer thought that teachers need to figure out strategies on teaching someone to know flow; teachers give strategies for memory, for example, and some strategies may be helpful for somebody to understand flow theory and know if they are reaching these components. Victoria thought that the prerequisite to experiencing flow is that the performer should have enough skills before going on the stage. She thought that the CSB is important for experiencing flow and reducing MPA. 


\section{Feedback}

The last question of the interview was "Do you think these questions are related to my research topic? Do you have any suggestions on this study?" All participants thought that all interview questions were related to this study topic, and four participants gave valuable suggestions for this study. David and Joe suggested explaining the concepts of flow and MPA before doing the interview for other interviewees, which was applied in later interviews. Andrea suggested using more ways to collect data, like mixed methods, to support this study. Maggie suggested inviting a variety of students as participants to match the variety of music majors in this study.

\section{Theoretical Framework}

Combining the causes of MPA, strategies to overcome MPA, causes of flow, the relationship between flow and MPA, and the strategies for using flow to reduce MPA, a framework of three themes for facilitating flow and reducing MPA appeared from the data that was consistent with the related research literature. These themes consisted of preparation of performers, modeling by teachers, and construction of flow experience (Figure 11). 


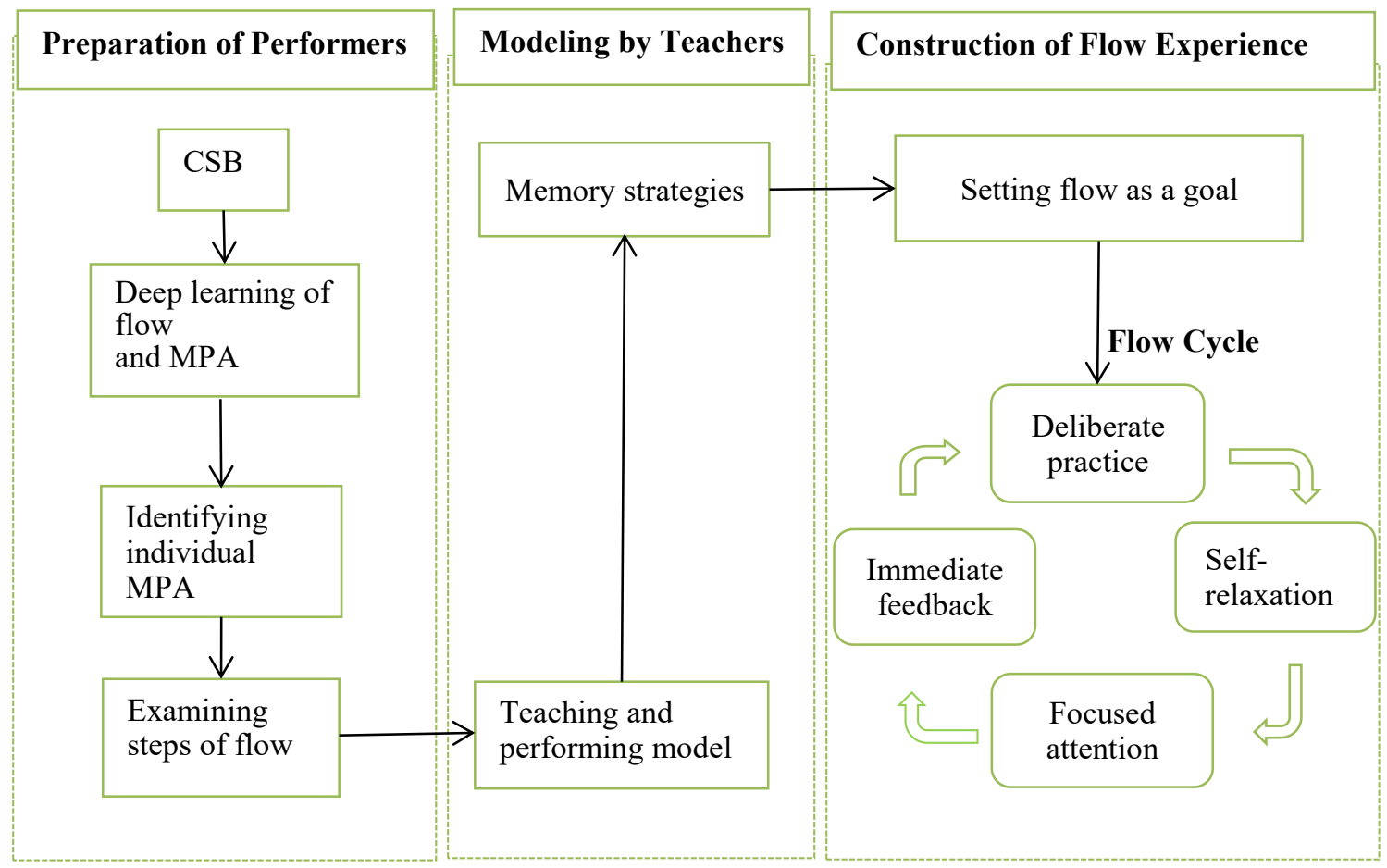

Figure 11. Theoretical framework: facilitating flow and reducing MPA

\section{Preparation of performers}

The first theme of the framework is the preparation of performers. Based on Question 5 data from the interviews, performers need a good preparation before performing to facilitate flow and reduce MPA. Preparation includes challenge/skill balance (CSB), deep learning of flow and MPA, identifying individual MPA, and examining steps of flow.

Challenge/skill balance (CSB). Both flow and MPA were associated with CSB (Fullagar et al., 2013). Music that is too difficult will leave a musician nervous and a piece that is too easy will lead to boredom (Jackson \& Csikszentmihalyi, 1999). In Csikszentmihalyi's flow model, the "flow" part illustrates CSB, and "anxiety" describes the feeling one tends to have when challenges are perceived to be higher than one's skill. All participants agreed with this model in the interviews. For example, David said, 
If the music is very challenging, I am going to feel anxiety. The anxiety usually goes away the more I practice. The more practice, and the better I practice, the less anxiety I have. I am not going to play something in public anyway if I am not able to, so my skill level should match the music.

Jennifer stated that if you don't have the skills to do something, you will have anxiety, and if you have something really hard, you will not go into flow. Victoria thought that the prerequisite for achieving flow is that the performer should have sufficient skills before going on stage. Thus, it seems appropriate to keep CSB as the first component for music performers to achieve flow and reduce MPA.

Deep learning of flow and MPA. Even though all participants took psychology and music education classes that covered flow and MPA, some of them asked for more explanation on these two concepts during interviews, and some needed more knowledge to understand flow theory. Joe said that if random people were asked about this, they probably wouldn't know what flow theory was, so they wouldn't understand how to relate flow and MPA. As mentioned previously, David gave a suggestion to explain the concepts of flow and MPA before doing the interviews for future interviewees. Maggie said that she didn't know about the concept of flow until taking a music education class in her doctoral program of study. Jennifer said she was "kind of familiar with flow, but not really." Thus, educating music performers about flow and MPA seems important. The flow concept needs to be learned in depth to assist in reducing MPA.

Music educators should not only cover flow and MPA concepts but also examine the strategies on facilitating flow and reducing MPA. Andrea thought that music education coursework should cover flow and MPA concepts, especially the specific steps on facilitating and achieving flow. Jennifer said that music teachers need to figure out strategies for teaching someone to understand flow, including strategies for memory and 
for understanding the nine components of flow and whether they are reaching them.

Identifying individual MPA. Participants in this study had different levels, causes, and strategies for overcoming MPA. For MPA levels, some had general nervousness, like Rebecca, and some had serious nervousness, like Andrea. The main causes of their MPA included a combination of things. If it's a really busy day, Rebecca is not able to think about performing; she will be less nervous if she has had a relaxing day. Other responses included audience and environment (David), desire to do well (Joe), high expectation and less practice (Andrea), family approval (Maggie), memory (Jennifer), and external pressure (Victoria). Their individual strategies on reducing MPA were also different. For example, Rebecca used the playing of long warm-ups, David used a segmented memory strategy, Joe used relaxation methods, like deep breathing, and Andrea used adequate practice time. Thus, identifying individual MPA is important for performers to reduce their own MPA.

Maggie thought that the first thing we should know is what causes MPA, assess it individually, and then, figure out what can be done to manage those anxieties and set up a flow experience. Identifying an individual's MPA includes a cause analysis, an assessment of MPA, and strategies on managing those specific types of anxieties.

Examining steps of flow. In the interviews, Joe and Andrea discussed that examining the specific steps of flow is a good way to begin using flow to reduce their MPA. However, flow facilitators have primarily been studied in the field of sports, not music (Nakamura \& Csikszentmihalyi, 2014; Jackson, 1992; Swann et al., 2012). Interestingly, though, Sinnamon, Moran, and O'Connell (2012) found that the way in which flow was experienced in the music conservatory did not differ from the experience 
of flow in sports. Thus, in future studies, it may be productive to test the effects of facilitators of flow in sports as transferred to music performance. These effects include appropriate focus, effective preparation, optimal motivation, optimal arousal, positive thoughts and emotions, confidence, optimal environmental and situational conditions, positive feedback, starting well, and positive team play and interaction (Jackson, 1992; Jackson, 1995). Such studies may provide specific steps to achieve flow in music performance.

\section{Modeling by Teachers}

The second theme of the framework on facilitating flow and reducing MPA is modeling by teachers, which includes providing teaching and performance models and sharing memory strategies. This theme supports Bakker's (2005) study, which indicated that flow may cross over from teachers to their students.

Teaching and performing model. Maggie thought that music teachers could describe the steps students can take to set themselves up for a flow experience. She described the first step as letting students know it is possible to experience flow and make sure students prepare and prepare in correct ways. Then, modeling and demonstrating performance is another key component. As noted previously, Rebecca said that if she can teach herself to get in the flow more often, she thought she would be less anxious, but she didn't know how to do that.

Teachers need to teach and to model performing music in ways that reflect the specific steps of flow experience. The implication for music teachers is that they should not only teach knowledge of flow and MPA, but also demonstrate to students what flow and MPA experiences look like, especially using flow to decrease MPA. The implication 
for music learners is that they should not only learn from teachers' teaching but also learn from their performance modeling.

Memory strategies. Teachers provide students with memory strategies that can help them facilitate flow and reduce MPA. Rebecca and Jennifer attributed their MPA to memorization. The main method for Jennifer to overcome her MPA was using memory strategies taught by her teacher. She explained,

My piano professor helped me to really process my feelings and we always had the opportunity to practice on the stage that we were going to be performing on. So, I have more anxiety for solo piano than for singing in a group or singing in a church. With more experience, my anxiety has been alleviated, but with piano, she really helped me memorize music in different ways. So, I would look at the section, I would read through the piece of music just visually and to be able to recognize different sections of the music. So, I would have the music in my head visually to look at. She would have me like skip ahead and play one section, then go back to the beginning, just like I'm pointing different places. I got to play on the piano that I was performing on, so just a lot of memory strategies helped me a lot to feel confident.

Similarly, David used segmented memory strategy to overcome his MPA.

Based on individual differences, music teachers should provide multiple memory strategies for students to practice and find the most effective one for themselves. Mishra (2011) invested the effectiveness of four memorization strategies: holistic, segmented, serial, and additive, and found that the holistic strategy was significantly more efficient than the segmented and serial strategies. But, for David and Jennifer, a segmented strategy worked best for them, so when teachers teach or select memory strategies for students, they need to base these strategies on the students' practice preferences and individual differences.

\section{Construction of Flow Experience}

The third theme of the framework to facilitate flow and reduce MPA is the 
construction of a flow experience. The first step in the construction of a flow experience is setting flow as a goal and the second step is experiencing a flow cycle that includes deliberate practice, self-relaxation, focused attention, and immediate feedback.

Setting flow as a goal. Previous researchers have indicated that flow and MPA are antithetical experiences, such that "when flow was highest, performance anxiety was lowest and vice versa" (Fullagar et al., 2013, p. 236). Also, participants in this study all thought that flow and MPA have a negative relationship; when they experienced flow, they had low anxiety or no anxiety. Rebecca said that using flow as a goal can help to overcome MPA - if she could teach herself to get in flow more often, she would be less anxious. David thought flow is the ultimate goal in a music performance. Thus, setting flow as a goal is the first step in constructing a flow experience.

Experiencing a flow cycle. Flow experiences don't happen all the time. Most participants experienced flow sometimes, although Maggie just experienced flow once, and only David experienced flow very often. Therefore, factors and conditions for occurrence of flow are worthy of analysis and study. Based on the causes and strategies to overcome MPA, causes of participants' flow experiences and strategies on using flow to reduce MPA, the flow cycle includes four parts: deliberate practice, self-relaxation, focused attention, and immediate feedback.

Flow cycle begins with the deliberate practice. Based on the interview with David who experienced flow very often, the factors that led to his flow experience are the abilities to eliminate anxiety and engage in segmented learning during his deliberate practice rehearsals. He used performance cues and flow signal in his deliberate practice. 
He discussed a technique called "performance cue" that a musician can use when learning a piece of music:

For example, if you are going to perform a three - movement sonata from memory that lasts 20 or 25 minutes, you need to establish weigh points along the way. The cues act as weigh points and help keep you on track: where you are, where you've been, and where you're going. If you use the cues, you won't lose your place. They keep you on track. The better my sense of performance cues, the more confident I am, and the less anxiety I have. So, it's fair to say that good performance cues minimize performance anxiety.

Another aspect of David's deliberate practice is using flow as a signal that you are ready to perform in public, as noted previously.

The second part of the flow cycle is self-relaxation. Self-relaxation was used by most participants for overcoming their MPA or facilitating their flow experience, even though they used different individual methods to relax themselves. Rebecca used self-talk for relaxation. She thought that the factors that led her to a flow experience were relaxing, getting herself to the stage or wherever she was playing, just being able to tell herself "OK, I am already here. I am already playing. I got over that anxious moment. Now I am relaxed." David used slowing down and relaxation to collect himself during music performance and he suggested not to rush things, because if he rushes, the performance goes too fast. Thus, his relaxation strategy is to slow down and take it easy. Joe used taking slow and deep breaths to overcome his MPA. Andrea used some body exercises to relax herself, like deep breathing, stretching her arms and legs, and shoulder exercises. She said she experienced flow more often in her practice than in formal performance because she felt more relaxed in the practice room than in the formal performance environment. Maggie used breathing strategies, too, but she mainly used focused attention, to be discussed in the next section. Victoria used talking to others before her 
performance to relax herself. Accordingly, music performers can use their own relaxation preferences to relax themselves before music performance. Both physical and psychological methods may facilitate flow and reduce MPA.

The third part of the flow cycle is focused attention. "Concentration on task at hand" is one of the nine components of flow (Csikszentmihalyi, 1990). All participants thought that if performers had "concentration on task at hand," it would be easier to get into a flow state and reduce anxiety. This factor led to Jennifer's flow experience during high levels of intense focus. Joe focused his mind on having fun or on the "bigger" picture of why he is performing to reduce MPA. Maggie allowed herself flow opportunities though meditation, mindfulness, focus on the task at hand, and silencing her internal voice. An inhibitor of focused attention is negative thoughts, so David thought that the main thing for a live performance is the performer's attitude. Another strategy of David's to overcome negative thoughts is that he wants to detach himself from thinking about what notes he is playing and think instead about shaping an artistic expression and conveying an aesthetically pleasing interpretation of the music for the audience.

The last part of the flow cycle is immediate feedback, another one of the nine components of flow. David thought the response from the audience was important for his MPA. He said,

One thing to keep in mind though is that if the audience response is really good, and you keep on playing longer than you should, all of a sudden you are not playing very well and you know it. Then your anxiety level will go up and your audience response will drop off. So, you gotta know when to quit. When you've done your job, get off of the stage as soon as you can. Leave the audience wanting more.

Immediate feedback, another of the nine components of flow, also comes from team interactions. This factor led to Maggie's flow experience as an ensemble member in 
which performers developed close personal connections. They all played together for a very long time, so they knew each other, including their conductor. Ensemble members all knew their conductor's visual cues and non-verbal facial expressions during music performance, and they understood what was needed. All participants agreed that immediate feedback is a factor that can lead to a flow experience and lower MPA.

\section{Conclusion}

The purpose of this study was to confirm the relationship between flow and MPA and to provide a theoretical framework on using flow to alleviate MPA. Findings indicated that the relationship between flow and MPA was negative, which means that if someone is very anxious, it is more difficult to experience flow, and, if a person is in flow, there is no anxiety. Most participants thought that flow components could lead to a sense of flow and reduce MPA. Also, they thought that the CSB model can reflect the relationship between flow and MPA. These results indicated that the use of flow components and the CSB model can help to reduce MPA.

A theoretical framework was derived from the analysis of these interviews and identified three steps for facilitating flow and reducing MPA: preparation of performers, modeling by teachers, and construction of flow experience. The preparation of performers includes keeping a challenge/skill balance (CSB), deep learning of flow and MPA, perhaps through music education classes, identifying individual MPA (causes, levels, and effects), and examining specific steps of flow in one's music performance. Teachers of performers should provide modeling to show their students what flow and MPA are and provide memory strategies for their students. Then, performers need to construct a flow experience by setting flow as a goal and experiencing a flow cycle which 
includes deliberate practice, self-relaxation, focused attention, and immediate feedback. This framework provides specific strategies on facilitating flow and reducing MPA, filling an important gap in the literature and supporting the idea of using flow to reduce MPA.

This study has illuminated new opportunities for research on both flow and MPA. Variables linking flow and MPA should be studied specifically to provide more detailed strategies on using flow to reduce MPA, such as memory, meditation, relaxation, deliberate practice, and focus training. Experimental or behavioral studies might examine the effects of implementation of various strategies on performers' MPA feelings. The facilitators and inhibitors of flow in music performance also require additional study.

A limitation of this study is that only seven interviewees were queried because of time. Also, because of their different personalities (e.g., some interviewees were more talkative than others) and their level of conceptual understanding of flow and MPA, some interviewees provided rich information for every question of the interview, while some interviewees provided less information. In future studies, increasing the number of interviewees and interview questions and including participants at various levels of music study may provide richer data.

Overall, studying the relationship between flow and MPA and how to use flow to reduce MPA remains an area deserving of future research. Using aspects of flow could provide a relatively easy, convenient, and effective way for musicians to relieve anxious feelings and alleviate physical symptoms that may impair performance of those experiencing problems with MPA. 


\section{CHAPTER FIVE}

\section{Summary and Conclusions}

\section{Introduction}

Music performance is an art of time, unlike painting, literature, or composing, which can be modified and replenished adequately before completion. Once performers start their playing, they have no room to go back. Thus, music performance is unrepeatable, which can influence one of the most common and the most serious problems of music performers-Music Performance Anxiety (MPA). The incidence of MPA for performers is quite high, and MPA can affect musicians at any stage of their careers (Cohen \& Bodner, 2018a). Thus, ways to reduce or overcome MPA are worthy of study by researchers.

Recent researchers have found that flow was significantly and negatively correlated with MPA (Allison \& Duncan, 1988; Cohen \& Bodner, 2018a; Cohen \& Bodner, 2018b; Fullagar, Knight, \& Sovern, 2013; Kirchner, Bloom, \& Skutnick-Henley, 2008). Also, flow and MPA have been associated with motivation (Nakamura \& Csikszentmihalyi, 2002), emotion (Cohen \& Bodner, 2018a), attention/distraction (Izard, 1977; Rankin, Walsh, \& Sweeny, 2018), happiness (Marin \& Bhattacharya, 2013; Sabino, Camargo, Chagas, \& Osório, 2018), wellbeing (Lamont, 2012; Fritz \& Avsec, 2007), and Musical Emotional Contagion (MEC) (Cohen \& Bodner, 2018a). Findings suggest that flow has positive correlations and MPA has negative correlations with these factors. Accordingly, facilitating flow may provide a powerful tool for helping to alleviate MPA.

However, previous studies have not provided specific methods for utilizing flow to reduce MPA for music performance. Therefore, I sought to confirm the relationship 
between flow and MPA through quantitative data and provide a theoretical framework for facilitating flow and reducing MPA through qualitative data. The findings of the two studies reported here support the potential efficacy of using flow to reduce MPA.

\section{Research Questions and Method}

The purpose of this dissertation was to explore the relationship between flow and MPA and to provide a theoretical framework for using flow to alleviate MPA. The following primary research questions guided my work: What is the relationship between flow and MPA? How can we use flow to reduce MPA? Do age, gender, educational level, major, performance time, performance form, and performance frequency have effects on rating scale measures of flow and MPA? In order to answer these research questions, I completed a comprehensive literature review on flow and MPA (Chapter Two), a quantitative study involving music students with different educational levels and different majors (Chapter Three), and a qualitative study involving graduate music education students (Chapter Four).

\section{Major Findings}

\section{Literature Review}

The purpose of this literature review was to explore the relationship between flow and MPA, respectively, through definitions, causes, effects, treatments/facilitators, and measurements and to provide a theoretical basis for using flow to reduce MPA. The following questions guided my exploration: What is MPA? What are MPA's incidence rates, effects, attributions, treatments, and measures? What is flow? What are flow's components, conditions, facilitators, inhibitors, effects, and measures? What is the relationship between flow and MPA? 
Based on this review of the literature, I concluded that flow and MPA are two opposite experiences yet facilitating flow can help to reduce MPA. These conclusions are consistent with several previous studies (Allison \& Duncan, 1988; Cohen \& Bodner, 2018a; Cohen \& Bodner, 2018b; Fullagar et al., 2013; Kirchner, Bloom, \& SkutnickHenley, 2008). However, the current body of literature does not provide specific strategies on using flow to reduce MPA, therefore, additional studies are warranted.

Flow may cross over from teachers to their students (Bakker, 2005). This suggests that music teachers who are positive, motivated and cheerful in their music teaching play an important role in demonstrating and modeling, they also need to stress the importance of selecting suitable music for their students in order to address CSB and provide scaffolding opportunities to promote learning. In addition, music teachers can share their own flow experiences with their students and explain how they personally facilitate flow in their own performing.

To thoroughly connect flow and MPA, their interrelationships must be clearly elucidated through continued theory refinement, such as Challenge/Skill Balance (CSB) and Zone of Proximal Development (ZPD). Some factors related to flow and MPA deserve further study, such as motivation, attention, and confidence. Flow experience has high levels of motivation, attention, and confidence, while MPA has low levels of these factors, thus, studying these factors can help to provide more specific strategies on using flow to reduce MPA. Additionally, the nine components of flow can lead an individual to a flow experience, but the effects of these nine components on MPA need further study. Finally, research methods should be varied in future studies to better determine the relationship between flow and MPA. For example, mixed methods research could 
provide multiple types of data on this topic. Previous research has focused on quantitative methodology, primarily due to an emphasis on scale development.

\section{Quantitative study}

The purpose of this study was to confirm the relationship between flow experience and MPA through quantitative data. In so doing, the following two research questions were posed: 1) What is the relationship between flow and MPA? and, 2) Do age, gender, education, major, performance experience and performance form have effects on flow and music performance anxiety?

Canonical correlation tests between flow dimensions and MPA factors indicated that four dimensions of flow (clear goals, unambiguous feedback, autotelic experience, and sense of control) may be associated with MPA. Similarly, results of the Pearson correlation tests showed that items of these four dimensions of flow (clear goals, unambiguous feedback, autotelic experience, and loss of self-consciousness) were most significantly and negatively correlated with specific items on the MPA scale. Thus, strategies from the five dimensions identified may be useful to music performers in reducing their MPA. Based on Table 5, clear goals towards both learning of music and for performance may help performers to reduce their depression or hopelessness. Unambiguous feedback, including immediate feedback before, during and after their own performance as well as feedback from themselves and others (teachers, audiences, peers), may help performers to reduce their worry and dread and improve their controllability. Autotelic experience, such as selecting favorite pieces to perform so that they can enjoy the experience of music performance for its own sake, may help performers to reduce their proximal somatic anxiety. Developing a sense of control using focused attention 
strategies, like meditation and mindfulness, to quiet negative thoughts, focus attention on music, and achieve the "loss of self-consciousness" in their performance may help performers reduce their pre- and post-performance rumination.

Two positive correlations between items of the K-MPAI-R (Kenny, 2009) and AFSS (Payne, Jackson, Noh, \& Stine-Morrow, 2011) indicated that the more people trust others, the less concerned they are with how they present themselves. Also, the clearer the goals that performers have, the more they will remain committed to performing, even though it has caused great anxiety in the past. Thus, music performers should work towards building trust in others and set clear goals for their performances, which can help them focus their attention on their music track.

Participant gender, age, education level, major, and performance form were shown to have no direct impact on flow experience. Performance time and performance frequency were significantly positively correlated with five items of flow dimensions (unambiguous feedback, concentration task at hand, sense of control). This indicates that increasing practice and performing hours and taking an active part in various performances may help music performers to achieve unambiguous feedback, focused attention, sense of control, and facilitate their flow experience.

Gender, age, major, and performance frequency were showed to have no direct impact on MPA. Education level was positively correlated with two items of the K-MPAI -R. Performance time and performance form were negatively correlated with one item of the K-MPAI-R. These results indicated that music performers should continue learning by spending more time practicing to prepare for their performance and to reduce their MPA, especially for soloists. 


\section{Qualitative study}

In order to investigate ways on using flow to reduce MPA, seven graduate music education students were interviewed as participants in this grounded theory study. These participants reported their music study background, MPA experience, flow experience, the relationship between flow and MPA, whether and how they use flow to reduce MPA, and also provided feedback on the study. The following research questions guided my exploration: What is the relationship between flow and MPA experience? How can we use flow to reduce MPA?

All participants in this study thought that the relationship between flow and MPA was negative, which means that if individuals are anxious, it is harder to experience flow, and if individuals are in flow, there is limited or no anxiety. One participant also stated, however, that if someone is just normally anxious, which is a fairly typical experience, then, after getting over that, flow can be experienced. Thus, reducing anxiety may assist in facilitating flow, which can help to reduce MPA.

A theoretical framework was derived from these interviews and three steps for facilitating flow and reducing MPA were identified: preparation of performers, modeling by teachers, and construction of the flow experience. The preparation of performers includes keeping a Challenge/Skill Balance (CSB), deep learning of flow and MPA through music education classes, identifying individual MPA (causes, levels, and effects), and examining specific steps of flow in music performance. Teachers of performers should provide modeling to show their students what flow and MPA are and provide memory strategies for their students. Performers need to construct a flow experience by setting flow as a goal and experiencing a flow cycle which includes deliberate practice, 
self-relaxation, focused attention, and immediate feedback. This framework provides specific strategies for facilitating flow and reducing MPA, filling an important gap in the literature and supporting the idea of using flow to reduce MPA.

\section{Discussion}

\section{Implications for music performance}

Based on the quantitative data, music performers can use four flow dimensions that are significantly negative to MPA to prepare their performance and reduce their MPA. These include clear goals, unambiguous feedback, loss of self-consciousness, and autotelic experience.

Clear goals. Working towards a goal helps focus concentration and avoid distractions. Performance in music is a process of completing different goals. A pertinent goal in music performance is expressing music accurately and emotionally rather than paying too much attention to the things that affect the performance itself. Clear goals must not be too big, nor too vague. For example, the music teacher arranges weekly tasks and goals, then music students divide them further into smaller steps to make them clearer for themselves based on their own abilities and time.

Unambiguous feedback. Unambiguous feedback should be given before, during, and after the performance. In daily practice and in lessons, formative assessment can be carried out by teachers and further feedback can be given by way of peers and selfassessment. Daily practice is a cyclical process from beginning to end: practicefeedback-improvement-practice. Only when receiving timely feedback can performers adjust their performance in practice. During performance, immediate feedback comes from the audience and the performers themselves. Emotional communication with the 
audience through music can be beneficial when done in a positive way, as it may also help to instill confidence in the performer. Useful strategies for improving self-feedback might include observing and evaluating other musicians' performances, giving selffeedback during daily practice, and multiple performance rehearsals. During postperformance, students should evaluate the positive aspects of their performance and reflect on ways in which their performance can be improved.

Loss of self-consciousness. Individuals often spend a lot of mental energy monitoring how they appear to others. In a flow state, people are too involved in the activity to care about protecting their ego (Csikszentmihalyi, 1990). Although selection of repertoire may help the musician reach this state, it is also important for teachers and performers to consider the achievability of works and to choose music that is accessible and enjoyable for the performer.

Autotelic experience. Flow is an intrinsically rewarding experience: the activity becomes autotelic, an end in itself, done for its own sake (Csikszentmihalyi, 1990). This concept allows musicians to reflect on the relationship and reasons why they perform and attend musical performances. Although music students perform music at specific events such as evaluations, competitions, and degree recitals, any performances can lead to having a negative effect on the student; therefore, teachers can carry out an important role by delivering positive encouragement and assist the student by modeling reflection and re-setting of goals.

\section{Implications for music teachers}

Teachers' education. Before modeling positive performance behavior for music students, music teachers should know about flow and MPA and the relationship between 
these two constructs very well. Music education teachers should have sufficient knowledge of flow and MPA as well as pedagogical methods on how to teach flow and reduce MPA, thus, these constructs should be a part of the music educator's curriculum. Music performance teachers should understand flow and MPA and how to insert these into their music teaching. Ways for music teachers to learn about flow and MPA include watching online courses/videos, reading literature, attending conferences and lectures related to flow and MPA, and communicating with professional teachers and colleagues.

Modeling positive performance behavior. Bakker's study (2005) indicated that flow may cross over from teachers to their students: "the more flow experiences music teachers reported, the higher the frequency of comparable experiences among their students" (p. 38). Thus, music teachers who are positive, motivated, and cheerful in their music teaching play an important role in demonstrating and modeling of positive performance behavior for their students. In addition, music teachers can share their own flow experiences with their students and explain how they personally facilitate flow in their own performing.

Selection of music that falls into CSB. Based on the findings of this study, it may be inferred that music teachers can play an important role by selecting suitable music for their students in order to address CSB and by providing scaffolding opportunities. According to Csikszentmihalyi (1990), activities are seen as pleasurable when the challenge is matched to the person's skill level. If an activity is too difficult and skill levels are low, anxiety will result. Thus, music teachers should consider students' skill levels, task difficulty, and music preferences in their selection of music. 
Memory strategies. Mishra (2011) investigated the effectiveness of four memorization strategies: holistic, segmented, serial, and additive, and found that "the holistic strategy was significantly more efficient than the segmented and serial strategies" (p. 60). But, for two of the participants in the qualitative study, segmented strategy worked best. When teachers instruct or select memory strategies for our students, they need to base these strategies on their students' practice preferences and individual differences. Thus, different memory strategies may have more positive effects on students and should be considered when selecting memorization approaches. Teachers can provide all these memory strategies for their students to practice and find the student's best one for their music preparation prior to a performance.

\section{Implications for music students}

Good preparation. Good preparation can help music students facilitate flow and reduce MPA. The first preparation is keeping the CSB in mind while practicing and performing. High challenges can be motivational for students studying and performing, but challenges that are too high based on skill level will lead to MPA. In addition, students need to study flow and MPA, analyze their personal levels and causes of MPA and explore their own flow experiences, and find corresponding strategies to facilitate flow and reduce MPA. Moreover, students can try different strategies found in the literature review and explore additional ways to reduce their MPA using behavioral, psychological, cognitive, environmental, and skill strategies. Lastly, music students need to prepare well and accumulate stage experience to strengthen their self-confidence for performance. 
Construction of flow experience. Flow is the ultimate goal of music performance (David), thus, the achievement of this state should be the target of music students. A framework for facilitating flow and reducing MPA, as discussed in Chapter Four, provides a flow cycle that includes deliberate practice, self-relaxation, focused attention, and immediate feedback. Deliberate practice includes using flow as a signal that you are ready to perform in public and incorporating good performance cues. Also, music performers can employ different ways to relax themselves before music performance. Moreover, music students can use meditation and mindfulness strategies to focus their attention and to assist in silencing the internal negative voice. Lastly, music students not only need immediate feedback from themselves and others (teachers, peers, and audiences), but they also need to build a good relationship with other performers/conductors, especially when performing in an ensemble. Accordingly, music students can practice this flow cycle and improve their opportunity to experience flow based on their individualized practice.

\section{Conclusion}

The purpose of this dissertation was to explore the relationship between flow and MPA and to provide a theoretical framework for using flow to alleviate MPA. Based on the data, the relationship between flow and MPA is negative, yet facilitating flow can help to reduce MPA. The construction of a framework for facilitating flow and reducing MPA in this study (preparation of performers, modeling by teachers, and construction of flow experiences) fills an important gap in the literature and supports the idea of using flow to reduce MPA. The specific steps of this framework comprise behavioral (e.g., deep learning of flow and MPA), psychological (e.g., identify individual MPA), and 
cognitive strategies (e.g., setting flow as a goal), which overlap with many of the approaches in the literature review. The framework also provides suggestions from three aspects: performers, teachers, and construction of flow experience. Consequently, this dissertation provides a comprehensive approach for using flow to reduce MPA.

As a positive psychological method of treatment for MPA, flow theory is important because extant literature and the research data of this dissertation have shown that music performers who are in flow cannot be in high MPA. Music performers can gradually apply three steps of the framework presented in Chapter Five to reduce their MPA, facilitate flow, and improve their performance quality. Based on information provided by the literature reviewed, it also may be concluded that music performers can also start from aspects of behavior (e.g., anxiety hierarchy), psychology (e.g., selfhypnosis), cognition (e.g., Stress Inoculation Training), environment (e.g., easy environment), performer themselves (e.g., self-confidence), and skills (e.g., using correct methods of practice) to find more ways to overcome their own MPA.

This dissertation also illuminated new opportunities for researchers. Flow experience needs further experimental study to test its effects on different music performers' MPA and determine its role in alleviating MPA. Additionally, variables linking flow and MPA should be studied separately to provide more detailed strategies on using flow to reduce MPA (e.g., motivation, meditation, relaxation, mindfulness, expectation, confidence, personality, environment, and memory). Moreover, other scales for measuring flow and MPA, found in the literature review, can be utilized in future studies to further clarify the relationship between flow and MPA. Also, there are opportunities to refine Csikszentmihalyi's flow model, CSB, and Vygotsky's ZPD to be 
more specific to music performance. Finally, the implications for pedagogy related to flow and MPA, with consequences for teachers and deep learning by students, are other important outcomes of this study. Accordingly, studying the relationship between flow and MPA and how to use flow to reduce MPA remains an important area for future research. The more that musicians can learn about strategies to reduce anxiety that interferes with their well-being and, consequently, with their performing, the better they will be able to alleviate negative feelings and experiences in order to present musical performances that are pleasurable to themselves as well as to their audiences. 


\section{References}

Allison, M. T., \& Duncan, M. C. (1988). Women, work, and flow. In M.

Csikszentmihalyi \& I. S. Csikszentmihalyi (Eds.), Optimal experience: Psychological studies of flow in consciousness (pp. 118-137). New York, NY: Cambridge University Press. An earlier version of this chapter was published in "Leisure Sciences," 1987, 9 (3), 143-161.

Anderson, M. (2013a). Performance anxiety-how musicians can handle this-part one [Video file]. Retrieved from https://www.youtube.com/watch?v=HJA6g2nzFKs

Anderson, M. (2013b). Performance anxiety - how musicians can handle this - part two [Video file]. Retrieved from https://www.youtube.com/watch?v=7cKCiHa9j3g\&t=1s

Andrew, S., Farida, M., Charlotte, P., Pilip, P., Clare, P., \& Zarni, W. (1995). The impact of stage fright on student actors. British Journal of Psychology, 86(1), 27-39. doi:10.1111/j.2044-8295.1995.tb02544.x

Appel, S.S. (1976). Modifying solo performance anxiety in adult pianists. Journal of Music Therapy, 13(1), 2-16.

Bakker, A. B. (2001). Vragenlijst voor het meten van werkgerelateerde flow: De WOLF [Questionnaire for the assessment of work-related flow: The WOLF]. Utrecht University, Utrecht, The Netherlands: Department of Social and Organizational Psychology.

Bakker, A. B. (2005). Flow among music teachers and their students: The crossover of peak experiences. Journal of Vocational Behavior, 1(66), 26-44. doi:10.1016/j.jvb.2003.11.001 
Barcikowski, R. S., \& Stevens, J. P. (1975). A monte carlo study of the stability of canonical correlations, canonical weights and canonical variate-variable correlations. Multivariate Behavioral Research, 10(3), 353-364. doi:10.1207/s15327906mbr1003_8

Barlow, D. H. (2000). Unraveling the mysteries of anxiety and its disorders from the perspective of emotion theory. American Psychologist, 55(11), 1247-1263. doi: 10.1037/0003-066X.55.11.1247

Biasutti, M., \& Concina, E. (2014). The role of coping strategy and experience in predicting music performance anxiety. Musicae Scientiae, 18(2), 189-202. doi: $10.1177 / 1029864914523282$

Bloom, A. J., \& Skutnick-Henley, P. (2005). Facilitating flow experiences among musicians. The American Music Teacher, 54(5), 24-28.

Brodsky, W., Sloboda, J. A., \& Waterman, M. G. (1994). An exploratory investigation into auditory style as a correlate and predictor of music performance anxiety. Medical Problems of Performing Artists, 9, 101-112.

Brooker, E. (2018). Music performance anxiety: A clinical outcome study into the effects of cognitive hypnotherapy and eye movement desensitization and reprocessing in advanced pianists. Psychology of Music,46(1), 107-124. doi:10.1177/0305735617703473

Brotons, M. (1994). Effects of performing conditions on music performance anxiety and performance quality. Journal of Music Therapy, 31(1), 63-81. 
Burton, D. (1992). The Jekyll/Hyde nature of goals: Reconceptualizing goal setting in sport. In T. Horn (Ed.), Advances in sport psychology (pp. 221-250). Champaign, IL: Human Kinetics.

Butkovic, A., Ullén, F., \& Mosing, M. A. (2015). Personality related traits as predictors of music practice: Underlying environmental and genetic influences. Personality and Individual Differences, 74, 133-138. doi:10.1016/j.paid.2014.10.006

Carter, L., River, B., \& Sachs, M. (2013). Flow in sport, exercise, and performance: A review with implications for future research. Journal of Multidisciplinary Research, 5(3), 17- 31.

Cohen, J. (1988). Statistical power analysis for the behavioral sciences. Mahwah, NJ: Lawrence Erlbaum Associates, Inc.

Cohen, S., \& Bodner, E. (2018a). The relationship between flow and music performance anxiety amongst professional classical orchestral musicians. Psychology of Music, 47 (3), 420-435. doi: 10.1177/0305735618754689

Cohen, S., \& Bodner, E. (2018b). Music performance skills: A two-pronged approachfacilitating optimal music performance and reducing music performance anxiety. Psychology of Music. 1-18. doi: 10.1177/0305735618765349

Cox, B. J., \& Kenardy, J. (1993). Performance anxiety, social phobia, and setting effects in instrumental music students. Journal of Anxiety Disorders, 7, 49-60.

Craske, M. G., \& Craig, K. D. (1984). Musical performance anxiety-the three-systems model and self-efficacy theory. Behaviour Research and Therapy, 22(3), 267-280.

Creswell, J. W. (2013). Qualitative inquiry research design: choosing among five approaches. SAGE publications. 
Creswell. J. W., \& Miller, D. L. (2000). Determining validity in qualitative inquiry. Theory into Practice, 39(3), 124-130. doi: 10.1207/s15430421tip3903_2

Csikszentmihalyi, M. (1975). Beyond boredom and anxiety: experiencing flow in work and play. San Francisco, CA: Jossey-Bass.

Csikszentmihalyi, M. (1988). The flow experience and its significance for human psychology. In Csikszentmihalyi, M. \& Csikszentmihalyi, I.S. (Eds), Optimal experience: Psychological studies of flow in consciousness (pp. 15-35).

Cambridge, UK: Cambridge University Press.

Csikszentmihalyi, M. (1990). Flow: The psychology of optimal experience. New York: Harper \& Row.

Csikszentmihalyi, M. (1991). Flow: The psychology of optimal experience. New York: Herpercollins.

Csikszentmihalyi, M. (1992). Flow: The psychology of happiness. London: Random House.

Csikszentmihalyi, M. (1994). Flow: The psychology of optima experience. New York: Simon \& Schuster, Inc.

Csikszentmihalyi, M. (1997). Finding flow: The psychology of engagement with everyday life. New York: BasicBooks.

Csikszentmihalyi, M. (2014). Apllications of flow in human development and education:

The collected works of Mihaly Csikszentmihalyi. New York: Springer

Csikszentmihalyi, M. (2017). 3 ideas to attain flow (with more frequency) [Video file]. Retrieved from https://www.youtube.com/watch?v=hydkq6KQAXc 
Csikszentmihalyi, M., \& Csikszentmihalyi, I. S. (1988). Introduction. In M.

Csikszentmihalyi \& I.S. Csikszentmihalyi (Eds.), Optimal experience:

Psychological studies of flow in consciousness (pp. 3-14). New York: Cambridge University Press.

Csikszentmihalyi, M., \& Larson, R. (2014). Validity and reliability of the experiencesampling method. In: Flow and the foundations of positive psychology (pp. 35-54). Dordrecht: Springer.

Custodero, L. A. (2002). Seeking challenge, finding skill: Flow experience and music education. Arts Education Policy Review, 103 (3), 3-9. doi:

$10.1080 / 10632910209600288$

Custodero, L. A. (2005). Observable indicators of flow experience: A developmental perspective on musical engagements in young children from infancy to school age. Music Education Research, 7 (2), 185-209. doi: 10.1080/14613800500169431

Deen, D. R. (1999). Awareness and breathing: Keys to the moderation of musical performance anxiety (Unpublished doctoral dissertation). University of Kentucky, Lexington.

Demerouti, E. (2006). Job characteristics, flow, and performance: The moderating role of conscientiousness. Journal of Occupational Health Psychology, 11(3), 266-280. doi:10.1037/1076-8998.11.3.266

Diaz, F. M. (2011). Mindfulness, attention and flow during music listening: An empirical investigation. Psychology of Music, 41(1), 42-58.

doi:10.1177/0305735611415144 
Diaz, F. M. (2018). Relationship among meditation, perfectionism, mindfulness, and performance anxiety among collegiate music students. Journal of Research in Music Education, 66(2), 150-167. doi: 10.1177/0022429418765447

Eğilmez, H. O. (2015). Pre-service music teachers' piano performance self-efficacy belief inversely related to musical performance anxiety levels. Educational Research and Reviews, 10(18), 2558-2567. doi:10.5897/ERR2015.2439

Erlandson, D. A., Harris, E. L., Skipper, B. L., \& Allen, S. D. (1993). Doing Naturalistic Inquiry: A Guide to Methods. Newbury Park, CA: Sage.

Fehm, L., \& Schmidt, K. (2006). Performance anxiety in gifted adolescent musicians. Journal of Anxiety Disorders, 20(1), 98-109. doi:10.1016/j.janxdis.2004.11.011

Fishbein, M., Middlestadt, S. E., Ottati, V., Straus, S., Ellis, A. (1988). Medical problems among ICSOM musicians: Overview of a national survey. Medical Problems of Performing Artists, 3,1-8.

Flett, M. R. (2015). Is flow related to positive feelings or optimal performance? Path analysis of challenge-skill balance and feelings. Sports Science Review, XXIV (12), 5-26. doi: 10.1515/ssr-2015-0006

Flow State Philosophy. (2017). Flow State Documentary-The Key To Living [Video file]. Retrieved from https://www.youtube.com/watch?v=OIawRHT3vng\&t=1136s

Fredrikson, M., \& Gunnarsson, R. (1992). Psychobiology of stage fright: The effect of public performance on neuroendocrine, cardiovascular and subjective reactions. Biological Psychology, 33(1), 51-61. 
Fritz, B. S., \& Avsec, A. (2007). The experience of flow and subjective well-being of music students. Horizons of Psychology, 16(2), 5-17.

Fullagar, C. J., Knight, P. A., \& Sovern, H. S. (2013). Challenge/skill balance, flow, and performance anxiety. Applied Psychology: An International Review, 62(2), 236259. doi: 10.1111/j.1464-0597.2012.00494.x

Garner, A. M. (2014). Preparing the mind and body for performance: Conquering stage fright through effective practice. Clavier Companion, 6(4), 54-57.

Grishman, A. (1989). Musicians' performance anxiety: The effectiveness of modified progressive muscle relaxation in reducing physiological, cognitive, and behavioral symptoms of anxiety. Dissertation Abstracts International, 50(6-B), 2622.

Guba, E. G., \& Lincoln, Y. S. (2005). Paradigmatic controversies, contradictions, and emerging confluences. In N. K. Denzin \& Y. S. Lincoln (Eds.), The Sage handbook of qualitative research (pp. 191-215). Thousand Oaks, CA: Sage Publications, Ltd.

Gudde, A. (2014). The power of flow [Video file]. Retrieved from https://www.youtube.com/watch?v=WqRRgz2o78w

Hallam, S. (2002). Musical motivation: Towards a model of synthesizing the research. Music Education Research, 4(2), 225-244. doi: 10.1080/1461380022000011939

Hanton, S., \& Jones, G. (1999). The acquisition and development of cognitive skills and strategies: I. Making the butterflies fly in formation. Sport Psychologist, 13(1), 121. doi:10.1123/tsp.13.1.1

Harley, A. E., Buckworth, J., Katz, M. L., Willis, S. K., Odoms-Young, A., \& Heaney, C. A. (2009). Developing long-term physical activity participation: A grounded 
theory study with African-American women. Health Education \& Behavior, 36 (1), 97-112. doi: 10.1177/1090198107306434

Harris, S. R. (1986). A psychologist views music performance anxiety. American Music Teacher, 35(3), 24-25, 40.

Hopkins, M. (2013). Programming in the zone: Repertoire selection for the large ensemble. Music Educators Journal, 99(4), 69-74. doi:10.1177/0027432113480184

Horn, T. S. (2008). Advances in sport psychology. Champaign, IL: Human Kinetics, Izard, C. E. (1977). Human emotions. New York: Plenum Press.

Jackson, S. (1992). Athletes in flow: A qualitative investigation of flow states in elite figure skaters. Journal of Applied Sport Psychology, 4(2), 161-180.

Jackson, S. (1995). Factors influencing the occurrence of flow state in elite athletes. Journal of Applied Sport Psychology, 7(2), 138-166. doi: $10.1080 / 10413209508406962$

Jackson, S. A., \& Csikszentmihalyi, M. (1999). Flow in sports: The keys to optimal experiences and performances. Champaign, IL: Human Kinetics, Inc.

Jackson, S. A., \& Eklund, R. C. (2002). Assessing flow in physical activity: The Flow State Scale-2 and Dispositional Flow Scale-2. Journal of Sport and Exercise Psychology, 24, 133-150.

Jackson, S. A., \& Marsh, H. (1996). Development and validation of a scale to measure optimal experience: The Flow State Scale. Journal of Sport and Exercise Psychology, 18, 17-35. 
Jackson, S. A., \& Kimiecik, J. C. (2008). The flow perspective of optimal experience in sport and physical activity. In T. S. Horn (Ed.), Advances in sport and exercise psychology 3rd ed. (pp. 377-399). Champaign, IL: Human Kinetics.

Jensen, P. S., \& Kenny, D. T. (2004). The effects of yoga on the attention and behavior of boys with attention-deficit/hyperactivity disorder (ADHD). Journal of Attention Disorders, 7 (4), 205-216. doi:10.1177/108705470400700403

John, S. H., \& Nicola, S. S. (2016). The role of adherence in the effects of a mindfulness intervention for competitive athletes: Changes in mindfulness, flow, pessimism, and anxiety. Journal of Clinical Sport Psychology, 10(2), 99-117. doi: 10.1123/jcsp.2015-0020

Kaspersen, M., \& Gotestam, K. G. (2002). A survey of music performance anxiety among Norwegian music students. The European Journal of Psychiatry, 16(2), 69-80.

Kendrick, M. J., Craig, K. D., Lawson, D. M., \& Davidson, P. O. (1982). Cognitive and behavioural therapy for musical-performance anxiety. Journal of Consulting and Clinical Psychology, 50(3), 353-362.

Kenny, D. T. (2004). Music performance anxiety: Is it the music, the performance or the anxiety? Music Forum, Australia

Kenny, D. T. (2005). A systematic review of treatments for music performance anxiety. Anxiety, Stress, and Coping, 18(3), 183-208. doi: 10.1080/10615800500167258

Kenny, D. T. (2006). Music performance anxiety: Origins, phenomenology, assessment and treatment. Journal of Music Research, 31, 51-64. 
Kenny, D. T. (2009). The factor structure of the revised Kenny Music Performance Anxiety Inventory. International Symposium on Performance Science. 37-41, Utrecht: Association Européenne des Conservatoires.

Kenny, D. T. (2011). The psychology of music performance anxiety. Oxford, UK: Oxford University Press.

Kenny, D. T. (2018). Psychometric properties of the Kenny-Music Performance Anxiety Inventory modified for general performance anxiety. Polish Psychological Bulletin, 49(3), 332-343. doi: 10.24425/119500

Kenny, D. T., \& Ackermann, B. (2015). Performance-related musculoskeletal pain, depression and music performance anxiety in professional orchestral musicians: A population study. Psychology of Music, 43 (1), 43-60. doi:

$10.1177 / 0305735613493953$

Kenny, D. T., Davis, P, J., \& Oates, J. (2004). Music performance anxiety and occupational stress amongst opera chorus artists and their relationship with state and trait anxiety and perfectionism. Journal of Anxiety Disorders, 18(6), 757-777. doi:10.1016/j.janxdis.2003.09.004

Kenny, D. T., Driscoll, T., \& Ackermann, B. (2014). Psychological well-being in professional orchestral musicians in Australia: A descriptive population study. Psychology of Music, 42(2), 210-232. doi:10.1177/0305735612463950

Kenny, D. T., \& Osborne, M. S. (2006). Music performance anxiety: New insights from young musicians. Advances in Cognitive Psychology, 2(2-3), 103-112. Retrieved from file://D:/Documents/Downloads/12\%20(3).pdf 
Kim, Y. S. (2008). The Effect of improvisation-assisted desensitization, and musicassisted progressive muscle relaxation and imagery on reducing pianists' music performance anxiety. Journal of Music Therapy, 45(2), 165-191. doi:10.1093/jmt/45.2.165

Kirchner, J. M., Bloom, A. J., \& Skutnick-Henley, P. (2008). The relationship between performance anxiety and flow. Medical Problems of Performing Artists, 23(2), $59-65$.

Knudson, D. V. \& Lindsey, C. (2014). Type i and type ii errors in correlations of various sample sizes. Comprehensive Psychology, 3(1), 1-5. doi:10.2466/03.CP.3.1

Kubzansky, L. D., \& Stewart, A. J. (1999). At the intersection of anxiety, gender and performance. Journal of Social and Clinical Psychology, 18(1), 76-97.

Lamont, A. (2012). Emotion, engagement and meaning in strong experiences of music performance. Psychology of Music, 40(5), 574-594. doi

$10.1177 / 0305735612448510$

LeBlanc, A., Jin, Y. C., Obert, M., \& Siivola, C. (1997). Effect of audience on music performance anxiety. Journal of Research in Music Education, 45 (3), 480-496. doi: $10.2307 / 3345541$

Lehrer, P. M. (1987). A review of the approaches to the management of tension and stage fright in music performance. Journal of Research in Music Education, 35(3), 143 153.

Lehrer, P. M., Goldman, N. S., \& Strommen, E. F. (1990). A principal components analysis assessment of performance anxiety among musicians. Medical Problems of Performing Artists, 5(1), 12-18. 
Li, L. (2015). A comparative study of stage performance anxiety on piano and vocal music students (Master's thesis). Retrieved from CNKI database (J604.6).

Li, L. (2017). Effect of performance forms (memorized and non-memorized) and gender on piano students' stage performance anxiety. Unpublished manuscript.

MacDonald, R., Byrne, C., \& Carlton, L. (2006). Creativity and flow in musical composition: An empirical investigation. Psychology of Music, 34(3), 292-306. doi: $1177 / 0305735606064838$.

Mansberger, N. B. (1988). The effects of performance anxiety management training on musicians' self-efficacy, state anxiety and musical performance quality (Unpublished doctoral dissertation). Western Michigan University, Kalamazoo. Manvelyan, M. (2018). Overcoming stage fright—-"grow in flow" online course [Video file]. Retrieved from https://www.youtube.com/watch?v=hA9zp94b5-s\&t=41s.

Marin, M., \& Bhattacharya, J. (2013). Getting into the musical zone: Trait emotional intelligence and amount of practice predict flow in pianists. Frontiers in Psychology, 22(4), 1-14. doi:10.3389/fpsyg.2013.00853

Martin, A. J., \& Jackson, S. A. (2008). Brief approaches to assessing task absorption and enhanced subjective experience: Examining 'short' and 'core' flow in diverse performance domains. Motivation and Emotion, 32 (3), 141-157. doi:10.1007/s11031-008-9094-0

Meichenbaum, D. (1985). Stress inoculation training. In M. Donald (Eds.). The evolution of cognitive behavior therapy: A personal and professional journey with don meichenbaum. New York: Pergamon. 
Michiko, Y., Kazutoshi, K., Takayuki, M., \& Tatsuyuki, O. (2009). Music performance anxiety in skilled pianists: Effects of social-evaluative performance situation on subjective, autonomic, and electromyographic reactions. Experimental Brain Research, 199(2), 117-126. doi: 10.1007/s00221-009-1979-y

Mishra, J. (2011). Influence of strategy on memorization efficiency. Music Performance Research, 4, 60-71.

Moneta, G. B. (2004). The flow experience across cultures. Journal of Happiness Studies, 5(2), 115-121. doi: 10.1023/B:JOHS.0000035913.65762.b5

Mor, S., Day, H., \& Flett. G. (1995). Perfectionism, control, and components of performance anxiety in professional artists. Cognitive Therapy and Research, 19(2), 207-225. doi: 10.1007/BF02229695

Murphy, S., \& Jowdy, D. (1992). Imagery and mental practice. In T. Horn (Ed), Advances in sport psychology (pp.221-250). Champaign, IL: Human Kinetic.

Nagel, J. J. (2017). Managing stage fright: A guide for musicians and music teachers. New York: Oxford University Press.

Nagle, J. J., Himle, D. P., \& Papsdorf, J. D. (1989). Cognitive-behavioural treatment of musical performance anxiety. Psychology of Music, 17, 12-21.

Nakamura, J., \& Csikszentmihalyi, M. (2002). The concept of flow. In C.R. Snyder \& J.S. Lopez (Eds.), Handbook of positive psychology (pp. 89-105). New York: Oxford University Press.

Nakamura, J., \& Csikszentmihalyi, M. (2014). The concept of flow. In M. Csikszentmihalyi (Eds.), Flow and the Foundations of Positive Psychology (pp.239-263). Dordrecht: Springer. 
Neftel, K. A., Adler, R. H., Kappeli, L., Rossi, M., Dolder, M., Kaser, H. E. et al. (1982). Stage fright in musicians: A model illustrating the effect of beta blockers. Psychosomatic Medicine, 44(5), 461-469.

Nijs, L., Coussement, P., Moens, B., Amelinck, D., Lesaffre, M., \& Leman, M. (2012). Interacting with the music paint machine: Relating the constructs of flow experience and presence. Interacting with Computers, 24, 237-250. doi:10.1016/j.intcom.2012.05.002

O'Neill, S. (1999). Flow theory and the development of musical performance skills. Bulletin of the Council for Research in Music Education, 141, 129-134. Retrieved from http://www.jstor.org/stable/40318998

Osborne, M. S., \& Kenny, D. T. (2005). Development and validation of a music performance anxiety inventory for gifted adolescent musicians. Journal of Anxiety Disorders. 19(7), 725-751. doi: 10.1016/j.janxdis.2004.09.002

Osborne, M. S., Kenny, D. T., \& Holsomback, R. (2005). Assessment of music performance anxiety in late childhood: A validation study of the music performance anxiety inventory for adolescents (MPAI-A). International Journal of Stress Management, 12(4), 312-330. doi:10.1037/1072-5245.12.4.312

Owen, T. (2009). University music students' experiences of performance anxiety and how they cope with it (Unpublished dissertation). The University of British Columbia, Vancouver.

Papageorgi, I., Hallam, S., \& Wekch, G. F. (2007). A conceptual framework for understanding musical performance anxiety. Research Studies in Music Education. 28(1), 83-107. doi: 10.1177/1321103X070280010207 
Parncutt, R., \& McPherson, G. E. (2002). The science and psychology of music performance. New York: Oxford University Press.

Payne, B. R., Jackson, J. J., Noh, S.R., \& Stine-Morrow, E. L. (2011). In the zone: Flow state and cognition in older adults. Psychology of Aging, 26 (3), 738-743. doi: $10.1037 / \mathrm{a} 0022359$

Privette, G. (1983). Peak experience, peak performance, and flow: A comparative analysis of positive human experiences. Journal of Personality and Social Psychology, 45, 1361-1368.

Rankin, K., Walsh, L. C., \& Sweeny, K. (2018). A better distraction: Exploring the benefits of flow during uncertain waiting periods. Emotion, 1,1-11. Advance online publication. http://dx.doi.org/10.1037/emo0000479

Robertson, D. U., \& Eisensmith, K. E. (2010). Teaching students about performance anxiety: The scratch Pad pop-up model. Music Educators Journal, 97(2), 31-35. doi: $10.1177 / 0027432109335078$

Robson, K. E., \& Kenny, D. T. (2017). Music performance anxiety in ensemble rehearsals and concerts: A comparison of music and non-music major undergraduate musicians. Psychology of Music, 45(6), 868-885. doi: $10.1177 / 0305735617693472$

Roland, D. (1992). The development and evaluation of a modified cognitive-behavioural treatment for musical performance anxiety (Doctoral dissertation). Retrieved from https://ro.uow.edu.au/

Ryan, C. (2004). Gender differences in children's experience of music performance anxiety. Psychology of Music, 32(1), 89-103. doi: 10.1177.0305735604039284 
Ryan, C. (2005). Experience of music performance anxiety in elementary school children. International Journal of Stress Management, 12 (4), 331-342. doi:10.1037/10725245.12 .4 .331

Ryan, C., \& Andrews, N. (2009). An investigation into the choral singer's experience of music performance anxiety. Journal of Research in Music Education, 57(2), 108126. doi: $10.1177 / 0022429409336132$

Sabino, A. D. V., Camargo, C. M., Chagas, M. H.N., \& Osório, F. L. (2018). Facial recognition of happiness is impaired in musicians with high music performance anxiety. Psychiatry, 9(5), 1-5. doi: 10.3389/fpsyt.2018.00005

Salmon, P. G. (1990). A psychological perspective on musical performance anxiety: A review of the literature. Medical Problems of Performing Artists, 5(1), 2-11.

Salmon, P. G., \& Meyer, R. G. (1992). Notes from the Green Room: Coping with stress and anxiety in musical performance. New York: Lexington Books.

Salmon, P., Schrodt, R., \& Wright, J. (1989). A temporal gradient of anxiety in a stressful performance context. Medical Problems of Performing Artists, 4(2), 77-80.

Seligman, M. (1995). The optimistic child. Sydney: Random House.

Sinnamon, S., Moran, A., \& Connell, M. O. (2012). Flow among musicians: measuring peak experiences of student performers. Journal of Research in Music Education, 60 (1), 6-25. doi: 10.1177/0022429411434931

Sloboda, J. A. (1991). Musical expertise. In K. A. Ericsson \& J. Smith (Eds.), Towards a general theory of expertise: prospects and limits (pp. 153-171). Cambridge, UK: Cambridge University Press. 
Spahn, C. (2011). Psychosomatische medizin und psychotherapie. In: Spahn, C., Richter, B., Altenmüller, E. (Eds.). MusikerMedizin: Diagnostik, therapie und prävention von musikerspezifischen erkrankungen. Stuttgart: Schattauer.

Spahn, C. (2015). Treatment and prevention of music performance anxiety. Progress in Brain Research, 217(7), 129-140. doi: 10.1016/bs.pbr.2014.11.024

Stevens, J. P. (1986). Applied multivariate statistics for the social sciences. Hillsdale, NJ: Erlbaum

Steptoe, A. (2001). Negative emotions in music making: The problem of performance anxiety. Music and Emotion: Theory and Research, 291-307. New York: Oxford University Press.

Steptoe, A., \& Fidler, H. (1987). Stage fright in orchestral musicians: A study of cognitive and behavioural strategies in performance anxiety. British Journal of Psychology, 78, 241-249.

Steptoe, A., \& Helen, F. (1987). Stage fright in orchestral musicians: A study of cognitive and behavioral strategies in performance anxiety. British Journal of Psychology,78(2), 241-249. doi: 10.1111/j.20448295.1987.tb02243.x

Strauss, A., \& Corbin, J. (1998). Basics of qualitative research: Techniques and procedures for developing grounded theory. Thousand Oaks, CA:Sage.

Studer, R., Gomez, P., Hildebrandt, H., Arial, M., \& Danuser, B. (2011). Stage fright: Its experience as a problem and coping with it. International Archives of Occupational \& Environmental Health, 84(7), 761-771. doi: 10.1007/s00420010-0608-1 
Swann, C., Keegan, R., Piggott, D., \& Crust, L. (2012). A systematic review of the experience, occurrence, and controllability of flow states in elite sport. Psychology of Sport and Exercise, 13(6), 807-819. doi:10.1016/j.psychsport.2012.05.006

Sweeney, G. A., \& Horan, J. J. (1982). Separate and combined effects of cue-controlled relaxation and cognitive restructuring in the treatment of music performance anxiety. Journal of Counseling Psychology, 29(5), 486-497.

Tabachnick, B. G., \& Fidell, L. S. (1989). Using multivariate statistics. Los Angeles: California State University, Northridge.

Tartalone, P. M. (1992). Patterns of performance anxiety among university musicians preparing for brass area jury recitals: Physiological arousal and perceived state anxiety. Dissertation Abstracts International, 54, 24A

Topoğlu, O. (2014). Musical performance anxiety: relations between personal features and state anxiety levels of pre-service music teachers. International Online Journal of Educational Sciences, 6(2), 337-348. doi:10.15345/iojes.2014.02.008

Ullén, F., de Manzano, Ö., Theorell, T., \& Harmat, L. (2010). The physiology of effortless attention: Correlates of state flow and flow proneness. In B. Bruya (Ed.), Effortless attention: A new perspective in the cognitive science of attention and action (pp. 205-217). Cambridge, MA: MIT Press.

Ullén, F., de Manzano, Ö., Almeida, R., Magnusson, P. K. E., Pedersen, N. L., Nakmura, J., et al. (2012). Proneness for psychological flow in everyday life: Associations with personality and intelligence. Personality and Individual Differences, 52, 167-172. 
Valentine, E. (2002). The fear of performance. In R. John (Eds). Musical performance: A guide to understanding (pp.168-182). Cambridge: Cambridge University Press.

Valentine, E. R., Fitzgerald, D. F. P., Gorton, T. L., Hudson, J. A., \& Symonds, E. R. C. (1995). The effect of lessons in the Alexander Technique on music performance in high and low stress situations. Psychology of Music, 23 (2), 129-141.

van Kemenade, J. F. L. M., \& van Son, M. J. M. (1995). Performance anxiety among professional musicians in symphonic orchestras: A self-report study. Psychological Reports, 77, 555-562.

Vygotsky, L. S. (1978). Interaction between learning and development. In Gauvain, M \& Cole, M (Eds.), Readings on the development of children (pp.34-40). New York, NY: Macmillan

Walker, I. J., \& Nordin-Bates, S. M. (2010). Performance anxiety experiences of professional ballet dancers: The importance of control. Journal of Dance Medicine \& Science, 14(4), 133-145.

Wardle, A. (1969). Behavior modification by reciprocal inhibition of instrumental music performance anxiety. Journal of Band Research,11(1), 18.

Wesner, R. B., Noyes, R. \& Davis, T. L. (1990). The occurrence of performance anxiety among musicians. Journal of Affective Disorders, 18(3), 177-185.

doi:10.1016/0165-0327(90)90034-6

Wills, G., \& Cooper, C. L. (1988). Pressure sensitive: Popular musicians under stress. London: Sage. 
Wilson, G. D., \& Roland, D. (2002). Performance anxiety. In R. Parncutt \& G. McPherson (Eds.). The science and psychology of music performance: Creative strategies for teaching and learning (pp. 47-61). New York: Oxford University Press.

Wolfe, M. L. (1989). Correlates of adaptive and maladaptive musical performance anxiety. Medical Problems of Performing Artists, 4(1), 49-56.

Wrigley, W. J., \& Emmerson, S. B. (2011). The experience of the flow state in live music performance. Psychology of Music, 41(3), 292-305. doi:

$10.1177 / 0305735611425903$

Yerkes, R. M., \& Dodson, J. D. (1908). The relation of strength of stimulus to rapidity of habit-formation. The Journal of Comparative Neurology, 18(5), 459-482. doi: 10.1002/cne.920180503

Yoshie, M., Kudo, K., Murakoshi, T., \& Ohtsuki, T. (2009). Music performance anxiety in skilled pianists: Effects of social evaluative performance situation on subjective, autonomic, and electromyographic reactions. Experimental Brain Research, 199(2), 117-126.

Zarza-Alzugaray, F. J., Orejudo, S., Casanova, O., \& Aparicio-Moreno, L. (2018). Music performance anxiety in adolescence and early adulthood: Its relation with the age of onset in musical training. Psychology of Music, 46(1), 18-32. doi:

$10.1177 / 0305735617691592$ 


\section{Appendix A}

\section{Informed Consent of Quantitative and Qualitative Studies}

$\mathrm{Li} \mathrm{Li}$

Ph.D. Student in Music Education

School of Music

University of Missouri-Columbia

Dear all,

\section{INFORMED CONSENT}

My name is Li Li and I am a doctoral student in music education at the University of Missouri. I am conducting a research study entitled Relationship between Flow and Music Performance Anxiety. The purpose of the research study is to explore the relationship between flow and music performance anxiety. I am writing to request your assistance with this project.

Your participation will involve filling in a questionnaire of two scales one for flow and one for music performance anxiety, based on your own music performance experience. Your participation in this study is voluntary. If you choose not to participate or to withdraw from the study at any time, you can do so without penalty. The results of the research study may be published but your identity will remain confidential and your name will not be disclosed to any outside party.

In this research, there are no foreseeable risks to you. A possible benefit of your participation is helping to find some ways to reduce music performance anxiety, through thinking about the relationship between flow and music performance anxiety.

Thank you for considering this request. If you have any questions concerning the research study, please contact me at 573-xxx-xxxx and 114gd@xxxx.xxxxxxx.xxx or my committee chair, Dr. Sims, who can be reached at simsw@xxxxxxxx.xxx or 573-xxx-xxxx. If you have questions regarding your rights as a participant in research, please feel free to contact the MU Institutional Review Board at 573-882-3181. 
$\mathrm{Li} \mathrm{Li}$

Ph.D. Student in Music Education

School of Music

University of Missouri-Columbia

\section{INFORMED CONSENT}

Dear all,

My name is Li Li and I am a doctoral student in music education at the University of Missouri. I am conducting a research study entitled Facilitating Flow and Alleviating Music Performance Anxiety. The purpose of the research study is to explore the relationship between flow and music performance anxiety and provide a theoretical framework on facilitating flow to alleviate or overcome music performance anxiety. I am writing to request your assistance with this project.

Your participation will involve an interview of approximately 30 minutes, in which you will describe your music learning background, flow experiences, music performance anxiety experiences, your opinions on the relationship between these two constructs, and how to use flow to reduce music performance anxiety. Interview will be audio recorded. I will also ask you to check the transcription of your interview for accuracy.

Your participation in this study is voluntary. If you choose not to participate or to withdraw from the study at any time, you can do so without penalty. The results of the research study may be published but your identity will remain confidential and your name will not be disclosed to any outside party.

In this research, there are no foreseeable risks to you .A possible benefit of your participation is identify your flow and music performance anxiety level and find some ways to reduce your music performance anxiety by using flow theory.

Thank you for considering this request. If you have any questions concerning the research study, please contact me at 573-xxx-xxxx and 114gd@xxxx.xxxxxxx.xxx or my committee chair, Dr. Sims, who can be reached at simsw@xxxxxxxx.xxx or 573-xxx-xxxx. If you have questions regarding your rights as a participant in research, please feel free to contact the MU Institutional Review Board at 573-882-3181 


\title{
Appendix B
}

\section{Permissions of AFSS and K-MPAI-R}

\section{¿PsycTESTS}

\author{
Activity Flow State Scale
}

\section{PsycTESTS Citation:}

Payne, B. R., Jackson, J. J., Noh, S. R., \& Stine-Morrow, E. A. L. (2011). Activity Flow State Scale [Database record].

Retrieved from PsycTESTS. doi: 10.1037/t06855-000

Test Shown: Full

Test Format:

Items are rated on a 5-point Likert ranging from 1 (strongly disagree) to 5 (strongly agree).

Source:

Payne, B. R., Jackson, J. J., Noh, S. R., \& Stine-Morrow, E. A. L. (2011). In the zone: Flow state and cognition in older adults. Psychology and Aging, 26(3), 738-743.

http://dx.doi.org/10.1037/a0022359

Permissions:

Test content may be reproduced and used for non-commercial research and educational purposes without seeking written permission. Distribution must be controlled, meaning only to the participants engaged in the research or enrolled in the educational activity. Any other type of reproduction or distribution of test content is not authorized without written permission from the author and publisher.

PsycTESTS $^{\text {TM }}$ is a database of the American Psychological Association 


\section{Kenny-Music Performance Anxiety Inventory-Revised}

Download Save to OneDrive - University of Missouri

Hi Li

You may use my scale - K-MPA for your study. Make sure you have the 40 version item $-I$ am attaching it here together with the scoring protocol.

Also go to https://www.researchgate.net/project/Music-performance-anxiety-characteristics-and-treatment to find all my papers on the K-MPAI and on MPA.

Good luck with your studies.

Dianna

DIANNA KENNY | Professor of Psychology, Professor of Music

Faculty of Arts and Social Sciences, The University of Sydney

Visiting Professor of Psychology, Macquarie University

Adjunct Professor of Music, Boston University, USA

Office 468, Merewether HO4

The University of Sydney

AUSTRALIA 2006 


\section{Appendix C}

Questionnaire of Flow and Music Performance Anxiety

Part 1: Your basic information

1. Gender: male ( ) female ( )

2. Age: ( )

3. Education: undergraduate ( ) graduate ( ) if neither, your position

4. Your music major(instrument)

5. How long have you performed music? years

6. What is your favorite performance form?

Solo ( ) Ensemble ( )

7. How often have you performed music in public?

Never ( ) Rarely ( ) Sometimes ( ) Usually ( ) Always ( ) 


\section{Part 2: Activity Flow State Scale (AFSS)}

Think about music performances that you performed before, particularly one that you enjoyed and /or found satisfying. Try to remember how you experienced that activity as you read each statement below. Provide a rating for each statement to indicate how well it describes your performance by circling the appropriate number.

\begin{tabular}{|c|c|c|c|c|c|c|}
\hline \multirow[b]{2}{*}{1} & \multicolumn{4}{|c|}{$\begin{array}{l}\text { Strongly } \\
\text { Disagree }\end{array}$} & \multicolumn{2}{|c|}{$\begin{array}{r}\text { Strongly } \\
\text { Agree } \\
\end{array}$} \\
\hline & I performed automatically, without having to think about it......... & 1 & 2 & 3 & 4 & \\
\hline 2 & 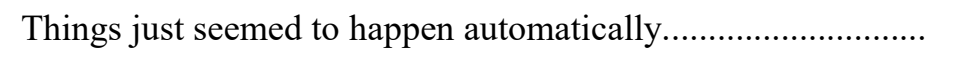 & 1 & 2 & 3 & 4 & \\
\hline 3 & I did things spontaneously without having to think........................... & 1 & 2 & 3 & 4 & \\
\hline 4 & I had a strong sense of what I wanted to accomplish .................... & 1 & 2 & 3 & 4 & \\
\hline 5 & I knew what I want to achieve & 1 & 2 & 3 & 4 & \\
\hline 6 & My goals were clearly defined . & 1 & 2 & 3 & 4 & \\
\hline 7 & My attention was focused entirely on what I was doing ............ & 1 & 2 & 3 & 4 & \\
\hline 8 & It was no effort to keep my mind on what was happening.......... & 1 & 2 & 3 & 4 & \\
\hline 9 & 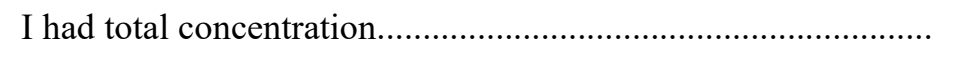 & 1 & 2 & 3 & 4 & \\
\hline 10 & I had no difficulty concentrating..... & 1 & 2 & 3 & 4 & \\
\hline 11 & $\begin{array}{l}\text { It was really clear to me how my performance was going .......... } \\
\text { I had a good idea while I was performing about }\end{array}$ & 1 & 2 & 3 & 4 & \\
\hline & 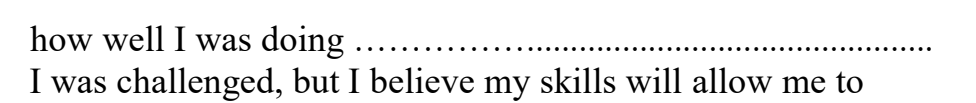 & 1 & 2 & 3 & 4 & \\
\hline 13 & meet that challenge & 1 & 2 & 3 & 4 & \\
\hline 14 & The challenge and my skills were at an equally high level.......... & 1 & 2 & 3 & 4 & \\
\hline 15 & I felt just the right amount of challenge......... & 1 & 2 & 3 & 4 & \\
\hline 16 & Time seemed to alter (either slows down or speeds up).......... & 1 & 2 & 3 & 4 & \\
\hline 17 & The way time passed seemed to be different from normal ......... & 1 & 2 & 3 & 4 & \\
\hline 18 & I lost my normal awareness of time....... & 1 & 2 & 3 & 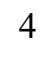 & \\
\hline 19 & I felt as though I had everything under control.... & 1 & 2 & 3 & 4 & \\
\hline J & I felt that I had everything under cc & 1 & 2 & 3 & & \\
\hline 21 & I was not concerned with how others might be evaluating me.... & 1 & 2 & 3 & & \\
\hline 22 & I was not concerned with how I was presenting myself................... & 1 & 2 & 3 & & \\
\hline 23 & I was not worried about what others might be thinking of me.... & 1 & 2 & 3 & & \\
\hline 24 & I really enjo. & 1 & 2 & 3 & & \\
\hline 25 & 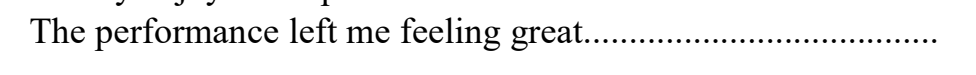 & 1 & 2 & 3 & & \\
\hline 26 & 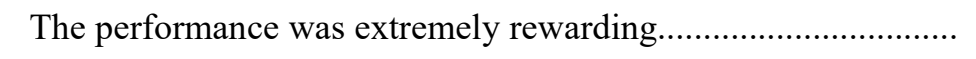 & 1 & 2 & 3 & 4 & 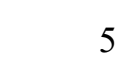 \\
\hline
\end{tabular}

Payne, Jackson, Noh \& Stine-Morrow. (2011). Activity Flow State Scale (AFSS) 


\section{Part 3: Kenny-Music Performance Anxiety Inventory-Revised (K-MPAI-R)}

Below are some statements about how you feel generally and how you feel before or during a performance. Please circle one number to indicate how much you agree or disagree with each statement.

\begin{tabular}{|c|c|c|c|c|c|c|c|}
\hline & $\begin{array}{l}\text { Strongly } \\
\text { Disagree }\end{array}$ & & & & & $\begin{array}{c}\text { Strongly } \\
\text { Agree }\end{array}$ & \\
\hline K_1 & I generally feel in control of my life ............................ & 6 & 5 & 43 & 2 & 1 & 0 \\
\hline K_2 & I find it easy to trust others . & 6 & 5 & 43 & 2 & 1 & 0 \\
\hline K_3 & Sometimes I feel depressed without knowing why. & 0 & 1 & 23 & 4 & 5 & 6 \\
\hline K_4 & $\begin{array}{l}\text { I often find it difficult to work up the energy to do } \\
\text { things }\end{array}$ & 0 & 1 & 23 & 4 & 5 & 6 \\
\hline K_5 & Excessive worrying is a characteristic of my family & 0 & 1 & 23 & 4 & 5 & 6 \\
\hline K_6 & I often feel that life has not much to offer me .......... & 0 & 1 & 23 & 4 & 5 & 6 \\
\hline K_7 & $\begin{array}{l}\text { Even if I work hard in preparation for a } \\
\text { performance, I am likely to make mistakes ............. }\end{array}$ & 0 & 1 & 23 & 4 & 5 & 6 \\
\hline K_8 & 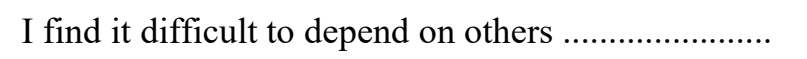 & 0 & 1 & 23 & 4 & 5 & 6 \\
\hline K_9 & My parents were mostly responsive to my needs .... & 6 & 5 & 43 & 2 & 1 & 0 \\
\hline K_10 & $\begin{array}{l}\text { Prior to, or during a performance, I get feelings } \\
\text { akin to panic................................................. }\end{array}$ & 0 & 1 & 23 & 4 & 5 & 6 \\
\hline K_11 & $\begin{array}{l}\text { I never know before a concert whether I will } \\
\text { perform well }\end{array}$ & 0 & 1 & 23 & 4 & 5 & 6 \\
\hline K_12 & $\begin{array}{l}\text { Prior to, or during a performance, I experience dry } \\
\text { mouth }\end{array}$ & 0 & 1 & 23 & 4 & 5 & 6 \\
\hline K_13 & I often feel that I am not worth much as a person... & 0 & 1 & 23 & 4 & 5 & 6 \\
\hline K_14 & $\begin{array}{l}\text { During a performance I find myself thinking about } \\
\text { whether I'll even get through it }\end{array}$ & 0 & 1 & 23 & 4 & 5 & 6 \\
\hline K_15 & $\begin{array}{l}\text { Thinking about the evaluation I may get interferes } \\
\text { with my performance }\end{array}$ & 0 & 1 & 23 & 4 & 5 & 6 \\
\hline K_16 & $\begin{array}{l}\text { Prior to, or during a performance, I feel sick or } \\
\text { faint or have a churning in my stomach..................... }\end{array}$ & 0 & 1 & 23 & 4 & 5 & 6 \\
\hline K_17 & $\begin{array}{l}\text { Even in the most stressful performance situations, I } \\
\text { am confident that I will perform well .............................. }\end{array}$ & 6 & 5 & 43 & 2 & 1 & 0 \\
\hline K_18 & $\begin{array}{l}\text { I am often concerned about a negative reaction } \\
\text { from the audience }\end{array}$ & 0 & 1 & 23 & 4 & 5 & 6 \\
\hline K_19 & Sometimes I feel anxious for no particular reason... & 0 & 1 & 23 & 4 & 5 & 6 \\
\hline K_20 & $\begin{array}{l}\text { From early in my music studies, I remember being } \\
\text { anxious about performing }\end{array}$ & 0 & 1 & 23 & 4 & 5 & 6 \\
\hline
\end{tabular}


K_21 I worry that one bad performance may ruin my career

K_22 Prior to, or during a performance, I experience

$\begin{array}{lllllll}0 & 1 & 2 & 3 & 4 & 5 & 6\end{array}$
increased heart rate like pounding in my chest...

K_23 My parents almost always listened to me

$\begin{array}{lllllll}6 & 5 & 4 & 3 & 2 & 1 & 0\end{array}$

K_24 I give up worthwhile performance opportunities due to anxiety

K_25 After the performance, I worry about whether I played well enough.

K 26 My worry and nervousness about my performance interferes with my focus and concentration.

K_27 As a child, I often felt sad

K_28 I often prepare for a concert with a sense of dread and $\begin{array}{lllllll}0 & 1 & 2 & 3 & 4 & 5 & 6\end{array}$ impending disaster.

K_29 One or both of my parents were overly anxious...

K_30 Prior to, or during a performance, I have increased muscle tension

K_31 I often feel that I have nothing to look forward to.

K_32 After the performance, I replay it in my mind over and over.

K_33 My parents encouraged me to try new things ........

K_34 I worry so much before a performance, I cannot sleep

$\begin{array}{lllllll}0 & 1 & 2 & 3 & 4 & 5 & 6\end{array}$

$\begin{array}{lllllll}0 & 1 & 2 & 3 & 4 & 5 & 6\end{array}$

$\mathrm{K} \_35$ When performing without music, my memory is reliable.

K_36 Prior to, or during a performance, I experience

$\begin{array}{lllllll}0 & 1 & 2 & 3 & 4 & 5 & 6\end{array}$

$\begin{array}{lllllll}0 & 1 & 2 & 3 & 4 & 5 & 6\end{array}$

$\begin{array}{lllllll}0 & 1 & 2 & 3 & 4 & 5 & 6\end{array}$
shaking or trembling or tremor.

K_37 I am confident playing from memory

K_38 I am concerned about being scrutinized by others

K_39 I am concerned about my own judgement of how I will perform

$\begin{array}{lllllll}0 & 1 & 2 & 3 & 4 & 5 & 6\end{array}$

$\begin{array}{lllllll}0 & 1 & 2 & 3 & 4 & 5 & 6\end{array}$

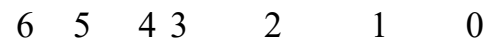

$\begin{array}{lllllll}0 & 1 & 2 & 3 & 4 & 5 & 6\end{array}$

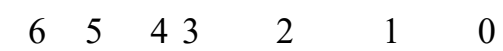

$\begin{array}{lllllll}0 & 1 & 2 & 3 & 4 & 5 & 6\end{array}$

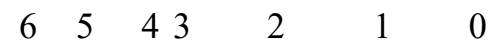

$\begin{array}{lllllll}0 & 1 & 2 & 3 & 4 & 5 & 6\end{array}$

$\begin{array}{lllllll}0 & 1 & 2 & 3 & 4 & 5 & 6\end{array}$

K_40 I remain committed to performing even though it causes me great anxiety....

$\begin{array}{lllllll}0 & 1 & 2 & 3 & 4 & 5 & 6\end{array}$

OKenny, D.T. (2009). Kenny-Music Performance Anxiety Inventory-Revised (K-MPAI-R) 


\section{Appendix D}

Pearson Correlation Coefficients between Items of AFSS and K-MPAI-R

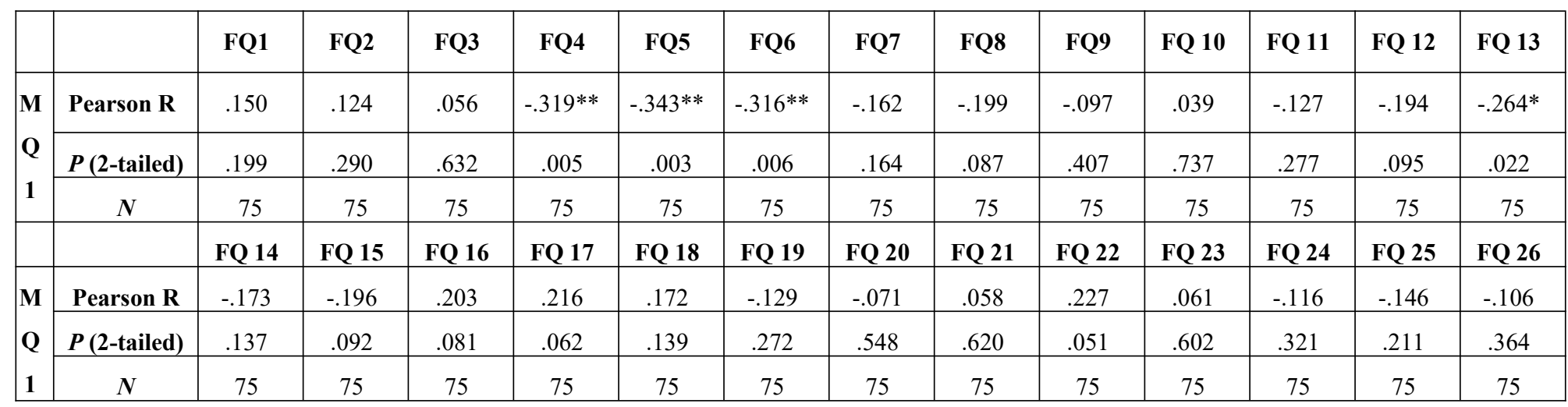

\begin{tabular}{|c|c|c|c|c|c|c|c|c|c|c|c|c|c|c|}
\hline & & FQ1 & FQ2 & FQ3 & FQ4 & FQ5 & FQ6 & FQ7 & FQ8 & FQ9 & FQ 10 & FQ 11 & FQ 12 & FQ 13 \\
\hline \multirow{4}{*}{$\begin{array}{l}\mathbf{M} \\
\mathbf{Q} \\
\mathbf{2}\end{array}$} & Pearson $R$ & .134 & $.268^{*}$ & .168 & -.103 & -.155 & $-.250 *$ & -.075 & .094 & .170 & .193 & .046 & .057 & -.027 \\
\hline & $P($ 2-tailed $)$ & .251 & .020 & .149 & .379 & .184 & .030 & .520 & .423 & .146 & .098 & .693 & .624 & .818 \\
\hline & $N$ & 75 & 75 & 75 & 75 & 75 & 75 & 75 & 75 & 75 & 75 & 75 & 75 & 75 \\
\hline & & FQ 14 & FQ 15 & FQ 16 & FQ 17 & FQ 18 & FQ 19 & FQ 20 & FQ 21 & FQ 22 & FQ 23 & FQ 24 & FQ 25 & FQ 26 \\
\hline \multirow{2}{*}{$\begin{array}{l}\text { M } \\
\text { Q }\end{array}$} & Pearson R & -.027 & .055 & .115 & $.233^{*}$ & .153 & .074 & .103 & .129 & $.258^{*}$ & $.321 * *$ & .172 & -.027 & -.041 \\
\hline & $P($ 2-tailed $)$ & .818 & .639 & .327 & .044 & .191 & .529 & .378 & .269 & .025 & .005 & .139 & .820 & .726 \\
\hline 2 & $N$ & 75 & 75 & 75 & 75 & 75 & 75 & 75 & 75 & 75 & 75 & 75 & 75 & 75 \\
\hline
\end{tabular}




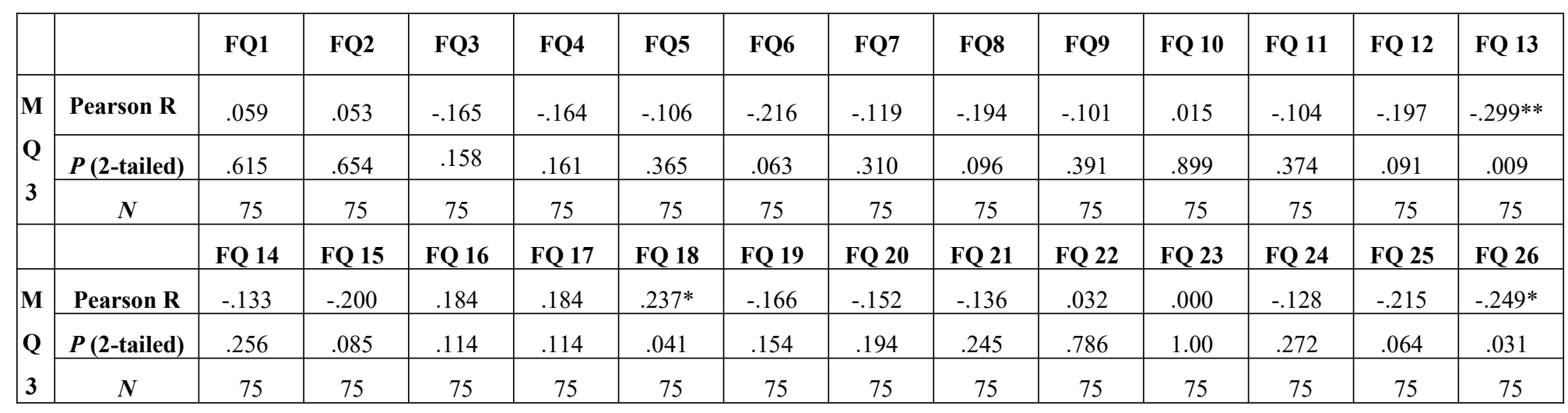

\begin{tabular}{|c|c|c|c|c|c|c|c|c|c|c|c|c|c|c|}
\hline & & FQ1 & FQ2 & FQ3 & FQ4 & FQ5 & FQ6 & FQ7 & FQ8 & FQ9 & FQ 10 & FQ 11 & FQ 12 & FQ 13 \\
\hline $\begin{array}{l}\mathbf{M} \\
\mathbf{Q}\end{array}$ & Pearson R & -.139 & -.179 & $-.263^{*}$ & .046 & .134 & -.029 & -.035 & -.135 & -.026 & -.149 & -.039 & -.047 & -.111 \\
\hline \multirow[t]{3}{*}{4} & $P($ 2-tailed $)$ & .235 & .123 & .023 & .698 & .250 & .805 & .769 & .247 & .824 & .203 & .737 & .687 & .342 \\
\hline & $N$ & 75 & 75 & 75 & 75 & 75 & 75 & 75 & 75 & 75 & 75 & 75 & 75 & 75 \\
\hline & & FQ 14 & FQ 15 & FQ 16 & FQ 17 & FQ 18 & FQ 19 & FQ 20 & FQ 21 & FQ 22 & FQ 23 & FQ 24 & FQ 25 & FQ 26 \\
\hline $\mathbf{M}$ & Pearson R & .000 & -.076 & -.031 & -.074 & .097 & -.202 & -.206 & $-.269 *$ & -.085 & .028 & -.141 & -.110 & -.141 \\
\hline Q & $P($ 2-tailed $)$ & 1.00 & .518 & .794 & .527 & .408 & .082 & .076 & .020 & .468 & .809 & .226 & .349 & .226 \\
\hline 4 & $N$ & 75 & 75 & 75 & 75 & 75 & 75 & 75 & 75 & 75 & 75 & 75 & 75 & 75 \\
\hline
\end{tabular}




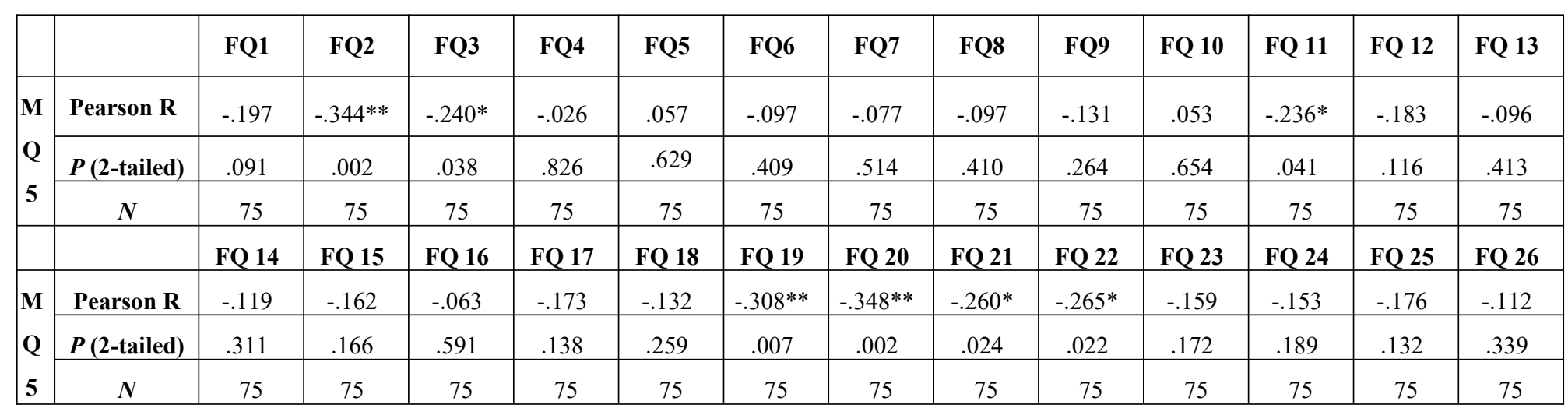

\begin{tabular}{|c|c|c|c|c|c|c|c|c|c|c|c|c|c|c|}
\hline & & FQ1 & FQ2 & FQ3 & FQ4 & FQ5 & FQ6 & FQ7 & FQ8 & FQ9 & FQ 10 & FQ 11 & FQ 12 & FQ 13 \\
\hline \multirow{4}{*}{$\begin{array}{l}\mathbf{M} \\
\mathbf{Q} \\
\mathbf{6}\end{array}$} & Pearson R & -.043 & -.146 & -.206 & $-.476 * *$ & $-.380^{* *}$ & $-.346 * *$ & -.189 & -.075 & -.190 & .121 & -.224 & -.183 & $-.269 *$ \\
\hline & $P$ (2-tailed) & .714 & .211 & .076 & . 000 & .001 & .002 & .104 & .524 & .102 & .300 & .054 & .116 & . 019 \\
\hline & $N$ & 75 & 75 & 75 & 75 & 75 & 75 & 75 & 75 & 75 & 75 & 75 & 75 & 75 \\
\hline & & FQ 14 & FQ 15 & FQ 16 & FQ 17 & FQ 18 & FQ 19 & FQ 20 & FQ 21 & FQ 22 & FQ 23 & FQ 24 & FQ 25 & FQ 26 \\
\hline M & Pearson R & $-.254 *$ & $-.284 *$ & -.024 & -.038 & -.085 & -.161 & -.162 & -.043 & -.026 & . 043 & -.141 & $-.286^{*}$ & -.178 \\
\hline Q & $P($ 2-tailed $)$ & .028 & .014 & .839 & .747 & .469 & .166 & .165 & .712 & .828 & .717 & .229 & .013 & .128 \\
\hline 6 & $N$ & 75 & 75 & 75 & 75 & 75 & 75 & 75 & 75 & 75 & 75 & 75 & 75 & 75 \\
\hline
\end{tabular}




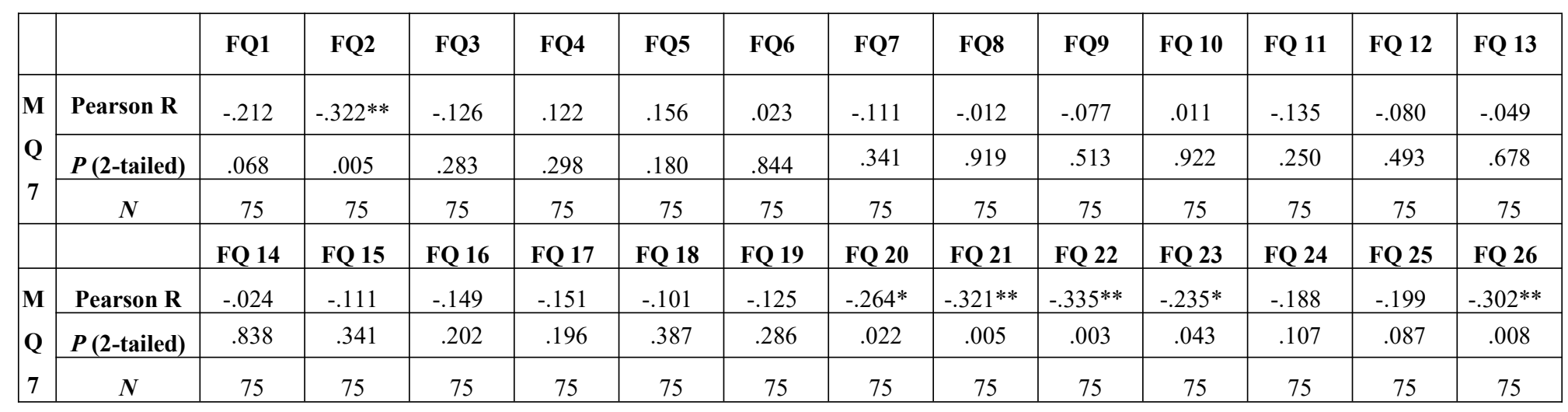

\begin{tabular}{|c|c|c|c|c|c|c|c|c|c|c|c|c|c|c|}
\hline & & FQ1 & FQ2 & FQ3 & FQ4 & FQ5 & FQ6 & FQ7 & FQ8 & FQ9 & FQ 10 & FQ 11 & FQ 12 & FQ 13 \\
\hline \multirow{4}{*}{$\begin{array}{l}\mathbf{M} \\
\mathbf{Q} \\
\mathbf{8}\end{array}$} & Pearson $\mathbf{R}$ & .179 & .119 & .096 & -.027 & $-.265^{*}$ & $-.303 * *$ & .014 & .060 & .065 & .177 & -.013 & -.185 & -.028 \\
\hline & $P($ 2-tailed $)$ & .124 & .307 & .412 & .074 & .022 & .008 & .903 & .608 & .579 & .129 & .911 & .111 & .813 \\
\hline & $N$ & 75 & 75 & 75 & 75 & 75 & 75 & 75 & 75 & 75 & 75 & 75 & 75 & 75 \\
\hline & & FQ 14 & FQ 15 & FQ 16 & FQ 17 & FQ 18 & FQ 19 & FQ 20 & FQ 21 & FQ 22 & FQ 23 & FQ 24 & FQ 25 & FQ 26 \\
\hline $\mathbf{M}$ & Pearson R & -.095 & -.142 & .045 & -.088 & .017 & -.042 & .008 & . 043 & .057 & .133 & -.101 & -.085 & -.047 \\
\hline Q & $P($ 2-tailed $)$ & .418 & .223 & .703 & .452 & .883 & .720 & .943 & .713 & .627 & .255 & .389 & .470 & 690 \\
\hline 8 & $N$ & 75 & 75 & 75 & 75 & 75 & 75 & 75 & 75 & 75 & 75 & 75 & 75 & 75 \\
\hline
\end{tabular}




\begin{tabular}{|c|c|c|c|c|c|c|c|c|c|c|c|c|c|c|}
\hline & & FQ1 & FQ2 & FQ3 & FQ4 & FQ5 & FQ6 & FQ7 & FQ8 & FQ9 & FQ 10 & FQ 11 & FQ 12 & FQ 13 \\
\hline \multirow{3}{*}{$\begin{array}{l}\mathbf{M} \\
\mathbf{Q} \\
\mathbf{9}\end{array}$} & Pearson $R$ & .058 & -.069 & .083 & -.164 & -.082 & -.025 & -.210 & -.125 & $-.242 *$ & -.006 & -.148 & -.128 & -.123 \\
\hline & $N$ & 75 & 75 & 75 & 75 & 75 & 75 & 75 & 75 & 75 & 75 & 75 & 75 & 75 \\
\hline & & FQ 14 & FQ 15 & FQ 16 & FQ 17 & FQ 18 & FQ 19 & FQ 20 & FQ 21 & FQ 22 & FQ 23 & FQ 24 & FQ 25 & FQ 26 \\
\hline $\mathbf{Q}$ & $P$ (2-tailed) & .636 & .090 & .998 & .780 & .100 & .893 & .983 & .121 & .181 & .012 & .227 & .040 & .047 \\
\hline 9 & $N$ & 75 & 75 & 75 & 75 & 75 & 75 & 75 & 75 & 75 & 75 & 75 & 75 & 75 \\
\hline
\end{tabular}

\begin{tabular}{|c|c|c|c|c|c|c|c|c|c|c|c|c|c|c|}
\hline & & FQ1 & FQ2 & FQ3 & FQ4 & FQ5 & FQ6 & FQ7 & FQ8 & FQ9 & FQ 10 & FQ 11 & FQ 12 & FQ 13 \\
\hline \multirow{4}{*}{$\begin{array}{l}\mathbf{M} \\
\mathbf{Q} \\
\mathbf{1 0}\end{array}$} & Pearson R & -.027 & -.189 & -.160 & -.192 & -.112 & -.166 & -.065 & -.107 & -.179 & -.086 & $-.286^{*}$ & $-.316^{* *}$ & -.143 \\
\hline & $P($ 2-tailed $)$ & .819 & .104 & .170 & .099 & .338 & .154 & .577 & .361 & .125 & .464 & .013 & .006 & .220 \\
\hline & $N$ & 75 & 75 & 75 & 75 & 75 & 75 & 75 & 75 & 75 & 75 & 75 & 75 & 75 \\
\hline & & FQ 14 & FQ 15 & FQ 16 & FQ 17 & FQ 18 & FQ 19 & FQ 20 & FQ 21 & FQ 22 & FQ 23 & FQ 24 & FQ 25 & FQ 26 \\
\hline $\mathbf{M}$ & Pearson R & -.122 & -.191 & -.107 & -.157 & -.019 & $-.246^{*}$ & $-.263^{*}$ & $-.247^{*}$ & -.224 & -.145 & $-.366^{* *}$ & $-.274^{*}$ & $37^{*}$ \\
\hline Q & $P$ (2-tailed) & .298 & .101 & .360 & .179 & .869 & .033 & .023 & .032 & .053 & .214 & .001 & .017 & .040 \\
\hline 10 & $N$ & 75 & 7 & 75 & 75 & 75 & 75 & 75 & 75 & 75 & 75 & 75 & 75 & 75 \\
\hline
\end{tabular}




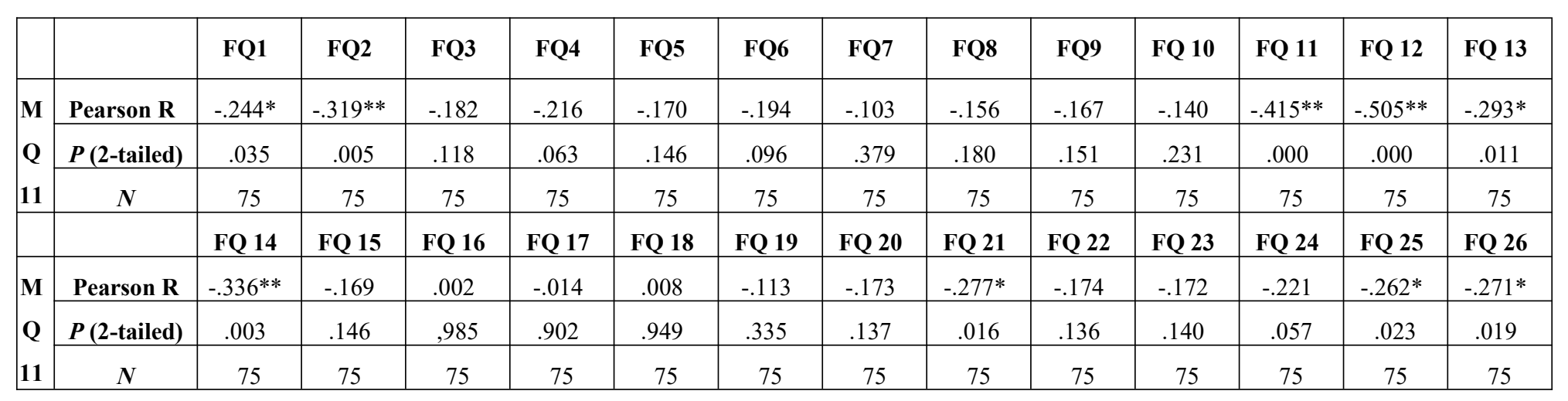

\begin{tabular}{|c|c|c|c|c|c|c|c|c|c|c|c|c|c|c|}
\hline & & FQ1 & FQ2 & FQ3 & FQ4 & FQ5 & FQ6 & FQ7 & FQ8 & FQ9 & FQ 10 & FQ 11 & FQ 12 & FQ 13 \\
\hline \multirow{4}{*}{$\begin{array}{l}M \\
Q \\
12\end{array}$} & Pearson R & .055 & -.005 & -.022 & -.070 & -.071 & -.221 & -.022 & -.013 & -.127 & -.008 & $-.296^{*}$ & $-.286^{*}$ & -.211 \\
\hline & $P$ (2-tailed) & .639 & .963 & .849 & .549 & .544 & .057 & .852 & .911 & .279 & .943 & .010 & .013 & .069 \\
\hline & $N$ & 75 & 75 & 75 & 75 & 75 & 75 & 75 & 75 & 75 & 75 & 75 & 75 & 75 \\
\hline & & FQ 14 & FQ 15 & FQ 16 & FQ 17 & FQ 18 & FQ 19 & FQ 20 & FQ 21 & FQ 22 & FQ 23 & FQ 24 & FQ 25 & FQ 26 \\
\hline $\mathbf{M}$ & Pearson R & -.149 & -.109 & .020 & .043 & .119 & -.047 & -.042 & -.130 & -.085 & -.105 & -.087 & -.157 & -.022 \\
\hline Q & $P$ (2-tailed) & .201 & .354 & .864 & .711 & .309 & .686 & .722 & .266 & .468 & .369 & .506 & .178 & .852 \\
\hline 12 & $N$ & 75 & 75 & 75 & 75 & 75 & 75 & 75 & 75 & 75 & 75 & 75 & 75 & 75 \\
\hline
\end{tabular}




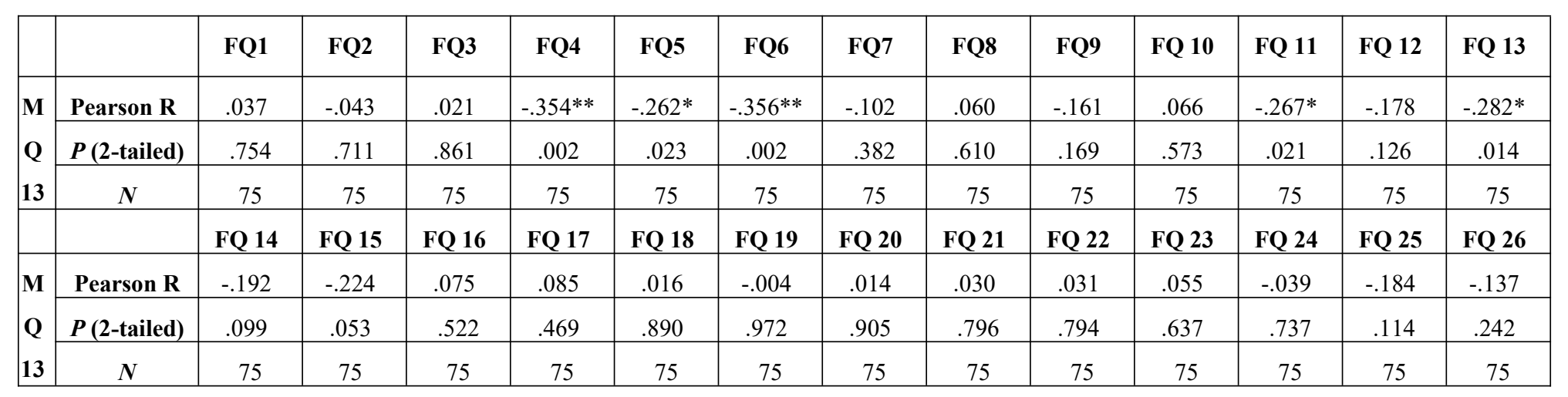

\begin{tabular}{|c|c|c|c|c|c|c|c|c|c|c|c|c|c|c|}
\hline & & FQ1 & FQ2 & FQ3 & FQ4 & FQ5 & FQ6 & FQ7 & FQ8 & FQ9 & FQ 10 & FQ 11 & FQ 12 & FQ 13 \\
\hline $\mathbf{M}$ & Pearson R & -.029 & -.132 & -.003 & -.179 & -.157 & -.224 & -.169 & -.158 & $-.228^{*}$ & -.086 & $-.382 * *$ & $-.316^{* *}$ & $-.253^{*}$ \\
\hline Q & $P(2$-tailed $)$ & .808 & .261 & .978 & .124 & .178 & .053 & .147 & .177 & .049 & .466 & .001 & .006 & .029 \\
\hline \multirow[t]{2}{*}{14} & $N$ & 75 & 75 & 75 & 75 & 75 & 75 & 75 & 75 & 75 & 75 & 75 & 75 & 75 \\
\hline & & FQ 14 & FQ 15 & FQ 16 & FQ 17 & FQ 18 & FQ 19 & FQ 20 & FQ 21 & FQ 22 & FQ 23 & FQ 24 & FQ 25 & FQ 26 \\
\hline $\mathbf{M}$ & Pearson R & -.179 & $-.278^{*}$ & .067 & .000 & .056 & $-.229 *$ & $-.292 *$ & -.10 & .02 & -.057 & $-.289^{*}$ & $-.345^{* *}$ & $-.230^{*}$ \\
\hline Q & $P(2$-tailed $)$ & .124 & .016 & .567 & .997 & .636 & .048 & .011 & .393 & .857 & .630 & .012 & .002 & .047 \\
\hline 14 & $N$ & 75 & 75 & 75 & 75 & 75 & 75 & 75 & 75 & 75 & 75 & 75 & 75 & 75 \\
\hline
\end{tabular}




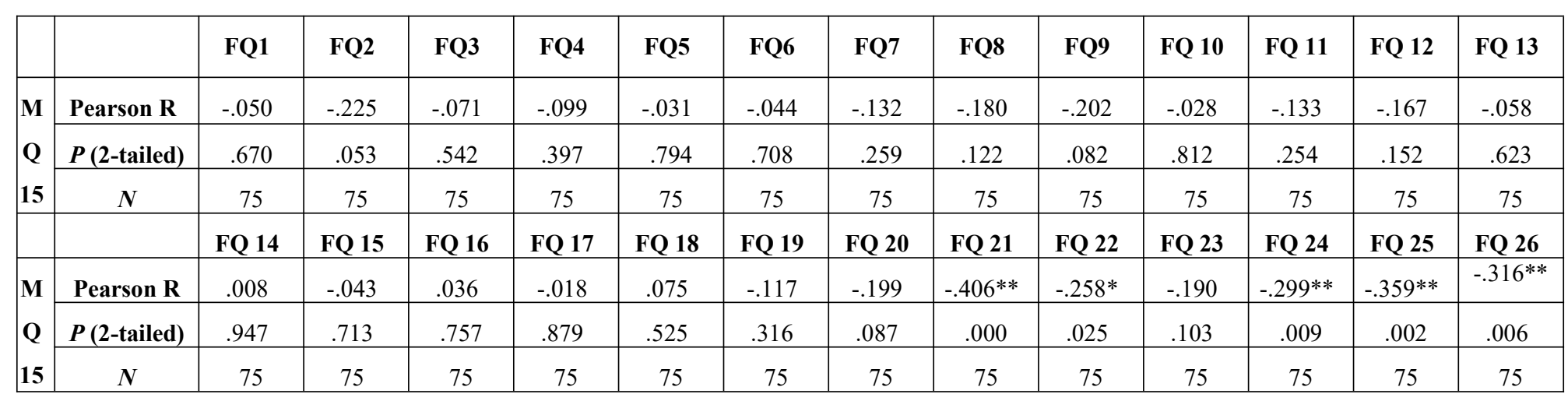

\begin{tabular}{|c|c|c|c|c|c|c|c|c|c|c|c|c|c|c|}
\hline & & FQ1 & FQ2 & FQ3 & FQ4 & FQ5 & FQ6 & FQ7 & FQ8 & FQ9 & FQ 10 & FQ 11 & FQ 12 & FQ 13 \\
\hline $\mathbf{M}$ & Pearson R & .074 & -.030 & -.093 & -.174 & -.146 & -.191 & -.066 &,- 220 & -.120 & .051 & -.206 & $-.245^{*}$ & -107 \\
\hline Q & $P($ 2-tailed $)$ & .526 & .798 & .427 & .136 & .212 & .100 & .573 & .058 & .305 & .662 & .077 & .034 & .360 \\
\hline \multirow[t]{2}{*}{16} & $N$ & 75 & 75 & 75 & 75 & 75 & 75 & 75 & 75 & 75 & 75 & 75 & 75 & 75 \\
\hline & & FQ 14 & FQ 15 & FQ 16 & FQ 17 & FQ 18 & FQ 19 & FQ 20 & FQ 21 & FQ 22 & FQ 23 & FQ 24 & FQ 25 & FQ 26 \\
\hline $\mathbf{M}$ & Pearson R & -.127 & -.038 & -.059 & -.143 & -.089 & -.211 & $-.238 *$ & -.105 & -.162 & -.113 & $-.352 * *$ & $-.315 * *$ & -.158 \\
\hline$Q$ & $P$ (2-tailed) & .277 & .744 & .617 & .220 & .446 & .070 & .040 & .371 & .164 & .334 & .002 & .006 & .175 \\
\hline 16 & $N$ & 75 & 75 & 75 & 75 & 75 & 75 & 75 & 75 & 75 & 75 & 75 & 75 & 75 \\
\hline
\end{tabular}




\begin{tabular}{|c|c|c|c|c|c|c|c|c|c|c|c|c|c|c|}
\hline & & FQ1 & FQ2 & FQ3 & FQ4 & FQ5 & FQ6 & FQ7 & FQ8 & FQ9 & FQ 10 & FQ 11 & FQ 12 & FQ 13 \\
\hline \multirow{3}{*}{$\begin{array}{l}\mathbf{M} \\
\mathbf{Q} \\
\mathbf{1 7}\end{array}$} & Pearson R & -.017 & -.107 & -.027 & -.135 & -.114 & -.169 & -.090 & -.177 & -.100 & .073 & -.111 & $-.237^{*}$ & -.160 \\
\hline & $N$ & 75 & 75 & 75 & 75 & 75 & 75 & 75 & 75 & 75 & 75 & 75 & 75 & 75 \\
\hline & & FQ 14 & FQ 15 & FQ 16 & FQ 17 & FQ 18 & FQ 19 & FQ 20 & FQ 21 & FQ 22 & FQ 23 & FQ 24 & FQ 25 & FQ 26 \\
\hline Q & $P$ (2-tailed) & .205 & .391 & .624 & .278 & .216 & .419 & .227 & .022 & .063 & .043 & .023 & .031 & .011 \\
\hline 17 & $N$ & 75 & 75 & 75 & 75 & 75 & 75 & 75 & 75 & 75 & 75 & 75 & 75 & 75 \\
\hline
\end{tabular}

\begin{tabular}{|c|c|c|c|c|c|c|c|c|c|c|c|c|c|c|}
\hline & & FQ1 & FQ2 & FQ3 & FQ4 & FQ5 & FQ6 & FQ7 & FQ8 & FQ9 & FQ 10 & FQ 11 & FQ 12 & FQ 13 \\
\hline \multirow{4}{*}{$\begin{array}{l}M \\
Q \\
18\end{array}$} & Pearson R & .075 & .031 & -.019 & -.090 & -.054 & -.043 & .023 & -.086 & .062 & -.125 & -.053 & -.136 & -.123 \\
\hline & $P$ (2-tailed) & .522 & .792 & .873 & .441 & .646 & .716 & .848 & .463 & .598 & .286 & .650 & .246 & .291 \\
\hline & $N$ & 75 & 75 & 75 & 75 & 75 & 75 & 75 & 75 & 75 & 75 & 75 & 75 & 75 \\
\hline & & FQ 14 & FQ 15 & FQ 16 & FQ 17 & FQ 18 & FQ 19 & FQ 20 & FQ 21 & FQ 22 & FQ 23 & FQ 24 & FQ 25 & FQ 26 \\
\hline $\mathbf{M}$ & Pearson $\mathbf{R}$ & -.104 & -.116 & -.002 & -.047 & .070 & -.054 & -.091 & -.220 & $-.279 *$ & $-.339 * *$ & -.114 & .035 & .054 \\
\hline Q & $P($ 2-tailed $)$ & .376 & .322 & .988 & .691 & .553 & .646 & .439 & .057 & .015 & .003 & .329 & .768 & .643 \\
\hline 18 & $N$ & 75 & 75 & 75 & 75 & 75 & 75 & 75 & 75 & 75 & 75 & 75 & 75 & 75 \\
\hline
\end{tabular}




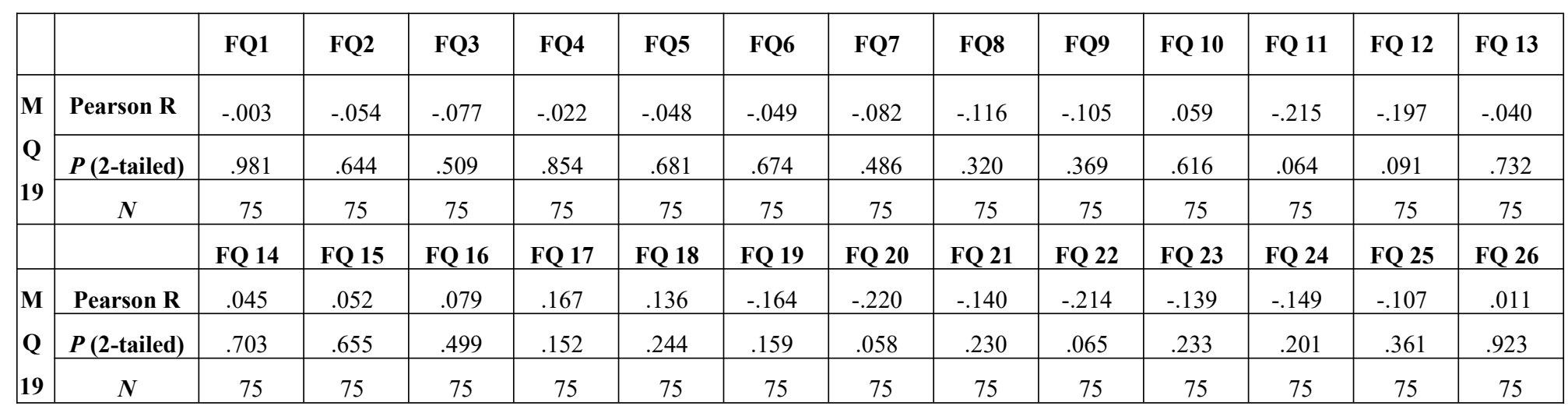

\begin{tabular}{|c|c|c|c|c|c|c|c|c|c|c|c|c|c|c|}
\hline & & FQ1 & FQ2 & FQ3 & FQ4 & FQ5 & FQ6 & FQ7 & FQ8 & FQ9 & FQ 10 & FQ 11 & FQ 12 & FQ 13 \\
\hline \multirow{4}{*}{$\begin{array}{l}\mathbf{M} \\
\mathbf{Q} \\
\mathbf{2 0}\end{array}$} & Pearson $R$ & -.098 & -.214 & -.164 & .173 & .224 & .167 & .005 & -.048 & .032 & -.118 & -.151 & -.221 & .035 \\
\hline & $P($ 2-tailed $)$ & .404 & .065 & .160 & .138 & .054 & .151 & .966 & .685 & .783 & .315 & .196 & .057 & .768 \\
\hline & $N$ & 75 & 75 & 75 & 75 & 75 & 75 & 75 & 75 & 75 & 75 & 75 & 75 & 75 \\
\hline & & FQ 14 & FQ 15 & FQ 16 & FQ 17 & FQ 18 & FQ 19 & FQ 20 & FQ 21 & FQ 22 & FQ 23 & FQ 24 & FQ 25 & FQ 26 \\
\hline $\mathbf{M}$ & Pearson R & -.011 & -.052 & -.076 & -.143 & -.075 & -.207 & $-.255^{*}$ & $-.328 * *$ & $-.357 * *$ & $-.274 *$ & -.168 & -.166 & -.086 \\
\hline Q & $P($ 2-tailed) & .928 & .659 & .518 & .222 & .521 & .074 & .027 & .004 & .002 & .017 & .149 & .155 & .464 \\
\hline 20 & $N$ & 75 & 75 & 75 & 75 & 75 & 75 & 75 & 75 & 75 & 75 & 75 & 75 & 75 \\
\hline
\end{tabular}




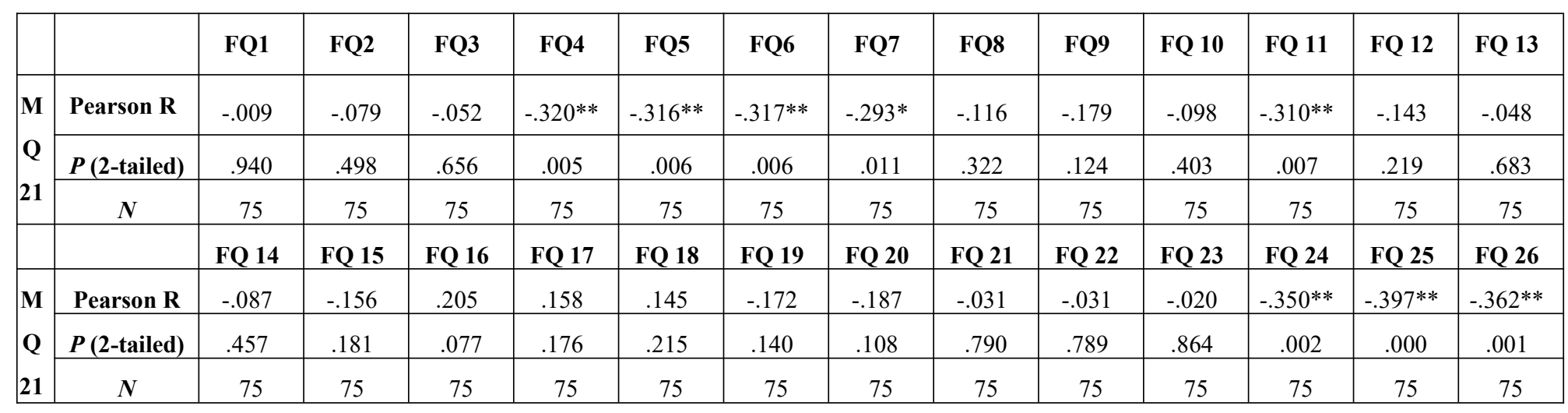

\begin{tabular}{|c|c|c|c|c|c|c|c|c|c|c|c|c|c|c|}
\hline & & FQ1 & FQ2 & FQ3 & FQ4 & FQ5 & FQ6 & FQ7 & FQ8 & FQ9 & FQ 10 & FQ 11 & FQ 12 & FQ 13 \\
\hline \multirow{4}{*}{$\begin{array}{l}\text { M } \\
\text { Q } \\
22\end{array}$} & Pearson R & .056 & -.093 & -.076 & -.202 & -.163 & -.143 & -.093 & -.070 & -.107 & . 068 & -.192 & -.214 & -.177 \\
\hline & $P$ (2-tailed) & .635 & .426 & .517 & .082 & .163 & .222 & .428 & .549 & .361 & .563 & .099 & .065 & .128 \\
\hline & $N$ & 75 & 75 & 75 & 75 & 75 & 75 & 75 & 75 & 75 & 75 & 75 & 75 & 75 \\
\hline & & FQ 14 & FQ 15 & FQ 16 & FQ 17 & FQ 18 & FQ 19 & FQ 20 & FQ 21 & FQ 22 & FQ 23 & FQ 24 & FQ 25 & FQ 26 \\
\hline $\mathbf{M}$ & Pearson R & -.106 & -.083 & -.043 & .081 & .137 & -.121 & -.161 & -.186 & -.147 & -.138 & -.028 & .021 & . 013 \\
\hline Q & $P$ (2-tailed) & .366 & .481 & .716 & .488 & .242 & .301 & .166 & .110 & .209 & .238 & .813 & .855 & .912 \\
\hline 22 & $N$ & 75 & 75 & 75 & 75 & 75 & 75 & 75 & 75 & 75 & 75 & 75 & 75 & 75 \\
\hline
\end{tabular}




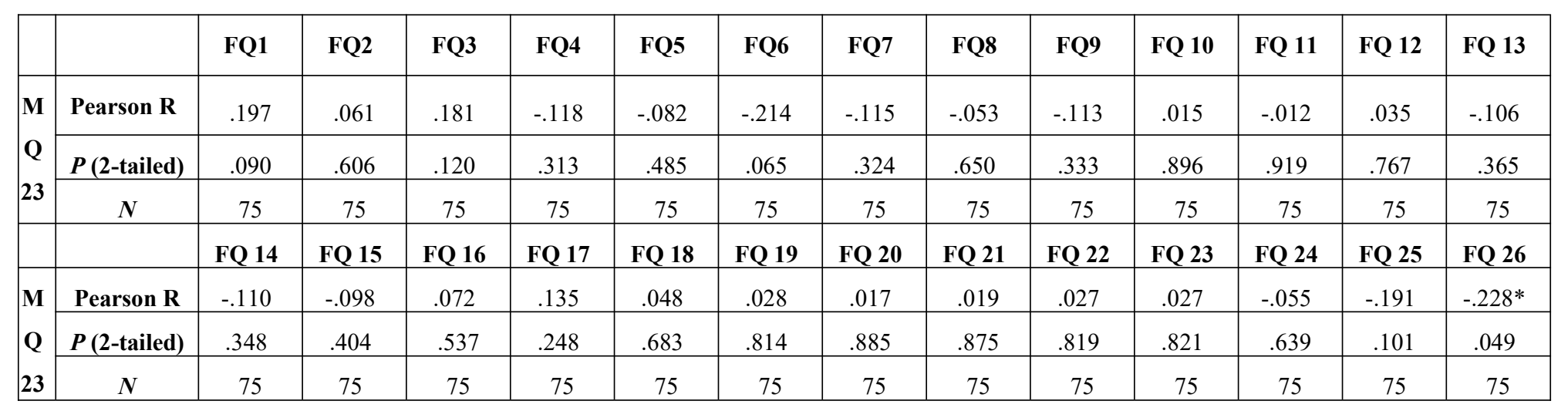

\begin{tabular}{|c|c|c|c|c|c|c|c|c|c|c|c|c|c|c|}
\hline & & FQ1 & FQ2 & FQ3 & FQ4 & FQ5 & FQ6 & FQ7 & FQ8 & FQ9 & FQ 10 & FQ 11 & FQ 12 & FQ 13 \\
\hline \multirow{4}{*}{$\begin{array}{l}\text { M } \\
\text { Q } \\
24\end{array}$} & Pearson R & .006 & -.208 & -.162 & $-.288^{*}$ & $-.344 * *$ & $-.341 * *$ & -.219 & -.114 & -.126 & .096 & -.134 & -.141 & -.110 \\
\hline & $P($ 2-tailed) & 960 & .073 & .166 & .012 & .002 & .003 & .060 & .330 & .280 & .412 & .253 & .228 & .346 \\
\hline & $N$ & 75 & 75 & 75 & 75 & 75 & 75 & 75 & 75 & 75 & 75 & 75 & 75 & 75 \\
\hline & & FQ 14 & FQ 15 & FQ 16 & FQ 17 & FQ 18 & FQ 19 & FQ 20 & FQ 21 & FQ 22 & FQ 23 & FQ 24 & FQ 25 & FQ 26 \\
\hline \multirow{3}{*}{$\begin{array}{l}\mathbf{M} \\
\mathbf{Q}\end{array}$} & Pearson R & $-.240^{*}$ & -.225 & .008 & -.051 & -.004 & $-.435^{* *}$ & $-.324 * *$ & .018 & .065 & .084 & $-.377^{* *}$ & $-.328 * *$ & $-274 *$ \\
\hline & $P($ 2-tailed) & .038 & .053 & 944 & .661 & .705 & .000 & .005 & .876 & .582 & .473 & .001 & .004 & .017 \\
\hline & $N$ & 75 & 75 & 75 & 75 & 75 & 75 & 75 & 75 & 75 & 75 & 75 & 75 & 75 \\
\hline
\end{tabular}




\begin{tabular}{|c|c|c|c|c|c|c|c|c|c|c|c|c|c|c|}
\hline & & FQ1 & FQ2 & FQ3 & FQ4 & FQ5 & FQ6 & FQ7 & FQ8 & FQ9 & FQ 10 & FQ 11 & FQ 12 & FQ 13 \\
\hline \multirow{3}{*}{$\begin{array}{c}M \\
Q \\
25\end{array}$} & Pearson R & -.120 & -.196 & -.198 & -.059 & .042 & -.005 & -.028 & -.020 & -.080 & .032 & -.186 & -.108 & -.143 \\
\hline & $N$ & 75 & 75 & 75 & 75 & 75 & 75 & 75 & 75 & 75 & 75 & 75 & 75 & 75 \\
\hline & & FQ 14 & FQ 15 & FQ 16 & FQ 17 & FQ 18 & FQ 19 & FQ 20 & FQ 21 & FQ 22 & FQ 23 & FQ 24 & FQ 25 & FQ 26 \\
\hline \multirow{2}{*}{$\begin{array}{l}\text { M } \\
\text { Q } \\
25\end{array}$} & $P$ (2-tailed) & .918 & .317 & .776 & .700 & .776 & .441 & .372 & .016 & .067 & .196 & .967 & .168 & .358 \\
\hline & $N$ & 75 & 75 & 75 & 75 & 75 & 75 & 75 & 75 & 75 & 75 & 75 & 75 & 75 \\
\hline
\end{tabular}

\begin{tabular}{|c|c|c|c|c|c|c|c|c|c|c|c|c|c|c|}
\hline & & FQ1 & FQ2 & FQ3 & FQ4 & FQ5 & FQ6 & FQ7 & FQ8 & FQ9 & FQ 10 & FQ 11 & FQ 12 & FQ 13 \\
\hline \multirow{4}{*}{$\begin{array}{l}M \\
Q \\
26\end{array}$} & Pearson $\mathbf{R}$ & -.195 & $-.442 * *$ & $-.242 *$ & .030 & .105 & .052 & -.070 & -.110 & -.170 & -.140 & $-.312^{* *}$ & -.178 & -.004 \\
\hline & $P$ (2-tailed) & .094 & .000 & .036 & .801 & .370 & .657 & .550 & .345 & .144 & .232 & .006 & .128 & .970 \\
\hline & $N$ & 75 & 75 & 75 & 75 & 75 & 75 & 75 & 75 & 75 & 75 & 75 & 75 & 75 \\
\hline & & FQ 14 & FQ 15 & FQ 16 & FQ 17 & FQ 18 & FQ 19 & FQ 20 & FQ 21 & FQ 22 & FQ 23 & FQ 24 & FQ 25 & FQ 26 \\
\hline \multirow{3}{*}{$\begin{array}{l}M \\
Q \\
26\end{array}$} & Pearson R & -.038 & -.225 & -.101 & -.135 & -.152 & $-.307 * *$ & $-.294 *$ & $-.249 *$ & $-.274 *$ & $-.245^{*}$ & -.178 & -.225 & -.218 \\
\hline & $P$ (2-tailed) & .748 & .052 & .387 & .249 & .193 & .007 & .011 & .031 & .017 & .034 & .126 & .052 & .060 \\
\hline & $N$ & 75 & 75 & 75 & 75 & 75 & 75 & 75 & 75 & 75 & 75 & 75 & 75 & 75 \\
\hline
\end{tabular}




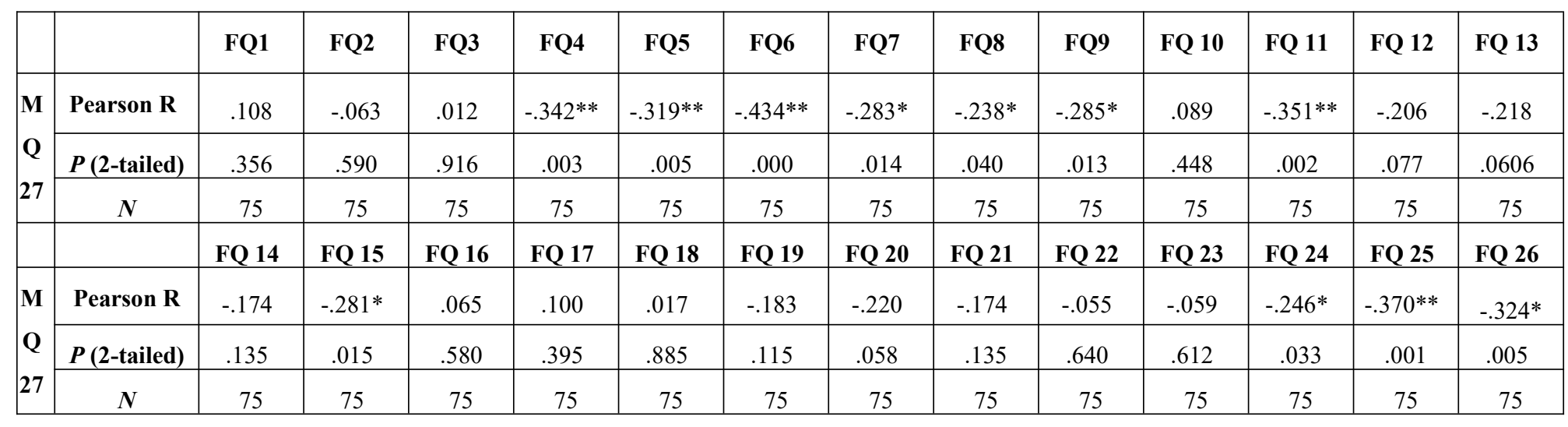

$\vec{u}$

\begin{tabular}{|c|c|c|c|c|c|c|c|c|c|c|c|c|c|c|}
\hline & & FQ1 & FQ2 & FQ3 & FQ4 & FQ5 & FQ6 & FQ7 & FQ8 & FQ9 & FQ 10 & FQ 11 & FQ 12 & FQ 13 \\
\hline \multirow{4}{*}{$\begin{array}{l}\text { M } \\
\text { Q } \\
28\end{array}$} & Pearson R & .011 & -.091 & -.064 & $-.377^{* *}$ & $-.350 * *$ & $-.300 * *$ & -.214 & -.026 & $-.237^{*}$ & .178 & $-.260^{*}$ & -.091 & -.188 \\
\hline & $P($ 2-tailed $)$ & .926 & .436 & .584 & .001 & .002 & .009 & .066 & .825 & .041 & .128 & .024 & .438 & .106 \\
\hline & $N$ & 75 & 75 & 75 & 75 & 75 & 75 & 75 & 75 & 75 & 75 & 75 & 75 & 75 \\
\hline & & FQ 14 & FQ 15 & FQ 16 & FQ 17 & FQ 18 & FQ 19 & FQ 20 & FQ 21 & FQ 22 & FQ 23 & FQ 24 & FQ 25 & FQ 26 \\
\hline M & Pearson R & -.199 & $-.246^{*}$ & -.102 & -.124 & -.044 & -.222 & $-.249 *$ & -.096 & .005 & .090 & $-.249 *$ & $-.356 * *$ & $-.276^{*}$ \\
\hline $\mathbf{Q}$ & $P$ (2-tailed) & .087 & .034 & .386 & .291 & .709 & .056 & .031 & .414 & .967 & .440 & .031 & .002 & .017 \\
\hline 28 & $N$ & 75 & 75 & 75 & 75 & 75 & 75 & 75 & 75 & 75 & 75 & 75 & 75 & 75 \\
\hline
\end{tabular}




\begin{tabular}{|c|c|c|c|c|c|c|c|c|c|c|c|c|c|c|}
\hline \multirow{3}{*}{$\begin{array}{c}\mathbf{M} \\
\mathbf{Q} \\
29\end{array}$} & Pearson R & .053 & -.105 & .043 & -.037 & -.004 & -.026 & -.039 & -.040 & -.067 & .156 & -.092 & -.083 & .016 \\
\hline & $N$ & 75 & 75 & 75 & 75 & 75 & 75 & 75 & 75 & 75 & 75 & 75 & 75 & 75 \\
\hline & & FQ 14 & FQ 15 & FQ 16 & FQ 17 & FQ 18 & FQ 19 & FQ 20 & FQ 21 & FQ 22 & FQ 23 & FQ 24 & FQ 25 & FQ 26 \\
\hline \multirow{2}{*}{$\begin{array}{l}\text { M } \\
\text { Q } \\
29\end{array}$} & $P(2$-tailed $)$ & .769 & .630 & .792 & .582 & .523 & .398 & .065 & .005 & .001 & .005 & .698 & .205 & .332 \\
\hline & $N$ & 75 & 75 & 75 & 75 & 75 & 75 & 75 & 75 & 75 & 75 & 75 & 75 & 75 \\
\hline
\end{tabular}

\begin{tabular}{|c|c|c|c|c|c|c|c|c|c|c|c|c|c|c|}
\hline & & FQ1 & FQ2 & FQ3 & FQ4 & FQ5 & FQ6 & FQ7 & FQ8 & FQ9 & FQ 10 & FQ 11 & FQ 12 & FQ 13 \\
\hline \multirow{4}{*}{$\begin{array}{l}\mathbf{M} \\
\mathbf{Q} \\
\mathbf{3 0}\end{array}$} & Pearson R & -.065 & -.169 & -.175 & -.052 & -.021 & -.005 & -.100 & -.139 & $-.308 * *$ & .003 & -.189 & -.052 & -.099 \\
\hline & $P$ (2-tailed) & .578 & .147 & .133 & .656 & .859 & .966 & .391 & .236 & .007 & .981 & .104 & .660 & .399 \\
\hline & $N$ & 75 & 75 & 75 & 75 & 75 & 75 & 75 & 75 & 75 & 75 & 75 & 75 & 75 \\
\hline & & FQ 14 & FQ 15 & FQ 16 & FQ 17 & FQ 18 & FQ 19 & FQ 20 & FQ 21 & FQ 22 & FQ 23 & FQ 24 & FQ 25 & FQ 26 \\
\hline M & Pearson R & -.085 & -.201 & -.029 & . 045 & .042 & $-.297 * *$ & $-.270^{*}$ & $-.303 * *$ & $-.282 *$ & -.141 & -.172 & $-.282^{*}$ & -.185 \\
\hline $\mathbf{Q}$ & $P$ (2-tailed) & .470 & .083 & .803 & .702 & .721 & .010 & .019 & .008 & .014 & .228 & .139 & .035 & .112 \\
\hline 30 & $N$ & 75 & 75 & 75 & 75 & 75 & 75 & 75 & 75 & 75 & 75 & 75 & 75 & 75 \\
\hline
\end{tabular}




\begin{tabular}{|c|c|c|c|c|c|c|c|c|c|c|c|c|c|c|}
\hline & & FQ1 & FQ2 & FQ3 & FQ4 & FQ5 & FQ6 & FQ7 & FQ8 & FQ9 & FQ 10 & FQ 11 & FQ 12 & FQ 13 \\
\hline \multirow{3}{*}{$\begin{array}{l}\mathbf{M} \\
\mathbf{Q} \\
\mathbf{3 1}\end{array}$} & Pearson R & .043 & -.027 & -.089 & -.192 & $-.236^{*}$ & $-.323 * *$ & $-.305^{* *}$ & -.182 & $-.232 *$ & .074 & $-.274^{*}$ & -.215 & -.197 \\
\hline & $N$ & 75 & 75 & 75 & 75 & 75 & 75 & 75 & 75 & 75 & 75 & 75 & 75 & 75 \\
\hline & & FQ 14 & FQ 15 & FQ 16 & FQ 17 & FQ 18 & FQ 19 & FQ 20 & FQ 21 & FQ 22 & FQ 23 & FQ 24 & FQ 25 & FQ 26 \\
\hline $\mathbf{Q}$ & $P($ 2-tailed $)$ & .189 & .016 & .114 & .379 & .697 & .078 & .082 & .349 & .229 & .310 & .006 & .001 & .028 \\
\hline 31 & $N$ & 75 & 75 & 75 & 75 & 75 & 75 & 75 & 75 & 75 & 75 & 75 & 75 & 75 \\
\hline
\end{tabular}

\begin{tabular}{|c|c|c|c|c|c|c|c|c|c|c|c|c|c|c|}
\hline & & FQ1 & FQ2 & FQ3 & FQ4 & FQ5 & FQ6 & FQ7 & FQ8 & FQ9 & FQ 10 & FQ 11 & FQ 12 & FQ 13 \\
\hline \multirow{4}{*}{$\begin{array}{l}\mathbf{M} \\
\mathbf{Q} \\
\mathbf{3 2}\end{array}$} & Pearson R & -.065 & -.172 & -.084 & -.082 & -.037 & .006 & -.065 & -.096 & -.172 & -.147 & -.188 & -.097 & -.037 \\
\hline & $P($ 2-tailed $)$ & .581 & .139 & .472 & .484 & .755 & .962 & .578 & .414 & .140 & .207 & .106 & .409 & .752 \\
\hline & $N$ & 75 & 75 & 75 & 75 & 75 & 75 & 75 & 75 & 75 & 75 & 75 & 75 & 75 \\
\hline & & FQ 14 & FQ 15 & FQ 16 & FQ 17 & FQ 18 & FQ 19 & FQ 20 & FQ 21 & FQ 22 & FQ 23 & FQ 24 & FQ 25 & FQ 26 \\
\hline $\mathbf{M}$ & Pearson R & -.016 & -.175 & -.090 & -.052 & .063 & -.035 & -.198 & $-.315 * *$ & $-.301 * *$ & -.207 & -.080 & -.113 & -.104 \\
\hline Q & $P($ 2-tailed) & .889 & .133 & .444 & .656 & .589 & .763 & .088 & .006 & .009 & .075 & .497 & .336 & .376 \\
\hline 32 & $N$ & 75 & 75 & 75 & 75 & 75 & 75 & 75 & 75 & 75 & 75 & 75 & 75 & 75 \\
\hline
\end{tabular}




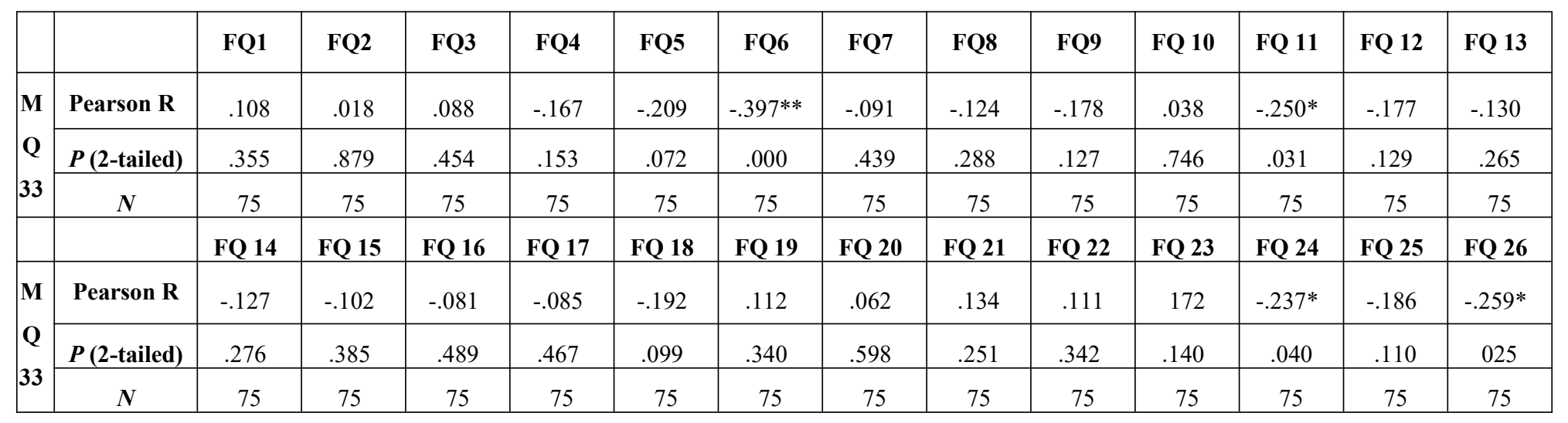

$\vec{\omega}$

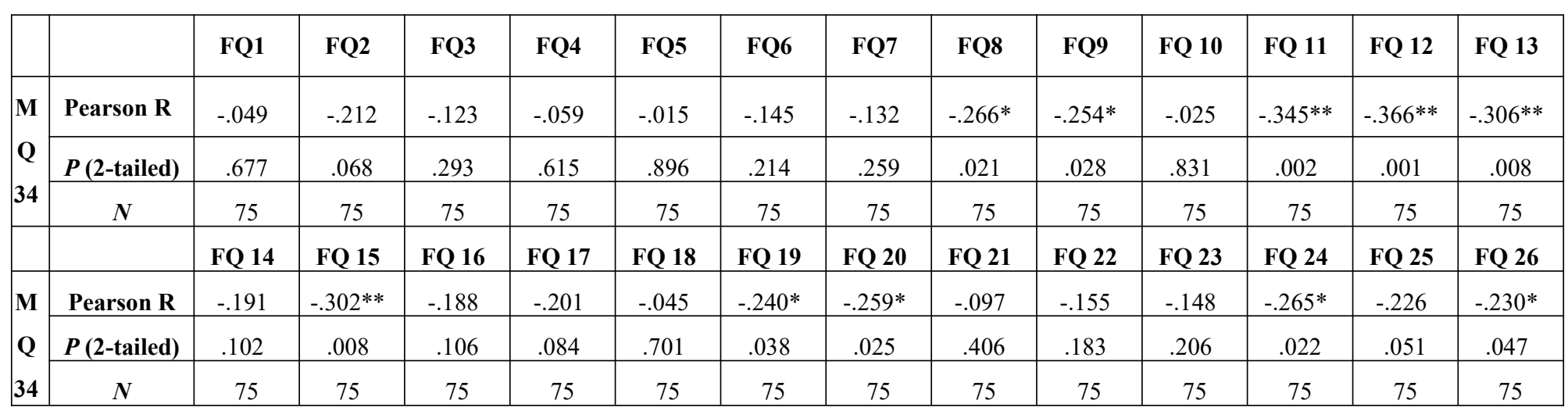




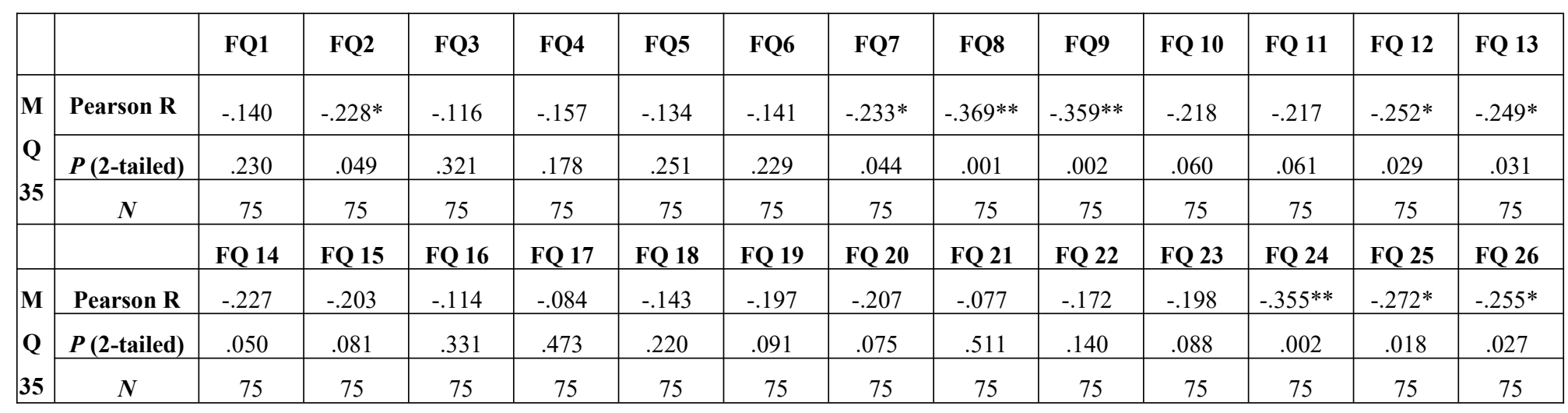

\begin{tabular}{|c|c|c|c|c|c|c|c|c|c|c|c|c|c|c|}
\hline & & FQ1 & FQ2 & FQ3 & FQ4 & FQ5 & FQ6 & FQ7 & FQ8 & FQ9 & FQ 10 & FQ 11 & FQ 12 & FQ 13 \\
\hline \multirow{4}{*}{$\begin{array}{l}\text { M } \\
\text { Q } \\
36\end{array}$} & Pearson R & .093 & -.057 & .019 & -.084 & -.129 & -.131 & -.113 & -.150 & -.208 & .126 & $-.272 *$ & $-.298 * *$ & -.188 \\
\hline & $P$ (2-tailed) & .426 & .628 & .871 & .471 & .270 & .261 & .336 & .200 & .073 & .283 & .018 & .009 & .105 \\
\hline & $N$ & 75 & 75 & 75 & 75 & 75 & 75 & 75 & 75 & 75 & 75 & 75 & 75 & 75 \\
\hline & & FQ 14 & FQ 15 & FQ 16 & FQ 17 & FQ 18 & FQ 19 & FQ 20 & FQ 21 & FQ 22 & FQ 23 & FQ 24 & FQ 25 & FQ 26 \\
\hline M & Pearson R & -.157 & -.034 & . 059 & .117 & .182 & -.181 & -.195 & .035 & .128 & .053 & $-.305^{* *}$ & -.205 & $-.230 *$ \\
\hline $\mathbf{Q}$ & $P$ (2-tailed) & .178 & .770 & .612 & .316 & .117 & .120 & .094 & .768 & .276 & .654 & .008 & .078 & .047 \\
\hline 36 & $N$ & 75 & 75 & 75 & 75 & 75 & 75 & 75 & 75 & 75 & 75 & 75 & 75 & 75 \\
\hline
\end{tabular}




\begin{tabular}{|c|c|c|c|c|c|c|c|c|c|c|c|c|c|c|}
\hline & & FQ1 & FQ2 & FQ3 & FQ4 & FQ5 & FQ6 & FQ7 & FQ8 & FQ9 & FQ 10 & FQ 11 & FQ 12 & FQ 13 \\
\hline \multirow{3}{*}{$\begin{array}{l}\mathbf{M} \\
\mathbf{Q} \\
\mathbf{3 7}\end{array}$} & Pearson R & .069 & -.108 & .000 & $-.234^{*}$ & $-.280^{*}$ & -.222 & -.135 & $-.318^{* *}$ & $-.236^{*}$ & -.140 & -.216 & $-.331 * *$ & -.100 \\
\hline & $N$ & 75 & 75 & 75 & 75 & 75 & 75 & 75 & 75 & 75 & 75 & 75 & 75 & 75 \\
\hline & & FQ 14 & FQ 15 & FQ 16 & FQ 17 & FQ 18 & FQ 19 & FQ 20 & FQ 21 & FQ 22 & FQ 23 & FQ 24 & FQ 25 & FQ 26 \\
\hline $\mathbf{Q}$ & $P($ 2-tailed $)$ & .142 & .188 & .367 & .465 & .788 & .910 & .962 & .720 & .545 & .825 & .078 & .012 & .072 \\
\hline 37 & $N$ & 75 & 75 & 75 & 75 & 75 & 75 & 75 & 75 & 75 & 75 & 75 & 75 & 75 \\
\hline
\end{tabular}

\begin{tabular}{|c|c|c|c|c|c|c|c|c|c|c|c|c|c|c|}
\hline & & FQ1 & FQ2 & FQ3 & FQ4 & FQ5 & FQ6 & FQ7 & FQ8 & FQ9 & FQ 10 & FQ 11 & FQ 12 & FQ 13 \\
\hline \multirow{4}{*}{$\begin{array}{l}\text { M } \\
\mathbf{Q} \\
\mathbf{3 8}\end{array}$} & Pearson R & -.027 & -.115 & -.135 & -.003 & -.016 & .040 & -.062 & -.066 & -.057 & .057 & -.223 & -.191 & -.074 \\
\hline & $P$ (2-tailed) & .820 & .326 & .247 & .980 & .888 & .733 & .598 & .575 & .630 & .628 & .055 & .102 & .531 \\
\hline & $N$ & 75 & 75 & 75 & 75 & 75 & 75 & 75 & 75 & 75 & 75 & 75 & 75 & 75 \\
\hline & & FQ 14 & FQ 15 & FQ 16 & FQ 17 & FQ 18 & FQ 19 & FQ 20 & FQ 21 & FQ 22 & FQ 23 & FQ 24 & FQ 25 & FQ 26 \\
\hline $\mathbf{M}$ & Pearson R & .020 & -.071 & . 042 & -.031 & .071 & -.049 & -.094 & $-.361 * *$ & $-.358 * *$ & $-.237^{*}$ & -.161 & -.154 & -.029 \\
\hline Q & $P$ (2-tailed) & .862 & .547 & .724 & .792 & .547 & .674 & .422 & .001 & .002 & .040 & .168 & .186 & .804 \\
\hline 38 & $N$ & 75 & 75 & 75 & 75 & 75 & 75 & 75 & 75 & 75 & 75 & 75 & 75 & 75 \\
\hline
\end{tabular}




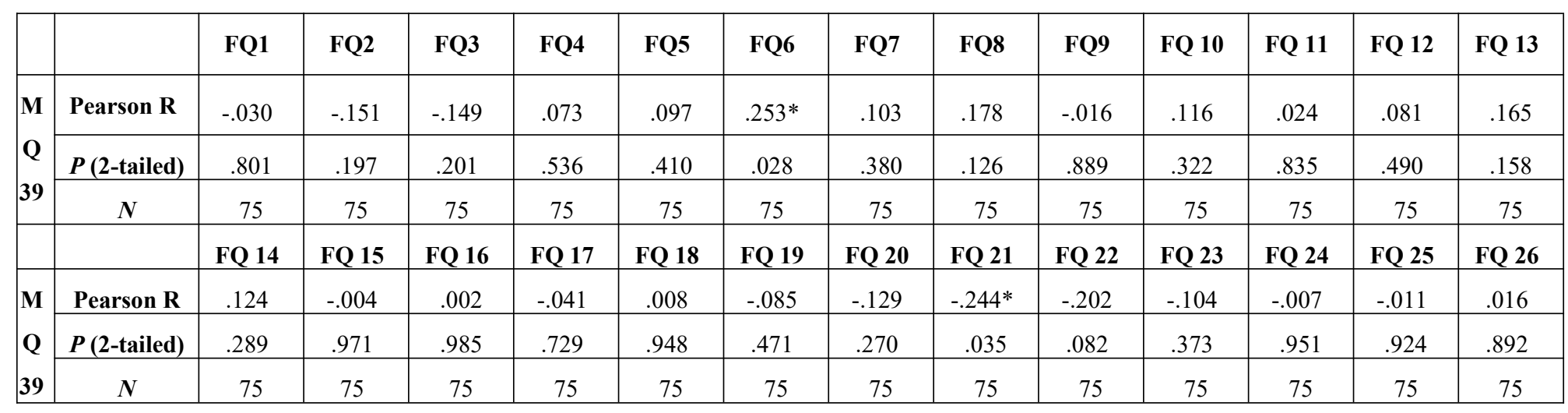

\begin{tabular}{|c|c|c|c|c|c|c|c|c|c|c|c|c|c|c|}
\hline & & FQ1 & FQ2 & FQ3 & FQ4 & FQ5 & FQ6 & FQ7 & FQ8 & FQ9 & FQ 10 & FQ 11 & FQ 12 & FQ 13 \\
\hline \multirow{4}{*}{$\begin{array}{l}\text { M } \\
\text { Q } \\
40\end{array}$} & Pearson R & -.031 & -.094 & -.030 & .227 & $.290^{*}$ & $.373 * *$ & $.242^{*}$ & .202 & .125 & -.106 & .007 & .145 & .178 \\
\hline & $P$ (2-tailed) & .792 & .421 & .797 & .050 & .012 & .001 & .037 & .082 & .286 & .364 & .956 & .216 & .127 \\
\hline & $N$ & 75 & 75 & 75 & 75 & 75 & 75 & 75 & 75 & 75 & 75 & 75 & 75 & 75 \\
\hline & & FQ 14 & FQ 15 & FQ 16 & FQ 17 & FQ 18 & FQ 19 & FQ 20 & FQ 21 & FQ 22 & FQ 23 & FQ 24 & FQ 25 & FQ 26 \\
\hline M & Pearson R & .211 & .074 & -.031 & -.044 & -.023 & .098 & .047 & -.021 & -.120 & .024 & .195 & $.236^{*}$ & .159 \\
\hline Q & $P(2$-tailed) & .069 & .527 & .792 & .710 & .842 & .401 & .687 & .855 & .305 & .838 & .094 & .042 & .173 \\
\hline 40 & $N$ & 75 & 75 & 75 & 75 & 75 & 75 & 75 & 75 & 75 & 75 & 75 & 75 & 75 \\
\hline
\end{tabular}

${ }^{* *}$. Correlation is significant at the 0.01 level (2-tailed).

*. Correlation is significant at the 0.05 level (2-tailed). 


\section{Appendix E}

Pearson Correlation Coefficients between Gender, Age, Education, Major, Performance Time, Performance Form, Performance Frequency and Flow

\begin{tabular}{|c|c|c|c|c|c|c|c|c|}
\hline \multicolumn{9}{|c|}{ Correlations } \\
\hline & & Gender & Age & Education & Major & Years & Form & $\begin{array}{l}\text { Performance } \\
\text { Frequency }\end{array}$ \\
\hline \multirow[t]{4}{*}{$\overline{\mathrm{FQ1}}$} & Pearson & & & & & & & \\
\hline & Correlation & .065 & .037 & .025 & -.011 & .143 & .000 & .222 \\
\hline & Sig. (2-tailed) & .580 & .753 & .834 & .927 & .222 & 1.000 & .055 \\
\hline & $\mathrm{N}$ & 75 & 75 & 75 & 75 & 75 & 75 & 75 \\
\hline \multirow[t]{4}{*}{$\overline{\mathrm{FQ} 2}$} & Pearson & & & & & & & \\
\hline & Correlation & .097 & -.020 & .031 & -.013 & .154 & .038 & .148 \\
\hline & Sig. (2-tailed) & .406 & .865 & .793 & .914 & .187 & .743 & .204 \\
\hline & $\mathrm{N}$ & 75 & 75 & 75 & 75 & 75 & 75 & 75 \\
\hline \multirow[t]{3}{*}{$\overline{\mathrm{FQ3}}$} & $\begin{array}{l}\text { Pearson } \\
\text { Correlation }\end{array}$ & .029 & .075 & .037 & -.093 & .126 & -.028 & .168 \\
\hline & Sig. (2-tailed) & .807 & .524 & .750 & .426 & .283 & .812 & .148 \\
\hline & $\mathrm{N}$ & 75 & 75 & 75 & 75 & 75 & 75 & 75 \\
\hline \multirow[t]{3}{*}{$\overline{\mathrm{FQ4}}$} & $\begin{array}{l}\text { Pearson } \\
\text { Correlation }\end{array}$ & .096 & .114 & .029 & -.058 & .226 & -.069 & .022 \\
\hline & Sig. (2-tailed) & .412 & .332 & .803 & .620 & .052 & .555 & .851 \\
\hline & $\mathrm{N}$ & 75 & 75 & 75 & 75 & 75 & 75 & 75 \\
\hline \multirow[t]{3}{*}{$\overline{\mathrm{FQ5}}$} & $\begin{array}{l}\text { Pearson } \\
\text { Correlation }\end{array}$ & -.014 & .147 & .012 & -.080 & $.231 *$ & -.138 & .038 \\
\hline & Sig. (2-tailed) & .907 & .209 & .917 & .495 & .047 & .238 & .747 \\
\hline & $\mathrm{N}$ & 75 & 75 & 75 & 75 & 75 & 75 & 75 \\
\hline \multirow[t]{3}{*}{$\overline{\mathrm{FQ6}}$} & $\begin{array}{l}\text { Pearson } \\
\text { Correlation }\end{array}$ & .052 & .099 & -.011 & -.010 & .159 & .006 & .064 \\
\hline & Sig. (2-tailed) & .661 & .396 & .927 & .935 & .173 & .961 & .927 \\
\hline & $\mathrm{N}$ & 75 & 75 & 75 & 75 & 75 & 75 & 75 \\
\hline
\end{tabular}




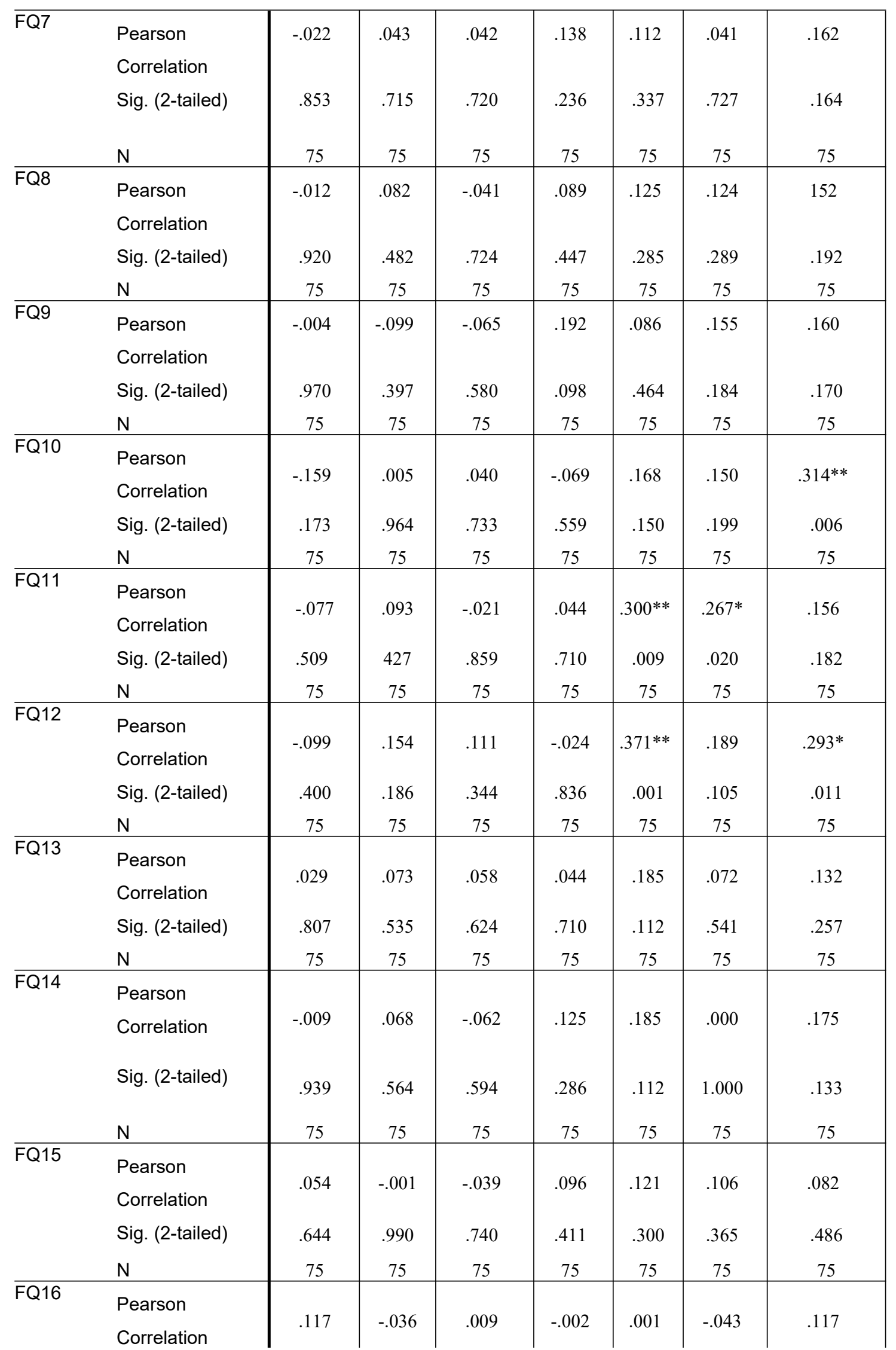




\begin{tabular}{|c|c|c|c|c|c|c|c|c|}
\hline & $\begin{array}{l}\text { Sig. (2-tailed) } \\
\mathrm{N}\end{array}$ & $\begin{array}{c}.316 \\
75\end{array}$ & $\begin{array}{c}.756 \\
75\end{array}$ & $\begin{array}{c}.941 \\
75\end{array}$ & $\begin{array}{c}.986 \\
75\end{array}$ & $\begin{array}{c}.994 \\
75\end{array}$ & $\begin{array}{c}.713 \\
75\end{array}$ & $\begin{array}{c}.318 \\
75\end{array}$ \\
\hline \multirow[t]{3}{*}{$\overline{\text { FQ17 }}$} & $\begin{array}{l}\text { Pearson } \\
\text { Correlation }\end{array}$ & .115 & -.010 & .027 & -.149 & .086 & -.077 & $.236^{*}$ \\
\hline & Sig. (2-tailed) & .325 & .933 & .815 & .203 & .463 & .512 & .042 \\
\hline & $\mathrm{N}$ & 75 & 75 & 75 & 75 & 75 & 75 & 75 \\
\hline \multirow[t]{3}{*}{$\overline{\text { FQ18 }}$} & $\begin{array}{l}\text { Pearson } \\
\text { Correlation }\end{array}$ & .143 & -.010 & -.142 & .032 & .034 & -.063 & .069 \\
\hline & Sig. (2-tailed) & .221 & .932 & .225 & .782 & .771 & .591 & .557 \\
\hline & $\mathrm{N}$ & 75 & 75 & 75 & 75 & 75 & 75 & 75 \\
\hline \multirow[t]{3}{*}{$\overline{\text { FQ19 }}$} & $\begin{array}{l}\text { Pearson } \\
\text { Correlation }\end{array}$ & -.156 & .089 & .079 & -.091 & .181 & .059 & $.315^{* *}$ \\
\hline & Sig. (2-tailed) & .182 & .447 & .499 & .437 & .121 & .613 & .006 \\
\hline & $\mathrm{N}$ & 75 & 75 & 75 & 75 & 75 & 75 & 75 \\
\hline \multirow[t]{3}{*}{$\overline{\text { FQ20 }}$} & $\begin{array}{l}\text { Pearson } \\
\text { Correlation }\end{array}$ & -.079 & .089 & .129 & -.033 & .192 & .068 & $.310^{* *}$ \\
\hline & Sig. (2-tailed) & .503 & .448 & .269 & .776 & .098 & .561 & .007 \\
\hline & $\mathrm{N}$ & 75 & 75 & 75 & 75 & 75 & 75 & 75 \\
\hline \multirow[t]{3}{*}{ FQ21 } & $\begin{array}{l}\text { Pearson } \\
\text { Correlation }\end{array}$ & .093 & .019 & .101 & .080 & .102 & -.040 & -.040 \\
\hline & Sig. (2-tailed) & .425 & .870 & .388 & .496 & .384 & .735 & .196 \\
\hline & $\mathrm{N}$ & 75 & 75 & 75 & 75 & 75 & 75 & 75 \\
\hline \multirow[t]{3}{*}{$\overline{\text { FQ22 }}$} & $\begin{array}{l}\text { Pearson } \\
\text { Correlation }\end{array}$ & .062 & -.015 & .104 & .002 & .137 & .055 & $.235^{*}$ \\
\hline & Sig. (2-tailed) & .595 & .899 & .375 & .988 & .240 & .641 & .043 \\
\hline & $\mathrm{N}$ & 75 & 75 & 75 & 75 & 75 & 75 & 75 \\
\hline \multirow[t]{3}{*}{$\overline{\mathrm{FQ} 23}$} & $\begin{array}{l}\text { Pearson } \\
\text { Correlation }\end{array}$ & .073 & .009 & .069 & -.081 & .186 & -.091 & 177 \\
\hline & Sig. (2-tailed) & .532 & .938 & .556 & .487 & .110 & .436 & .129 \\
\hline & $\mathrm{N}$ & 75 & 75 & 75 & 75 & 75 & 75 & 75 \\
\hline \multirow[t]{3}{*}{$\overline{\mathrm{FQ} 24}$} & $\begin{array}{l}\text { Pearson } \\
\text { Correlation }\end{array}$ & -.028 & .096 & .041 & .033 & .193 & .000 & $.286^{*}$ \\
\hline & Sig. (2-tailed) & .810 & .415 & .727 & .777 & .098 & 1.000 & .013 \\
\hline & $\mathrm{N}$ & 75 & 75 & 75 & 75 & 75 & 75 & 75 \\
\hline \multirow[t]{3}{*}{$\overline{\mathrm{FQ} 25}$} & $\begin{array}{l}\text { Pearson } \\
\text { Correlation }\end{array}$ & .097 & .142 & -.051 & .087 & $.240^{*}$ & .000 & 187 \\
\hline & Sig. (2-tailed) & .407 & .225 & .667 & .460 & .038 & 1.000 & .108 \\
\hline & $\mathrm{N}$ & 75 & 75 & 75 & 75 & 75 & 75 & 75 \\
\hline
\end{tabular}




\begin{tabular}{ll|l|l|l|l|l|l|l|} 
FQ26 & .085 & .211 & .025 & .112 & $.265^{*}$ & .040 & $.247^{*}$ \\
$\begin{array}{l}\text { Pearson } \\
\text { Correlation }\end{array}$ & & & & & & & \\
Sig. (2-tailed) & .470 & .069 & .834 & .339 & .022 & .732 & .033 \\
$\mathrm{~N}$ & & & & & & & \\
\hline
\end{tabular}

**. Correlation is significant at the 0.01 level (2-tailed).

*. Correlation is significant at the 0.05 level (2-tailed). 


\section{Appendix F}

Pearson Correlation Coefficients between Gender, Age, Education, Major, Performance Time, Performance Form, Performance Frequency and MPA

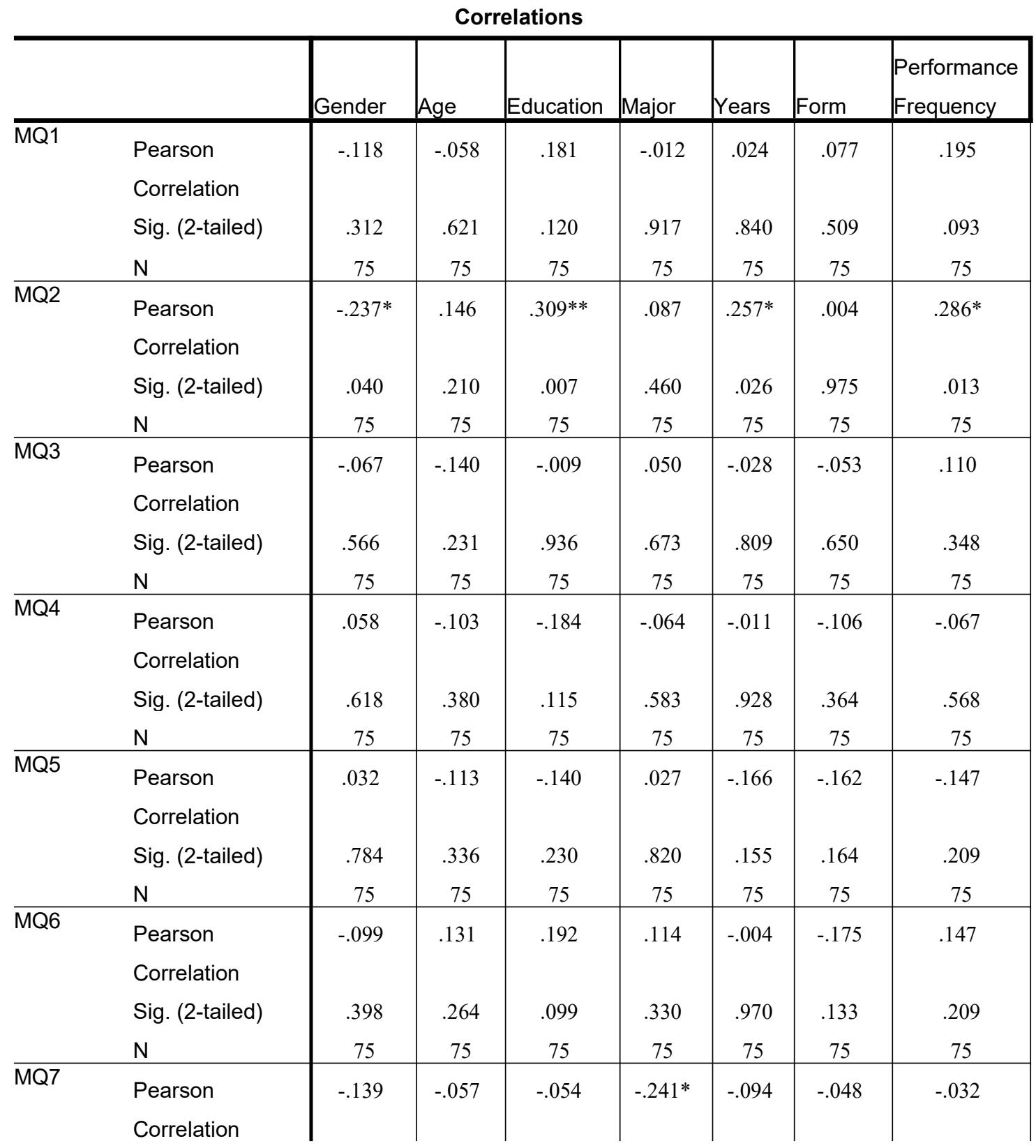




\begin{tabular}{|c|c|c|c|c|c|c|c|c|}
\hline & $\begin{array}{l}\text { Sig. (2-tailed) } \\
\mathrm{N}\end{array}$ & $\begin{array}{l}.236 \\
75 \\
\end{array}$ & $\begin{array}{l}.629 \\
75 \\
\end{array}$ & $\begin{array}{l}.643 \\
75 \\
\end{array}$ & $\begin{array}{l}.037 \\
75 \\
\end{array}$ & $\begin{array}{l}.422 \\
75 \\
\end{array}$ & $\begin{array}{l}.684 \\
75 \\
\end{array}$ & $\begin{array}{l}.784 \\
75 \\
\end{array}$ \\
\hline \multirow[t]{3}{*}{$\overline{\mathrm{MQ8}}$} & $\begin{array}{l}\text { Pearson } \\
\text { Correlation }\end{array}$ & -.059 & -.109 & .020 & .116 & -.116 & -.075 & -.014 \\
\hline & Sig. (2-tailed) & .617 & .354 & .865 & .320 & .320 & .524 & .906 \\
\hline & $\mathrm{N}$ & 75 & 75 & 75 & 75 & 75 & 75 & 75 \\
\hline \multirow[t]{3}{*}{$\overline{\mathrm{MQ9}}$} & $\begin{array}{l}\text { Pearson } \\
\text { Correlation }\end{array}$ & $-.269^{*}$ & .142 & .219 & -.200 & .032 & -.025 & $.257^{*}$ \\
\hline & Sig. (2-tailed) & .019 & .226 & .059 & .085 & .788 & .832 & .026 \\
\hline & $\mathrm{N}$ & 75 & 75 & 75 & 75 & 75 & 75 & 75 \\
\hline \multirow[t]{3}{*}{$\overline{\mathrm{MQ10}}$} & $\begin{array}{l}\text { Pearson } \\
\text { Correlation }\end{array}$ & .205 & -.219 & $-.256^{*}$ & .214 & -.227 & -.158 & -.172 \\
\hline & Sig. (2-tailed) & .077 & .059 & .026 & .066 & .050 & .176 & .139 \\
\hline & $\mathrm{N}$ & 75 & 75 & 75 & 75 & 75 & 75 & 75 \\
\hline \multirow[t]{3}{*}{$\overline{\mathrm{MQ11}}$} & $\begin{array}{l}\text { Pearson } \\
\text { Correlation }\end{array}$ & -.052 & -.044 & .038 & -.120 & $-.278^{*}$ & $-.237^{*}$ & -.106 \\
\hline & Sig. (2-tailed) & .657 & .708 & .748 & .304 & .016 & .041 & .367 \\
\hline & $\mathrm{N}$ & 75 & 75 & 75 & 75 & 75 & 75 & 75 \\
\hline \multirow[t]{3}{*}{$\overline{\mathrm{MQ12}}$} & $\begin{array}{l}\text { Pearson } \\
\text { Correlation }\end{array}$ & -.078 & .146 & -.019 & .100 & .044 & $-.298 * *$ & .014 \\
\hline & Sig. (2-tailed) & .507 & .213 & .872 & .396 & .711 & .009 & .903 \\
\hline & $\mathrm{N}$ & 75 & 75 & 75 & 75 & 75 & 75 & 75 \\
\hline \multirow[t]{3}{*}{$\overline{\mathrm{MQ13}}$} & $\begin{array}{l}\text { Pearson } \\
\text { Correlation }\end{array}$ & $-.236^{*}$ & .168 & .178 & -.031 & .099 & -.218 & .194 \\
\hline & Sig. (2-tailed) & .042 & .149 & .126 & .794 & .397 & .060 & .096 \\
\hline & $\mathrm{N}$ & 75 & 75 & 75 & 75 & 75 & 75 & 75 \\
\hline \multirow[t]{3}{*}{$\overline{\mathrm{MQ14}}$} & $\begin{array}{l}\text { Pearson } \\
\text { Correlation }\end{array}$ & .024 & .062 & .060 & -.025 & -.037 & -.121 & -.026 \\
\hline & Sig. (2-tailed) & .836 & .595 & .610 & .831 & .754 & .300 & .822 \\
\hline & $\mathrm{N}$ & 75 & 75 & 75 & 75 & 75 & 75 & 75 \\
\hline \multirow[t]{3}{*}{$\overline{\text { MQ15 }}$} & $\begin{array}{l}\text { Pearson } \\
\text { Correlation }\end{array}$ & -.195 & .075 & -.047 & .005 & -.002 & -.039 & .022 \\
\hline & Sig. (2-tailed) & .093 & .520 & .691 & .969 & .986 & .741 & .850 \\
\hline & $\mathrm{N}$ & 75 & 75 & 75 & 75 & 75 & 75 & 75 \\
\hline \multirow[t]{3}{*}{$\begin{array}{l}\text { MQ16 } \\
\text {. }\end{array}$} & $\begin{array}{l}\text { Pearson } \\
\text { Correlation }\end{array}$ & .099 & -.099 & -.188 & .059 & -.014 & -.079 & -.110 \\
\hline & Sig. (2-tailed) & .399 & .400 & .106 & .616 & .904 & .500 & .346 \\
\hline & $\mathrm{N}$ & 75 & 75 & 75 & 75 & 75 & 75 & 75 \\
\hline
\end{tabular}




\begin{tabular}{|c|c|c|c|c|c|c|c|c|}
\hline \multirow[t]{3}{*}{$\overline{\mathrm{MQ17}}$} & $\begin{array}{l}\text { Pearson } \\
\text { Correlation }\end{array}$ & .090 & -.128 & -.138 & .132 & -.189 & .008 & -.079 \\
\hline & Sig. (2-tailed) & .443 & .273 & .236 & .259 & .105 & .943 & .502 \\
\hline & $\mathrm{N}$ & 75 & 75 & 75 & 75 & 75 & 75 & 75 \\
\hline \multirow[t]{3}{*}{$\overline{\text { MQ18 }}$} & $\begin{array}{l}\text { Pearson } \\
\text { Correlation }\end{array}$ & .195 & -.117 & $-.246^{*}$ & $.292^{*}$ & -.198 & .151 & -.145 \\
\hline & Sig. (2-tailed) & .094 & .319 & .033 & .011 & .089 & .195 & .216 \\
\hline & $\mathrm{N}$ & 75 & 75 & 75 & 75 & 75 & 75 & 75 \\
\hline \multirow[t]{3}{*}{ MQ19 } & $\begin{array}{l}\text { Pearson } \\
\text { Correlation }\end{array}$ & $.274^{*}$ & -.216 & $-.272^{*}$ & . 107 & -.223 & -.190 & -.093 \\
\hline & Sig. (2-tailed) & .017 & .062 & .018 & .360 & .054 & .103 & .428 \\
\hline & $\mathrm{N}$ & 75 & 75 & 75 & 75 & 75 & 75 & 75 \\
\hline \multirow[t]{3}{*}{ MQ20 } & $\begin{array}{l}\text { Pearson } \\
\text { Correlation }\end{array}$ & .141 & $-.235^{*}$ & $-.230^{*}$ & .053 & $-.297 * *$ & -.083 & -.200 \\
\hline & Sig. (2-tailed) & .227 & .042 & .047 & .653 & .010 & .479 & .086 \\
\hline & $\mathrm{N}$ & 75 & 75 & 75 & 75 & 75 & 75 & 75 \\
\hline \multirow[t]{3}{*}{ MQ21 } & $\begin{array}{l}\text { Pearson } \\
\text { Correlation }\end{array}$ & .112 & .009 & .126 & .020 & -.109 & -.210 & .059 \\
\hline & Sig. (2-tailed) & .337 & .939 & .282 & .863 & .350 & .071 & .617 \\
\hline & $\mathrm{N}$ & 75 & 75 & 75 & 75 & 75 & 75 & 75 \\
\hline \multirow[t]{3}{*}{ MQ22 } & $\begin{array}{l}\text { Pearson } \\
\text { Correlation }\end{array}$ & .031 & -.143 & -.227 & .182 & -.142 & . 038. & .027 \\
\hline & Sig. (2-tailed) & .794 & .220 & .050 & .118 & .224 & .748 & .818 \\
\hline & $\mathrm{N}$ & 75 & 75 & 75 & 75 & 75 & 75 & 75 \\
\hline \multirow[t]{3}{*}{$\begin{array}{l}\overline{M Q 23} \\
\text {. }\end{array}$} & $\begin{array}{l}\text { Pearson } \\
\text { Correlation }\end{array}$ & -.058 & .053 & .179 & -.129 & .062 & .136 & .196 \\
\hline & Sig. (2-tailed) & .623 & .653 & .125 & .268 & .597 & .244 & .092 \\
\hline & $\mathrm{N}$ & 75 & 75 & 75 & 75 & 75 & 75 & 75 \\
\hline \multirow[t]{3}{*}{$\overline{\mathrm{MQ24}}$} & $\begin{array}{l}\text { Pearson } \\
\text { Correlation }\end{array}$ & . 161 & -.117 & -.026 & .092 & -.150 & . 028 & -.147 \\
\hline & Sig. (2-tailed) & .167 & .317 & .828 & .430 & .198 & .812 & .208 \\
\hline & $\mathrm{N}$ & 75 & 75 & 75 & 75 & 75 & 75 & 75 \\
\hline \multirow[t]{3}{*}{$\overline{\mathrm{MQ} 25}$} & $\begin{array}{l}\text { Pearson } \\
\text { Correlation }\end{array}$ & -.199 & -.075 & -.162 & .182 & -.018 & -.098 & .172 \\
\hline & Sig. (2-tailed) & .088 & .525 & .166 & .117 & .877 & .402 & .140 \\
\hline & $\mathrm{N}$ & 75 & 75 & 75 & 75 & 75 & 75 & 75 \\
\hline$\overline{M Q 26}$ & $\begin{array}{l}\text { Pearson } \\
\text { Correlation }\end{array}$ & -.021 & .117 & -.053 & .072 & -.024 & -.193 & -.011 \\
\hline
\end{tabular}




\begin{tabular}{|c|c|c|c|c|c|c|c|c|}
\hline & $\begin{array}{l}\text { Sig. (2-tailed) } \\
\mathrm{N}\end{array}$ & $\begin{array}{l}.855 \\
75\end{array}$ & $\begin{array}{c}.317 \\
75\end{array}$ & $\begin{array}{c}.653 \\
75\end{array}$ & $\begin{array}{c}.537 \\
75\end{array}$ & $\begin{array}{l}.837 \\
75\end{array}$ & $\begin{array}{c}.096 \\
75\end{array}$ & $\begin{array}{c}.924 \\
75\end{array}$ \\
\hline \multirow[t]{3}{*}{$\overline{\mathrm{MQ27}}$} & Pearson & -.169 & .016 & $.299 * *$ & $-.345^{* *}$ & .053 & -.103 & $.244 *$ \\
\hline & Sig. (2-tailed) & .147 & .891 & .009 & .002 & .653 & .377 & .035 \\
\hline & $\mathrm{N}$ & 75 & 75 & 75 & 75 & 75 & 75 & 75 \\
\hline \multirow[t]{3}{*}{ MQ28 } & $\begin{array}{l}\text { Pearson } \\
\text { Correlation }\end{array}$ & .056 & -.032 & -.106 & .022 & -.037 & -.004 & .008 \\
\hline & Sig. (2-tailed) & .635 & .786 & .364 & .849 & .755 & .975 & .945 \\
\hline & $\mathrm{N}$ & 75 & 75 & 75 & 75 & 75 & 75 & 75 \\
\hline \multirow[t]{3}{*}{ MQ29 } & $\begin{array}{l}\text { Pearson } \\
\text { Correlation }\end{array}$ & -.097 & -.146 & -.121 & -.215 & -.129 & .003 & -.004 \\
\hline & Sig. (2-tailed) & .410 & .213 & .300 & .064 & .272 & .977 & .973 \\
\hline & $\mathrm{N}$ & 75 & 75 & 75 & 75 & 75 & 75 & 75 \\
\hline \multirow{3}{*}{ MQ30 } & $\begin{array}{l}\text { Pearson } \\
\text { Correlation }\end{array}$ & -.001 & -.025 & .006 & -.130 & .056 & -.165 & .160 \\
\hline & Sig. (2-tailed) & .996 & .829 & .958 & .267 & .632 & .157 & .170 \\
\hline & $\mathrm{N}$ & 75 & 75 & 75 & 75 & 75 & 75 & 75 \\
\hline \multirow{3}{*}{ MQ31 } & $\begin{array}{l}\text { Pearson } \\
\text { Correlation }\end{array}$ & .000 & .086 & $.287^{*}$ & -.184 & .091 & -.061 & .177 \\
\hline & Sig. (2-tailed) & .998 & .464 & .013 & .114 & .440 & .605 & .128 \\
\hline & $\mathrm{N}$ & 75 & 75 & 75 & 75 & 75 & 75 & 75 \\
\hline \multirow[t]{3}{*}{ MQ32 } & $\begin{array}{l}\text { Pearson } \\
\text { Correlation }\end{array}$ & .015 & .127 & -.174 & .176 & -.015 & -.158 & -.091 \\
\hline & Sig. (2-tailed) & .897 & .277 & .137 & .131 & .896 & .176 & .437 \\
\hline & $\mathrm{N}$ & 75 & 75 & 75 & 75 & 75 & 75 & 75 \\
\hline \multirow[t]{3}{*}{ MQ33 } & $\begin{array}{l}\text { Pearson } \\
\text { Correlation }\end{array}$ & -.012 & .034 & .130 & -.147 & .022 & -.053 & .097 \\
\hline & Sig. (2-tailed) & .917 & .769 & .265 & .207 & .854 & .649 & .406 \\
\hline & $\mathrm{N}$ & 75 & 75 & 75 & 75 & 75 & 75 & 75 \\
\hline \multirow[t]{3}{*}{ MQ34 } & $\begin{array}{l}\text { Pearson } \\
\text { Correlation }\end{array}$ & .043 & .037 & -.104 & .071 & -.040 & -.076 & -.164 \\
\hline & Sig. (2-tailed) & .716 & .752 & .374 & .546 & .735 & .515 & .159 \\
\hline & $\mathrm{N}$ & 75 & 75 & 75 & 75 & 75 & 75 & 75 \\
\hline \multirow{3}{*}{ MQ35 } & $\begin{array}{l}\text { Pearson } \\
\text { Correlation }\end{array}$ & .186 & -.081 & -.101 & .032 & -.198 & -.060 & -.191 \\
\hline & Sig. (2-tailed) & .110 & .491 & .386 & .784 & .088 & .609 & .101 \\
\hline & $\mathrm{N}$ & 75 & 75 & 75 & 75 & 75 & 75 & 75 \\
\hline
\end{tabular}




\begin{tabular}{|c|c|c|c|c|c|c|c|c|}
\hline \multirow{2}{*}{ MQ36 } & \multirow{2}{*}{$\begin{array}{l}\text { Pearson } \\
\text { Correlation }\end{array}$} & .148 & $-.283^{*}$ & $-.291 *$ & .073 & \multirow{2}{*}{$-.242 *$} & \multirow{2}{*}{-.061} & \multirow{2}{*}{-.165} \\
\hline & & & & & & & & \\
\hline \multirow{4}{*}{ MQ37 } & Sig. (2-tailed) & .205 & .014 & .011 & .533 & .036 & .606 & .157 \\
\hline & $\mathrm{N}$ & 75 & 75 & 75 & 75 & 75 & 75 & 75 \\
\hline & Pearson & .103 & -.064 & -.134 & .203 & $-.233^{*}$ & -.111 & $-.241 *$ \\
\hline & Correlation & & & & & & & \\
\hline \multirow{4}{*}{ MQ38 } & Sig. (2-tailed) & .382 & .587 & .252 & .081 & .044 & .342 & .037 \\
\hline & $\mathrm{N}$ & 75 & 75 & 75 & 75 & 75 & 75 & 75 \\
\hline & Pearson & -.005 & -.022 & -.088 & .174 & -.098 & .088 & .050 \\
\hline & Correlation & & & & & & & \\
\hline \multirow{4}{*}{ MQ39 } & Sig. (2-tailed) & .969 & .853 & .454 & .135 & .404 & .454 & .669 \\
\hline & $\mathrm{N}$ & 75 & 75 & 75 & 75 & 75 & 75 & 75 \\
\hline & Pearson & .101 & .032 & -.063 & .089 & .074 & .055 & .179 \\
\hline & Correlation & & & & & & & \\
\hline \multirow{6}{*}{ MQ40 } & Sig. (2-tailed) & .388 & .782 & .591 & .446 & .528 & .640 & .125 \\
\hline & $\mathrm{N}$ & 75 & 75 & 75 & 75 & 75 & 75 & 75 \\
\hline & Pearson & .068 & .061 & -.084 & .089 & .173 & -.194 & .142 \\
\hline & Correlation & & & & & & & \\
\hline & Sig. (2-tailed) & .564 & .605 & .472 & .450 & .139 & .096 & .224 \\
\hline & $\mathrm{N}$ & 75 & 75 & 75 & 75 & 75 & 75 & 75 \\
\hline
\end{tabular}

**. Correlation is significant at the 0.01 level (2-tailed).

*. Correlation is significant at the 0.05 level (2-tailed). 


\section{Appendix G}

\section{Interview Protocol: The Relationship between Flow and Music Performance}

\section{Anxiety}

\section{Learning background}

Just to start off, could you talk about your music performance experience as a music student, from when you started, basically and the history?

\section{MPA experience}

1) Have you ever experienced anxiety/stage fright during your music performance? What's your feeling about that?

2) What factors do you think lead to your performance anxiety?

3) What strategies did you use for overcoming music performance anxiety?

4) Is it positive or negative for your performance? Why?

3. Flow experience

1) Have you ever experienced flow during your music performance? How is it?

2) What factors do you think lead to flow experience?

3) Is it positive or negative for your performance? Why?

4. Relationship

1) Do you think flow and anxiety are related? What is the relationship?

2) What component(s) of flow listed here is/are related with anxiety?
a. Clarity of goals and immediate feedback
b. A high level of concentration on a limited field
c. Balance between skills and challenge
d. The feeling of control 

e. Effortlessness
f. An altered perception of time
g. The melting together of action and consciousness
h. The autotelic quality of flow-experience

3) The picture below describes the effects of the skill/challenge balance discussed in Csikszentmihalyi's flow theory. Does your experience support this diagram?

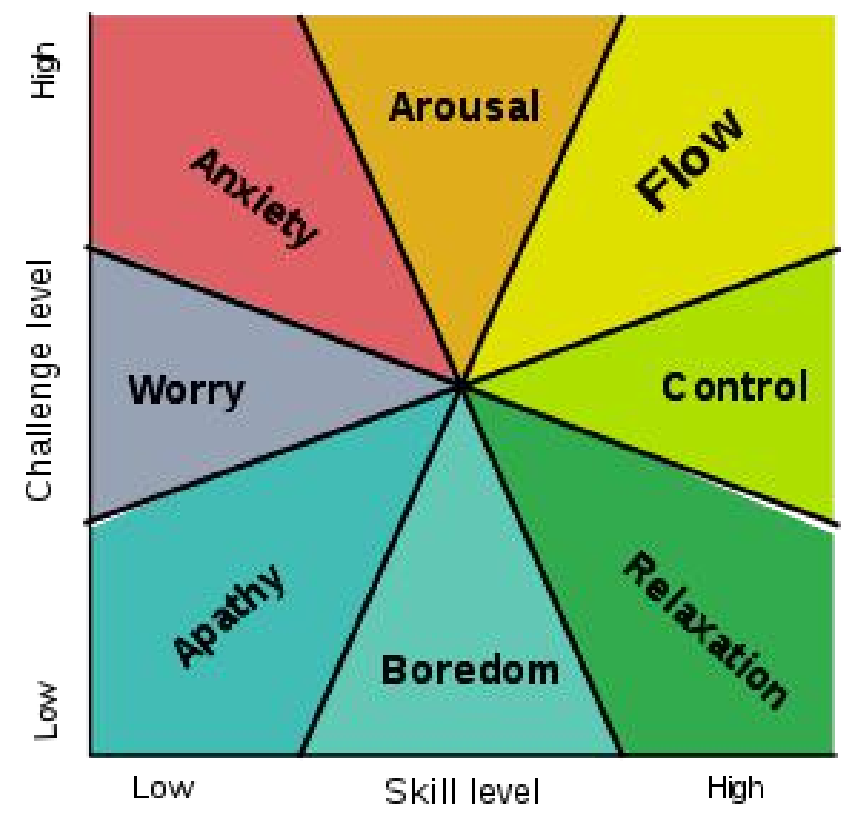

Mental state in terms of challenge level and skill level, according to Csikszentmihalyi's flow model.

\section{Strategies}

Do you think we can use flow theory or flow experience to reduce or overcome music performance anxiety? How? 


\section{Feedback}

Do you think these questions are related to my research topic? Do you have any suggestions for this study? 


\section{Appendix H}

\section{Interview Transcripts}

\section{Interview 1}

Time of interview: 4:00pm

Date: $11 / 6 / 2018$

Place: Townsend Hall 206

Interviewer: Li

Interviewee: Rebecca

$\mathrm{L}$ : Before we begin the interview, let me explain to you that the topic of my research is the relationship between flow experience and music performance anxiety. During the interview I will use a digital recorder to record your answers. From that I will make a transcription. When I finish that, I will give you a copy. Also, you should know that you will not suffer any ill effects from this research. Your participation is voluntary, and you can say no to any question that you do not feel comfortable answering. And finally, you can stop this interview at any time. If you want to do this interview, we will continue.

R: Sure

L: Just to start off, could you talk about your piano performance experience as a music student, from when you started basically, and the history?

R: Sure, I started playing piano when I was five years old, and I basically played ever since, most lessons of my childhood time were pretty informal, just with neighbors 
or people in my family, it wasn't really until the very end of high school that I got very serious about music and I found a really good teacher that helped me to get ready for college auditions and things like that. And then I went to college and I was a piano performance major, and then went to graduate school and was piano performance and pedagogy and now I am here, getting my PhD in music education.

L: Have you ever experienced anxiety/stage fright during your piano performance?

R: Sure, yeah, definitely growing up I didn't have a lot of anxiety, but once I got into college and played more serious, confusing, and complex music definitely I had some anxiety. I don't have some specific experience where I was like super nervous, but usually I was generally nervous and kind of just worked through it in the performance. But there was one time when I was playing in a student recital and my memory just completely left me, like right before starting to play. It was just gone, so that was probably the worst anxiety moment I ever had.

L: So, your feeling of anxiety during your performance was not good?

R: Yeah, definitely, much less confident.

L: Ok, do you know what factors lead to your music performance anxiety?

R: I think it is combination of things, I usually don't feel too nervous if I have a lot of time to prepare, so if I have less time to prepare, I definitely feel more nervous. It also depends what else I am doing that day, and I find that if it's a really busy day, I am not able to think about performing and I will be less nervous if I had a kind of relaxing day.

L: What strategies did you use for overcoming or reducing your performance anxiety? 
R: In college, I tended to play really long warm - ups, so I would get there super early and play everything multiple times to make sure I still have it, and the same thing in college, but when I went to graduate school I was busier and the strategy didn't seem to work very much anymore, so I tried to become more strategic and not play through the pieces that I would be performing, but instead gave myself scales and some unrelated warm - ups, just to warm up my fingers, so I didn't have to worry about my memory before performing.

L: So, do you think the memory is the main factor influencing your anxiety?

R: Yeah, definitely. I usually perform from memory and that's usually the thing I'm worried about. When I don't perform from memory, it's either an easier piece or I am playing with an instrumentalist or vocalist that I am not too worried about to begin with, or even if it's a complicated piece it's just nice to have music in front of me.

L: Is anxiety positive or negative for your piano performance? Why?

R: Positive, I mean no matter how much I practice, my ability is related to how nervous I get. So, if I feel really prepared, my ability feels confident. Then I feel less anxious.

L: Have you ever experienced flow during your piano performance?

R: Yeah, there will be times when you feel like you get in the zone and I've had that and just seem to go along and you are not worried about anything. And then something happens and you wake up and fall out of flow and that's always interesting. But yes, I've definitely experienced flow.

L: So, when do you experience flow? 
R: Usually it's in a longer performance, I think. I think when I'm not worried about the anxiety, then flow tends to happen. If I only play like a really short piece, I don't tend to experience flow.

L: What factors do you think lead to your flow experience?

R: I think part of it is just relaxing, kind of getting you to the stage or wherever you're playing, just being able to "OK, I am already here. I am already playing. I got over that anxious moment. Now I am relaxed". It's flow.

L: Is flow positive or negative for your music performance? Why?

R: I think it's positive although I've also noticed that sometimes if I feel really confident and like it's flowing, then I can also just stop thinking about the music so I am not thinking ahead anymore, and that can throw me off sometimes. So occasionally negative but mostly positive.

L: Do you think flow and anxiety are related?

R: Yeah, I can see how they can be related, I think that if you are really, really anxious, it's harder to experience flow. If you are just kind of normal anxious, it's a pretty typical experience. Then after you get over that little anxious moment and you're actually performing, that's when I usually say that I've experienced flow.

L: What component/components of flow as follows is/are related with anxiety?

1) Clarity of goals and immediate feedback

2) A high level of concentration on a limited field

3) Balance between skills and challenge

4) The feeling of control

5) Effortlessness 
6) An altered perception of time

7) The melting together of action and consciousness

8) The autotelic quality of flow-experience

R: I think the "feeling of control" is definitely related to anxiety, and "an altered perception of time" too. It seems like if I've got over the anxiousness and I enter into the flow and time seems to pass much faster than normal and I feel like more control, yes. Those will be the two that really stand out to me.

L: The picture below describes the effects of the skill/challenge balance discussed in Csikszentmihalyi's Flow Theory, which includes flow and anxiety. What do you think about this figure?

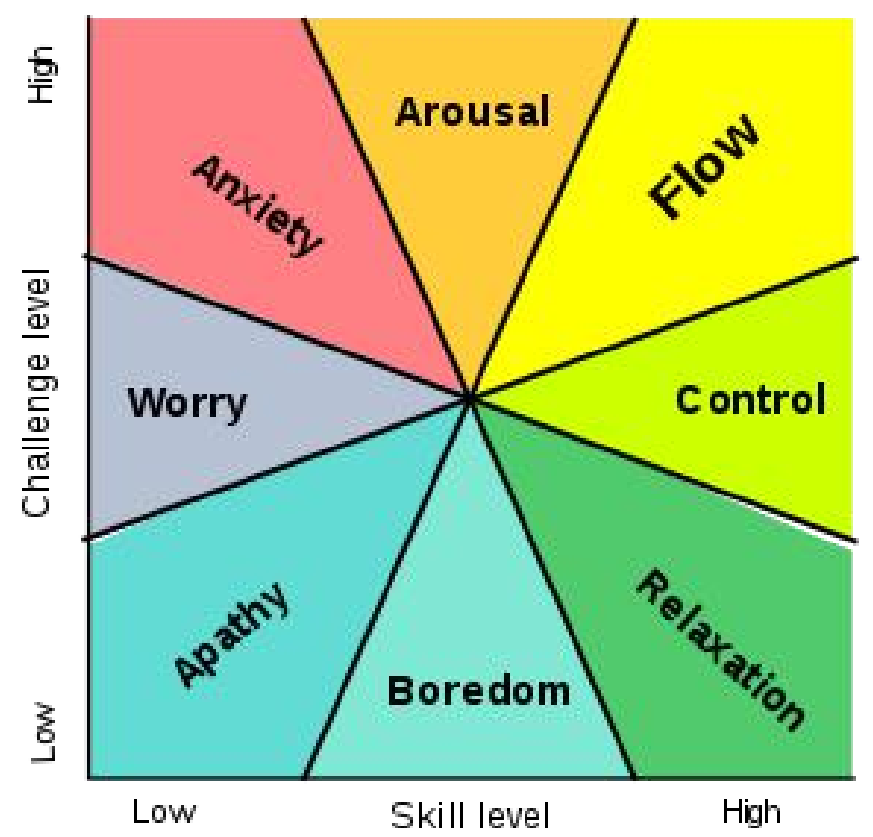

Mental state in terms of challenge level and skill level according to Csikszentmihalyi's flow model 
R: I agree with that, but I think anxiety should takes a larger portion. When you have medium or high skill level, I think it's still possible to be anxious. But other than that, I think I do agree with that.

L: So, what do you think about the relationship between anxiety and flow in this model?

R: I did agree with that although again I think they kind of also meet in middle sometimes. They are not totally opposites. I think sometime you can have high skill level and high challenge level, but still be anxious, and that's when I tend experience flow. I can be anxious and experience flow at the same time. So, I think they are in the right place, but they can overlap.

L: Which kind of relationship does anxiety and flow have?

R: I think anxiety is medium high to high, that's when I experience flow. if I am not anxious at all, I don't think I really experience flow.

L: Do you think we can use flow theory or flow experience to reduce or overcome music performance anxiety? Why?

R: Yes, I think kind of making flow as a goal can help you overcome anxiety. I am not sure how you would do that, how you would teach yourself to experience flow. When I experience it, it's kind of just automatic. It happens sometimes, it doesn't happen other times. But I think if I could teach myself to get in the flow more often, I think I would be less anxious.

L: Do you think these components of flow theory can help us to overcome anxiety? 
R: I think especially numbers 1 and 2 . If the performer had "Clarity of goals and immediate feedback" and "a high level of concentration on a limited field", I feel like it would be easier to get in the flow and reduce anxiety.

L: Last question, do you think these questions are related to my research topic? My research topic is the relationship between flow and music performance anxiety?

R: Yes, I think so, they are all related to your research topic.

L: OK. Thank you so much!

\section{Interview 2}

Time of interview: 7:00pm

Date: $11 / 6 / 2018$

Place: Townsend Hall 206

Interviewer: $\mathrm{Li}$

Interviewee: David

L: Before we begin the interview, let me explain to you that the topic of my research is the relationship between flow experience and music performance anxiety. During the interview I will use a digital recorder to record your answers. From that I will make a transcription. When I finish that, I will give you a copy. Also, you should know that you will not suffer any ill effects from this research. Your participation is voluntary, and you can say no to any question that you do not feel comfortable answering. And finally, you can stop this interview at any time.

D: OK. 
L: Just to start off, could you tell me about your piano performance experience as a music student, when you started? General background information?

D: I started to play piano when I was just a child. My grandmother was actually my first music teacher. She had a piano, and I would go to her house to practice. I practiced for much of my childhood on her piano. I also learned to play a few other instruments throughout my childhood and through high school and college. I got back to playing piano and started playing professionally during my college years. I've being playing professionally as a pianist ever since.

D: The styles I play are European classical and American popular music: jazz, blues, rhythm and blues, and rock and roll. I've played more live performances than I can possibly count I've played pretty much from the Northeastern U.S. to the Midwest and in Nevada and California.

L: Have you ever experienced anxiety or stage fright during a live performance? What are your feelings about that?

D: Yes, anxiety happens. It really depends on how well I prepared for the performance ahead of time. There is a technique called "performance cue" that a musician can practice with when learning a piece of music. For example, if you are going to perform a three - movement sonata from memory that lasts 20 or 25 minutes, you need to establish weigh points along the way. The cues act as weigh points and help keep you on track: where you are, where you've been, and where you're going. If you use the cues, you won't lose your place. They keep you on track. 
D: The better my sense of performance cues, the more confident I am, and the less anxiety I have. So, it's fair to say that good performance cues minimize performance anxiety.

D: You have to know what notes to play, of course, and when, and then you have to rehearse enough to know what cues to keep in mind. In your rehearsal, you have to think about what it is that you have to think about in your performance. Then it's just a matter of having to play from one cue to the next.

D: Anxiety, however, can still come up depending on the environment and the audience. If the audience doesn't really respect you, or the music you're playing, they will let you know. Or, if you play well, and the audience doesn't respond well, or if their response is not what you expected, your anxiety tends to rise. However, even if you give a performance that is not all that good, and the audience still responds well, performance anxiety drops.

D: One thing to keep in mind though is that if the audience response is really good, and you keep on playing longer than you should, all of a sudden you are not playing very well and you know it. Then your anxiety level will go up and your audience response will drop off. So, you gotta know when to quit. When you've done your job, get off of the stage as soon as you can. Leave the audience wanting more.

L: So, in conclusion, in the past, what are the main factors that have led to your performance anxiety?

D: How well I was prepared, how good my performance cues were, and audience reception.

L: What strategies did you use to overcome your performance anxiety? 
D: Good question! Like the memorization strategies?

L: Yes, any strategy you ever used for overcoming your own performance anxiety.

D: For memorization, I use a segmented strategy. On piano, I learn one hand at a time: right hand first for a little ways, then the left hand, and then put them together. Then I play the music over and over and go right hand only, then left hand only, and together until I can play the music absolutely perfectly without thinking about it. Then I go on to the next four measures, right hand only, left hand only, right hand only, left hand only, and then put them together. That's how I do it, with the segmented strategy, and one hand at a time.

L: OK, so you used this strategy in your practice, right? What about in your performance?

D: For a live performance, the main thing is to feel good inside and to feel confident about your ability to perform. You have to feel good about yourself. You can't go out there feeling like you will not be performing well. You have to think positively. That's my performance strategy. Another thing you need to do is collect yourself. Slow down and relax. Don't rush things. Maintain a real positive attitude, relax, and don't rush the performance. If you rush, music performance goes too fast. You have to slow down and take it easy.

L: What do you think about performance anxiety? Is it a positive or negative for your performance and why?

D: Performance anxiety while practicing can be helpful because it can act as a motivator. When you practice, worrying a little bit about how your performance will go will make you work. You will focus on your responsibilities, so a little anxiety during 
practice can be a healthy thing if you find yourself needing some motivation. But performance anxiety during performance is never a good thing.

L: Have you ever experienced flow during a performance?

D: I would say yes, very often, and that's what I work to achieve when I practice.

I want to be able to detach myself from thinking about what notes I'm playing to thinking instead about shaping an artistic expression and conveying an aesthetically pleasing interpretation of the music for the audience.

D: What I think about when I'm performing is my technique and the artistic expression I have in mind, rather than the notes, so I can get into the "flow" state. When I've done that I can think about realizing my musical expression. I can look around, I can look out at the audience, I can look off the stage, I can look at my shoes, I can look up at the lights, I can do whatever I want to, you know, because I am not thinking about playing the notes. So, yes, getting into a state of "flow" is a good thing.

L: What factors led to your flow experience?

D: The ability to eliminate anxiety and engaging in segmented learning during my deliberate practice rehearsals. Again, what matters most is the ability to focus attention and to repeatedly practice with hands separate. It's all about memory and memory recall. With good recall of the music, I don't have to think consciously about the notes. I only have to think consciously of the performance cues. Other than that, I can think about whatever I want and enjoy the flow state.

D: What inhibits flow is anxiety. If I have anxiety while I'm playing, I never achieve "flow." If I have anxiety during a performance, I lose "flow."

L: Is flow a positive or negative factor in your performance? 
D: Positive, flow is the ultimate goal in a performance. You are able to create an artistic interpretation of the music when you are in the "flow." You can shape the music and create an artistic expression if you want. You can be a creative and artistic musician. It allows you to be artistic.

L: Do you think "flow" and anxiety are related? Why?

D: I think flow and anxiety are like yin and yang. You can't have one without the other. They are connected like night and day. You need both, I guess, but not too much anxiety. Too much can be debilitating. A little anxiety can encourage you to practice when you don't want to and that's it. When you get on stage you shouldn't feel any anxiety unless you're getting off track. You should be feeling confident and happy about performing and anticipating a "flow" experience where you are free to create an artistic experience for your audience to enjoy. You shouldn't feel anxiety on stage.

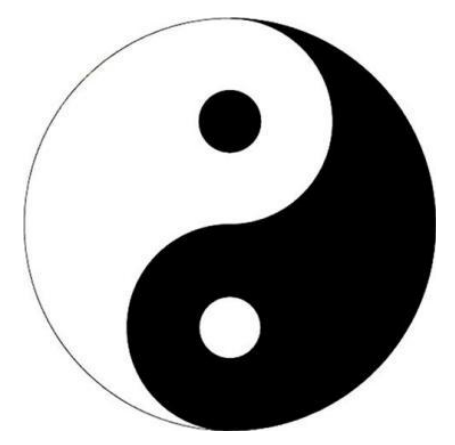

L: So what kind of relationship is there between flow and anxiety?

D: If my preparation is high, usually my performance anxiety is low. If I am not well prepared, my performance anxiety is usually high.

L: So, what's the relationship between anxiety and flow?

D: If I am in flow, there is no anxiety. If my flow experience rises, then my anxiety drops. 
L: What components of flow are related to your anxiety?

1) Clarity of goals and immediate feedback

2) A high level of concentration on a limited field

3) Balance between skills and challenge

4) The feeling of control

5) Effortlessness

6) An altered perception of time

7) The melting together of action and consciousness

8) The autotelic quality of flow-experience

D: "Clarity of goals" sounds like performance cues, and I think they are related to "flow." I am not sure about the time thing, and I don't think they have a relationship with anxiety. What component is related with anxiety? None of these.

L: The picture below describes the effects of the skill/challenge balance discussed in Csikszentmihalyi's Flow Theory, which includes flow and anxiety. What do you think about this figure? 


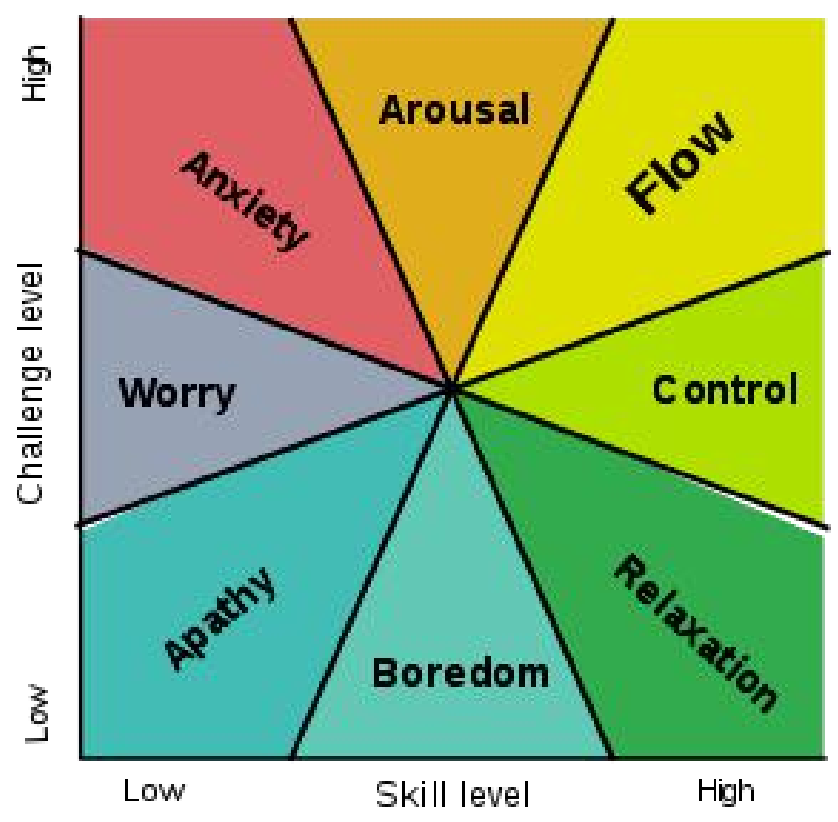

Mental state in terms of challenge level and skill level according to Csikszentmihalyi's flow model

D: If the music is very challenging, I am going to feel anxiety. The anxiety usually goes away the more I practice. The more practice, and the better I practice, the less anxiety I have. I am not going to play something in public anyway if I am not able to, so my skill level should match the music.

L: Do you think we can use the "flow" theory or "flow" experience to reduce or overcome music performance anxiety?

D: I think that when you know you are ready to perform in public, when you know you can just walk into a practice room and play your music, and detach yourself and think freely, and shape the music, I think you're in the flow and you know you are ready to perform. So, you can use "flow" in practice as a signal that you are ready to perform in public. Anxiety should naturally go away when you play in "flow." 
L: Do you think the questions I have asked you are related to my research topic?

D: Yes, I think every question is related to your topic, and I think they are very good interview questions.

L: Do you have any suggestions? Need I add something to this interview?

D: I think those are really good questions. My suggestion would be to explain the concepts of "flow" and "performance anxiety" before you do the interview for your future interviewees. Show them your definitions.

L: OK, thank you so much!

D: You're welcome.

\section{Interview 3}

Time of interview: 3:00pm

Date: $11 / 7 / 2018$

Place: Through Email

Interviewer: $\mathrm{Li}$

Interviewee: Joe

L: Before we begin the interview, let me explain to you that the topic of my research is the relationship between flow experience and music performance anxiety. When you finish interview questions, I will give you a copy. Also, you should know that you will not suffer any ill effects from this research. Your participation is voluntary, and you can say no to any question that you do not feel comfortable answering. And finally, you can stop this interview at any time. If you want to do this interview, we will continue.

J: Yes, I want to do this. 
L: Just to start off, could you talk about your music performance experience as a music student, from when you started basically, and the history?

$\mathrm{J}$ : I began performing at a very young age. I grew up in church where music was very vibrant and a major part of our lives. My father was a Minister of Music so I sang a lot in church in front of others. While in school, I often got chosen for solos and small ensembles and by the time I was in high school had performed a lot and did not have many qualms about performing. When I was in college I continued to perform in musicals, at church, and even at singing festivals. I viewed myself foremost as an educator who taught music, not as much as a performer, but I have been viewed by others as a performer as long as I can remember.

L: Have you ever experienced anxiety/stage fright during your music performance? What's your feeling about that?

J: Certainly. It was never debilitating, but even now when I perform I still have nervousness that creeps in. I don't think I view it as much as stage fright, but just nervous that I will do my best.

L: Do you know what factors lead to your performance anxiety?

$\mathrm{J}$ : The factors leading to my performance anxiety are rooted in my desire to do well. I want the audience to have an enjoyable experience listening to me, but also it would be embarrassing to mess up particularly since I have been characterized as a performer, music major, musician, and artist. Along with those labels comes a certain level of expectation from the crowd you are singing or playing for.

L: What strategies did you use for overcoming music performance anxiety? 
$\mathrm{J}$ : Being prepared and knowing what I'm doing really well. Taking slow, deep breaths. Focusing my mind on having fun or on the "bigger" picture of why I'm performing.

L: Is it positive or negative for your performance? Why?

$\mathrm{J}$ : Very positive. I love performing.

L: Have you ever experienced flow during your music performance? How is it?

J: I think I have. For me I experience flow when I'm so caught up in the moment that I lose track of time and sometimes that an audience is even there. For me, I feel very satisfied in the moment and don't want it to end.

L: What factors do you think lead to flow experience?

$\mathrm{J}$ : Excellent musicianship, receptive collaborative musicians and/or audience, great familiarity with what I'm singing/playing, when I'm so desperate to play/sing that my mind can't think about anything else.

L: Is it positive or negative for your performance? Why?

J: Extremely positive. It's like a good workout. I'm very tired afterwards, but in a good way. Those moments have garnered more praise from those listening than normal because they have seen me give myself completely over to the music and experience.

L: Do you think flow and anxiety are related? Why?

J: I think they can be. I think when I have experienced flow it has been because all anxiety has left me. Anxiety can get in the way of fully surrendering to the music and experience.

L: What component(s) of flow here is/are related with anxiety?

1) Clarity of goals and immediate feedback 
2) A high level of concentration on a limited field

3) Balance between skills and challenge

4) The feeling of control

5) Effortlessness

6) An altered perception of time

7) The melting together of action and consciousness

8) The autotelic quality of flow-experience

$\mathrm{J}$ : I think all of these are related to anxiety:

1) If you are anxious, you have a lack of clarity and you are worried about what the feedback will be.

2) You can't be fully concentrated on the music if you are anxious, you are worried about other things.

3) This one is probably not as closely related to anxiety

4) Feeling of control is not existent if you are overly anxious. You are surrendering to the fear more than the music.

5) You are putting too much effort into worrying about the anxiety and treating it than the music.

6) If you are anxious, you might be more concerned with "When is this going to end?" instead of a loss of time.

7) Again, if you are anxious, that is filling more of your headspace than focusing on the music.

Overall, the focus becomes treating the fear and anxiety and not the creative activity. 
L: The picture below describes the effects of the skill/challenge balance discussed in Csikszentmihalyi's Flow Theory, which includes flow and anxiety. What do you think about this figure?

$\mathrm{J}$ : I think this is an excellent depiction of managing the balance of skill and challenge. I can think of specific instances where I have felt all of these feelings and related it to the level of skill and challenge.

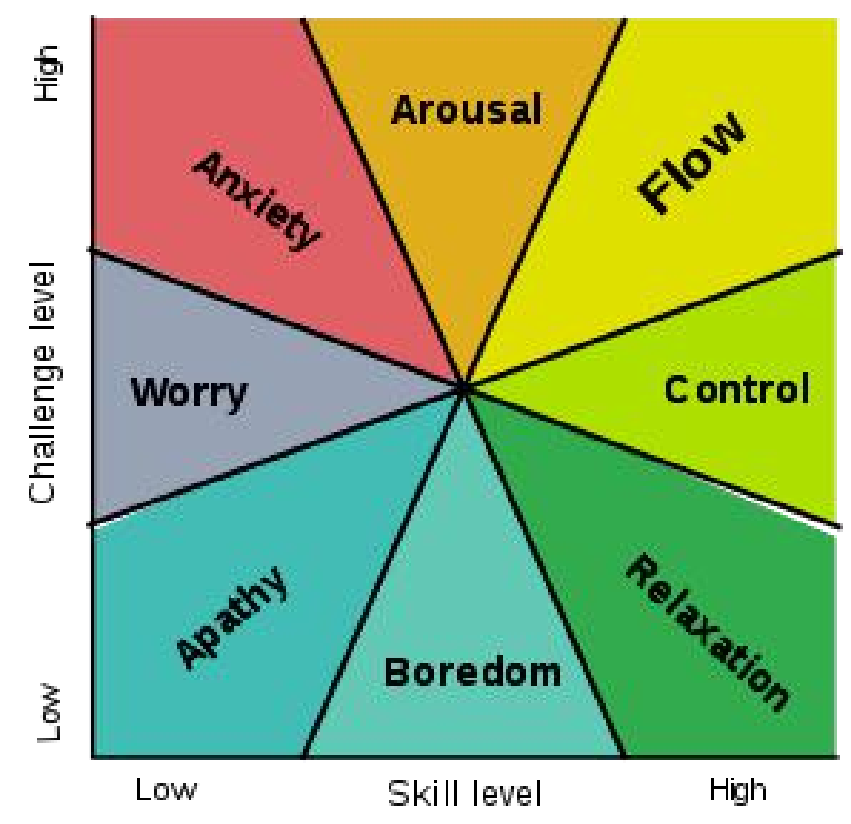

Mental state in terms of challenge level and skill level, according to Csikszentmihalyi's flow model

L: Do you think we can use flow theory or flow experience to reduce or overcome music performance anxiety? How? Why?

J: I think it's a good topic to discuss with performers so that they can see a bigger picture of understanding what can happen when anxiety gets in the way. But I think it will take specific strategies of overcoming performance anxiety to reduce the anxiety. 
Just knowing about flow won't help. Although, if we examine the steps to flow, perhaps some performers will get there more often.

L: Do you think these questions are related to my research topic? Do you have any suggestions for this study?

$\mathrm{J}$ : I think it is very interesting to examine how flow and performance anxiety are related. I think if you asked random people about this, they probably wouldn't know what flow theory was, so they wouldn't understand how to relate flow and MPA. If you're taking a more qualitative approach, I would ask the participants to describe a time when they were in flow (kind of like you did earlier in the interview) and then have them expound on that to see if you can draw any conclusions based on their responses. I think if you are surveying people in a quantitative way, you will need more explanation about flow theory. Also, question 11 is very open ended and could get you a wide variety of responses. Perhaps ask the question with more specificity like, "The picture below describes the effects of the skill/challenge balance discussed in Csikszentmihalyi's Flow Theory. Does your experience support this diagram?" What are you looking for from that question? 


\section{Interview 4}

Time of interview: $3: 00 \mathrm{pm}$

Date: $11 / 8 / 2018$

Place: Manor House 4i

Interviewer: Li

Interviewee: Andrea

L: Before we begin the interview, let me explain to you that the topic of my research is the relationship between flow experience and music performance anxiety. During the interview I will use a digital recorder to record your answers. From that I will make a transcription. When I finish that, I will give you a copy. Also, you should know that you will not suffer any ill effects from this research. Your participation is voluntary, and you can say no to any question that you do not feel comfortable answering. And finally, you can stop this interview at any time. If you want to do this interview, we will continue.

\section{A: OK.}

Li: Just to start off, could you talk about your music performance experience as a music student, from when you started basically, and the history?

A: OK, I was influenced by my mother and learned piano from ten years old. My mother was an elementary music teacher, so she taught me a lot of children's songs before I came to school. I performed music not very often until my college rehearsals. I normally did rehearsals for festivals and competitions.

Li: Have you ever experienced anxiety/stage fright during your music performance? What's your feeling about that? 
A: I had serious anxiety in most of my performances, but they didn't interrupt my performance except during one rehearsal. In the rehearsal, I was too nervous to remember my score, I couldn't find the key of my score, and I replayed and repeated until I couldn't remember anything of it, and finally, I gave up on that rehearsal. But it was a good thing for my performance later because, after that, I tried to prepare myself as much as possible to overcome my anxiety of performance, and I have never given up in any performance after that.

L: Do you know what factors lead to your performance anxiety?

A: Based on the most serious anxiety experience, I think the causes were poor preparation, poor practice, and high expectation of myself. Also, I had serious anxiety because I paid too much attention to others' opinions, like my advisor, competitors, classmates, friends, etc.

L: What strategies did you use for overcoming music performance anxiety? A: Practice, practice and practice, and enough preparation. Sometimes I used relaxation strategy, yeah.

L: What are your specific relaxation strategies?

A: Deep breath, stretching my arms and legs, shoulder exercises, and so on.

L: Is anxiety positive or negative for your performance? Why?

A: Negative, I don't like anxiety in my music performance at all, it's the biggest obstacle of my music performance.

L: Have you ever experienced flow during your music performance? How is it? 
A: Yes, sometimes I enjoyed my performance and forgot I was performing, but I think I experienced it in my rehearsal more often than in formal performance. Maybe because I was more relaxed in practice than in formal performance.

L: What factors do you think lead to flow experience?

A: Firstly, I love the piece I performed. Next, I was able to master the difficulty of the piece. Lastly, I was relaxed.

L: Is it positive or negative for your performance? Why?

A: Positive. Because it is enjoyable.

L: Do you think flow and anxiety are related? What relation?

A: Maybe they are negatively correlated. For me, anxiety is always negative for my performance, while flow is positive for my performance. I think so, because I never experienced flow and anxiety together. When I experienced flow, I had no anxiety, and when I experienced anxiety, it was impossible to experience flow.

L: What component(s) of flow here is/are related with anxiety?

1) Clarity of goals and immediate feedback

2) A high level of concentration on a limited field

3) Balance between skills and challenge

4) The feeling of control

5) Effortlessness

6) An altered perception of time

7) The melting together of action and consciousness

8) The autotelic quality of flow-experience

A: All these factors can help to reduce anxiety, I think. 
L: The picture below describes the effects of the skill/challenge balance discussed in Csikszentmihalyi's Flow Theory, which includes flow and anxiety. What do you think about this figure?

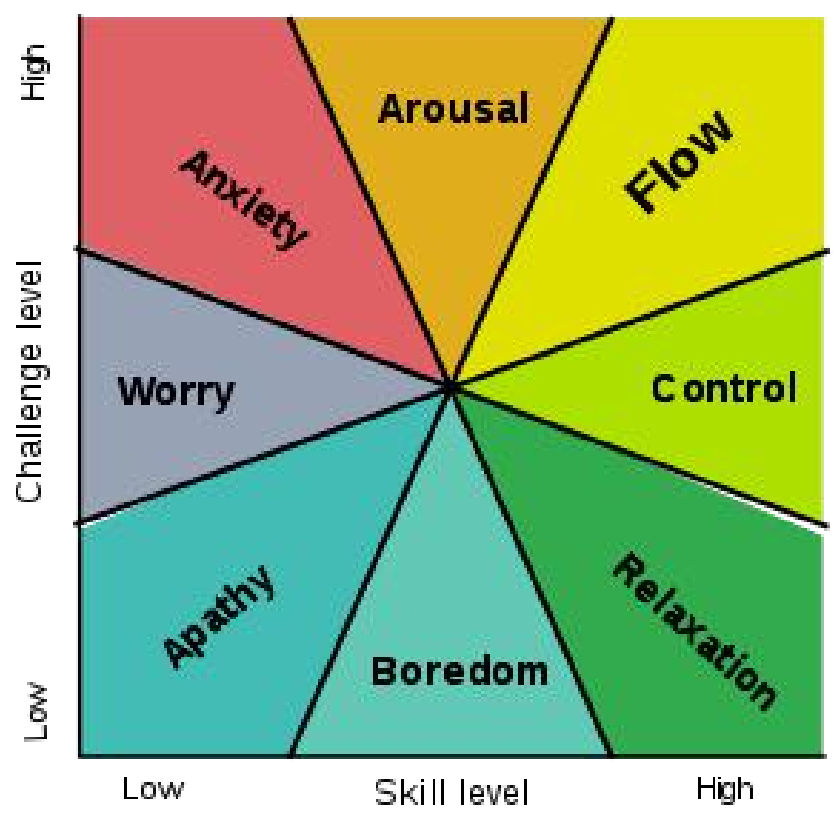

Mental state in terms of challenge level and skill level, according to Csikszentmihalyi's flow model

A: I don't agree with the "Apathy" part. At the beginning of my study, I had relatively low skills and played relatively low - challenge pieces, I experienced flow too, if I really loved that piece.

L: Do you think we can use flow theory or flow experience to reduce or overcome music performance anxiety? How?

A: Firstly, knowing what is flow and what is MPA, and what the characteristics of these two experiences are. So, music education should cover these concepts, especially in psychology class. Then, we should know the specific steps of achieving flow. 
L: Do you think these questions are related to my research topic? Do you have any suggestions for this study?

A: Yes, all the questions are related to your study, I suggest using more ways to collect data for your study, like using mixed method, combine quantitative and qualitative data to answer your questions.

\section{Interview 5}

Time of interview: 4:00pm

Date: $11 / 13 / 2018$

Place: Townsend Hall 206

Interviewer: $\mathrm{Li}$

Interviewee: Maggie

L: Before we begin the interview, let me explain to you that the topic of my research is the relationship between flow experience and music performance anxiety. During the interview I will use a digital recorder to record your answers. From that I will make a transcription. When I finish that, I will give you a copy. Also, you should know that you will not suffer any ill effects from this research. Your participation is voluntary, and you can say no to any question that you do not feel comfortable answering. And finally, you can stop this interview at any time. If you want to do this interview, we will continue.

M: Yes, I want to do that.

Li: Just to start off, could you talk about your music performance experience as a music student, from when you started basically, and the history? 
M: Absolutely, I started playing, actually, piano when I was six years old, I did that all the way through middle school and high school to when I was about 17 or 18 years old. I also started playing instrument ensemble, trumpet, and later I switched to French horn. From a very young age, I had many performance opportunities. You know, young child with piano recital, and I also sing in a church. I had solo performance opportunities and a variety of different studies for professional study. When I got into band and large ensembles, I had some large concert performances, and when I got into college, those performances staying professional, and I participated in university ensembles, large ensembles, wind ensembles, orchestras and march performances. My minor is French horn for my music education degree, so I had to present three recitals during my undergraduate degree in French horn. So, I have a background of a solo performer but also an ensemble performer as well.

L: Have you ever experienced anxiety/stage fright during your music performance? What's your feeling about that?

M: I remember I have always been in nervous. But I just remember, you know, being able to push those nerves to go away and be able to stay in that moment, especially as a solo performer, I think probably the most nervous I ever was probably from my diploma recital—an hour - and - a - half long, heavy material there. I remember probably that was the most nervous as a performer, but again, once I got in that moment and I started to play, the nervousness went away quickly.

L: Do you know what factors lead to your performance anxiety?

M: Oh, my family is very supportive of my musical study, and my family has a very strong musical background, so I always want to do well, not only for myself, but for 
my family.

L: What strategies did you use for overcoming music performance anxiety?

M: I had some exercises which sound very strange, also developed kind of meditation and mindfulness with breathing exercises that would help to kind of center me to focus on what I had to do. That helped me most and I still do it now before conducting an ensemble, just take a moment, kind of collect myself before I go to stage.

L: Is it positive or negative for your performance? Why?

M: Very positive for me to being able to find something like that. It helped me just focus and knew how I was going to do it. And I think also something else is positive for me is recognizing how my nervousness had changed based on how my route has changed. It changed to more internal reasoning, I guess, for the nervousness.

L: Have you ever experienced flow during your music performance? How is it?

M: Yes, I have, I have experienced flow.

L: What's your feeling of it?

M: Experienced...once, I think. When I was an undergraduate, and it was the best performance I ever had. I remember warming up, going to the performance, and sitting down. It was a very large conference, a thousand people watching, I remember looking at my conductor, I remember hearing and feeling the ensemble breathe, I remember the down beat, and I remember the concert especially. It was one hour long, and I played French horn during this performance.

L: What factors do you think lead to flow experience?

M: I think, for me, it is a very unique experience. I think in the ensemble, we are all very close. We all play together for a very long time, so we know each other. I knew 
French horn player behind me, I knew the principal saxophone player, I knew when she was sharp, I knew the French horn player to my right for a long time. Our conductor was consistent with everything, we knew her visual cues and her non - verbal facial expressions. So that relationship again because we worked together so long and we knew what happened for what happened, so that was a huge factor.

L: Is it positive or negative for your performance? Why?

M: Very positive.

L: Do you think flow and anxiety are related? What relation?

M: Negative,

L: What component(s) of flow here is/are related with anxiety?

1) Clarity of goals and immediate feedback

2) A high level of concentration on a limited field

3) Balance between skills and challenge

4) The feeling of control

5) Effortlessness

6) An altered perception of time

7) The melting together of action and consciousness

8) The autotelic quality of flow-experience

M: Let's see, I think, based on my flow experience, these all lead to flow and lower the anxiety level, so there is definitely a relationship there.

$\mathrm{L}$ : What do you think about this figure? 


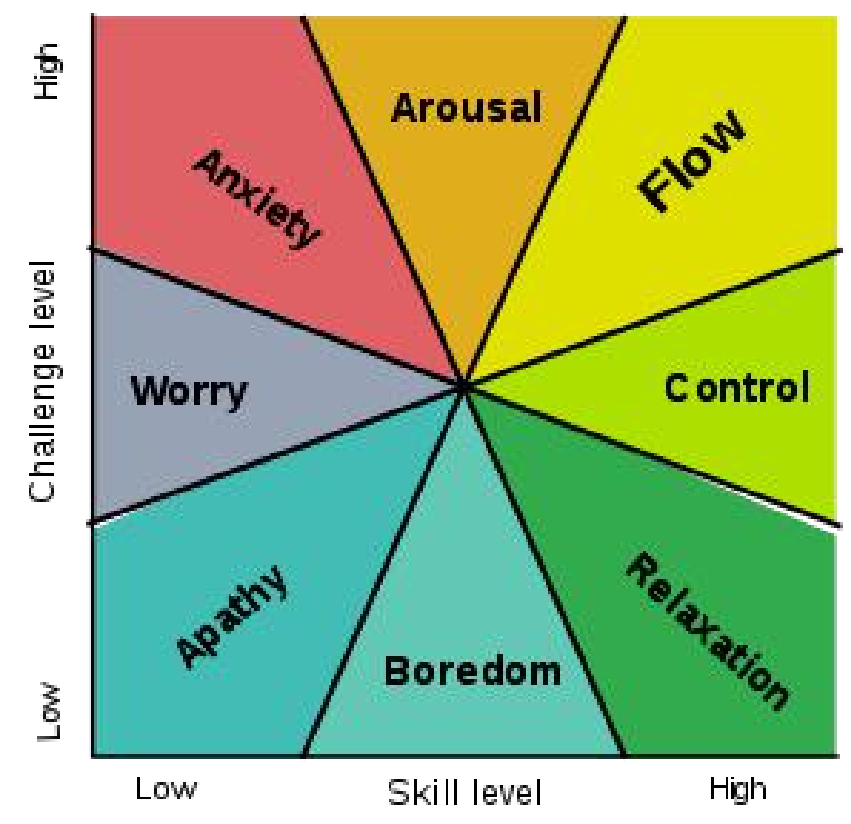

Mental state in terms of challenge level and skill level, according to Csikszentmihalyi's flow model.

M: I do agree with that.

L: Do you think we can use flow theory or flow experience to reduce or overcome music performance anxiety? How?

M: I think the first thing we should know is what causes music performance anxiety and assess it individually. And then figure out what we can do to manage those anxieties and then possibly try to set up a flow experience. So, for me, the breath, meditation, could help, just focus on the task at hand, quiet the voice like "don't forget the measure", I think you are allowing yourself those flow opportunities.

L: So, if students don't know what is flow is, how can we introduce flow to them?

M: That's a good question, because I didn't realize until our summer class. I think it is tough to describe how to introduce flow to our students but we can describe the steps 
you can take to set yourself up to this experience, make students prepare for the performance. So, I think the first step is letting your students know it's possible from there to go further. Like I said, make sure your students prepare and prepare correct ways. Maybe we identify anxiety earlier, teaching them and showing performance with that.

L: Do you think these questions are related to my research topic? Do you have any suggestions for this study?

M: Absolutely.

\section{Interview 6}

Time of interview: 6:00pm

Date: $11 / 15 / 2018$

Place: Townsend Hall 206

Interviewer: $\mathrm{Li}$

Interviewee: Jennifer

L: Before we begin the interview, let me explain to you that the topic of my research is the relationship between flow experience and music performance anxiety. During the interview I will use a digital recorder to record your answers. From that I will make a transcription. When I finish that, I will give you a copy. Also, you should know that you will not suffer any ill effects from this research. Your participation is voluntary, and you can say no to any question that you do not feel comfortable answering. And finally, you can stop this interview at any time. If you want to do this interview, we will continue. 


\section{$\mathrm{J}$ : All right.}

L: Just to start off, could you talk about your music performance experience as a music student, from when you started basically, and the history?

$\mathrm{J}$ : So, I started performing in a group at church in choir but I had solo performances in piano when I started taking lessons when I was seven. So, I would have solo piano recitals, but I really don't remember having like a lot of anxiety about performances until I was older, like in high school when the repertoire was harder to memorize and gave me a lot of anxiety performing. So, I guess I never had anxiety until I just starting memorizing in performing pieces.

L: OK, how many music performances did you have before?

J: I don't know, a lot.

L: Formal or informal?

$\mathrm{J}$ : Both, yeah, I performed in a church from high school and directed my students in their performances. I guess that also counts for my performances, and I had solo performances too. So, I had a lot.

L: Which instrument have you played?

J: I played piano and I've also had singing vocal performances, too.

L: Have you ever experienced anxiety/stage fright during your music performance? What's your feeling about that?

J: I started having anxiety when I was older and the pieces of music that I played were more difficult or in audition or performing in front of people that I didn't know.

L: Do you know what factors lead to your performance anxiety?

$\mathrm{J}$ : One of them was memorizing. Maybe I was messed up or forgot a section, and 
another one was the people I was performing in front of and what they will think about me. So really just like the failure aspect that gave me a lot of anxiety.

L: What strategies did you use for overcoming music performance anxiety?

J: My piano professor helped me to really process my feelings and we always had the opportunity to practice on the stage that we were going to be performing on. So, I have more anxiety for solo piano than for singing in a group or singing in a church. With more experience, my anxiety has been alleviated, but with piano, she really helped me memorize music in different ways. So, I would look at the section, I would read through the piece of music just visually and to be able to recognize different sections of the music. So, I would have the music in my head visually to look at. She would have me like skip ahead and play one section, then go back to the beginning, just like I'm pointing different places. I got to play on the piano that I was performing on, so just a lot of memory strategies helped me a lot to feel confident.

L: That's helpful

$\mathrm{J}$ : Yeah, she is really good.

L: Is it positive or negative for your performance? Why?

$\mathrm{J}$ : I think it was positive. Everybody has anxiety in performance in someway, and some people have strategies to overcome it and some people don't. I think that anxiety for performing can be overcome if somebody helps you and works with you and helps you to process your feelings. And then have strategies. Because if you have strategies, then you feel more confident and like you are able to fix it.

L: OK, next question, have you ever experienced flow during your music performance? You remember what flow is, right? We talked in our summer class before. 
J: I am kind of familiar with it but not really. I don't remember everything we talked about.

L: OK. Flow was named by Csikszentimihhalyi, and it is characterized by complete absorption in what one does and a resulting loss of one's sense of space and time.

$\mathrm{J}$ : Yes, in the moment.

L: So, based on the flow definition, have you ever experienced it before?

$\mathrm{J}$ : Yes, I think I have, I just never recognized that before—like really involved and focused on something. I have in practicing and performances, I just never identified it.

L: What factors do you think lead to flow experience?

J: High level of intense focus, I think, really enjoying what you are doing, feeling like a part of what you are creating and recognizing that you are creating music.

L: Is it positive or negative for your performance? Why?

J: Positive. You can have better performance if you use flow theory in your practice and performance.

L: Do you think flow and anxiety are related? What relation?

J: Yeah, but I think you can understand flow and use it and still have anxiety before performance.

L: What do you mean?

$\mathrm{J}$ : I mean that you can be experiencing flow in your practice and performance but you can still have anxiety. Even if you are practicing with flow theory in mind, you can still have anxiety before the performance.

L: What component(s) of flow here is/are related with anxiety? 
1) Clarity of goals and immediate feedback

2) A high level of concentration on a limited field

3) Balance between skills and challenge

4) The feeling of control

5) Effortlessness

6) An altered perception of time

7) The melting together of action and consciousness

8) The autotelic quality of flow experience

J: I think the "feeling of control" would be related to anxiety.

L: So, lead to anxiety or reduce anxiety?

$\mathrm{J}$ : This is to reduce anxiety. So, if you have more feeling of control, then it would reduce anxiety. Yeah, if you are doing all these things, I think all of them would reduce anxiety.

4) The picture below describes the effects of the skill/challenge balance discussed in Csikszentmihalyi's Flow Theory, which includes flow and anxiety. What do you think about this figure? 


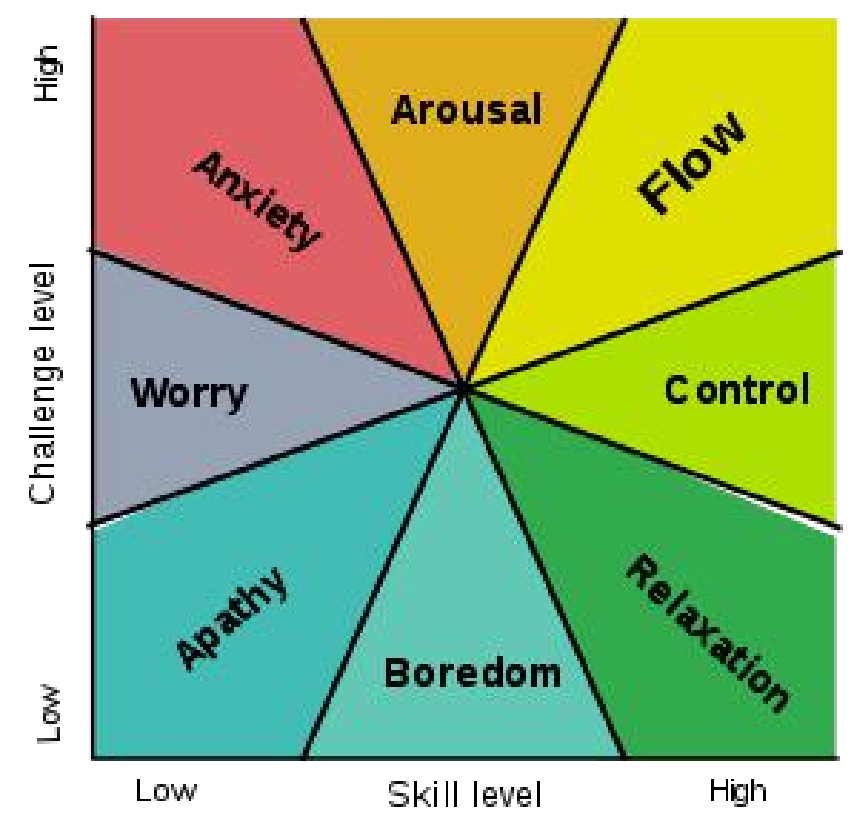

Mental state in terms of challenge level and skill level, according to Csikszentmihalyi's flow model.

J: Definitely, if you don't have the skills to do something, somebody gives you a really difficult piece of music, then you will have a lot of anxiety with it. But there is also a balance that if you are given something really, really hard and you can't do it, then there is not going to be flow.

L: So, do you agree or disagree with this model?

$\mathrm{J}:$...yes, I agree.

L: Do you think we can use flow theory or flow experience to reduce or overcome music performance anxiety?

$\mathrm{J}$ : Yeah, I think it is possible.

L: So how can we use it?

$\mathrm{J}$ : We need to figure out strategies for teaching someone to use flow theory, like my piano teachers. She gave strategies for memory and maybe some of those strategies 
would be useful to help someone understand flow theory and understand that if they are reaching those components and feeling control of what they are doing and they are enjoying it, then they are in the flow state.

L: So, you mean to teach students flow theory?

J: Yes, that will be helpful.

L: Do you think these questions are related to my research topic?

J: Yes, I do.

L: Do you have any suggestion for this study?

$\mathrm{J}$ : Maybe insuring your population is a variety of different musicians and performers. Like I performed a lot, but my performances are a little bit different. So, I guess a good background of different people maybe provide some ways they memorize music. Yeah. I think it's really good to introduce people to flow theory. That's really helpful.

\section{Interview 7}

Time of interview: 3:00pm

Date: $11 / 16 / 2018$

Place: Manor House 4i

Interviewer: $\mathrm{Li}$

Interviewee: Victoria

L: Before we begin the interview, let me explain to you that the topic of my research is the relationship between flow experience and music performance anxiety. During the interview I will use a digital recorder to record your answers. From that I will 
make a transcription. When I finish that, I will give you a copy. Also, you should know that you will not suffer any ill effects from this research. Your participation is voluntary, and you can say no to any question that you do not feel comfortable answering. And finally, you can stop this interview at any time. If you want to do this interview, we will continue.

$\mathrm{V}$ : Yes, I agree to do that.

L: Just to start off, could you talk about your music performance experience as a music student, from when you started basically, and the history?

V: I started learning pipa at five years old until going to university, but my major was not performance, it was music education. In the university, we had ensemble every Monday and we had a lot of opportunities of performance, like different festivals.

L: Did you have some competitions?

V: Yes, I had some and sometimes I have some solo performances.

L: Have you ever experienced anxiety/stage fright during your music performance? What's your feeling about that?

V: Yes, I had anxiety, but mostly in my solo performance instead of ensemble. When I learned a new piece and performed it for the first time, I felt anxiety. But later, when I performed it for the second time or third time, I didn't feel nervous.

L: What were your reactions to your anxiety?

$\mathrm{V}$ : Going to restroom frequently and sweating.

L: Do you know what factors lead to your performance anxiety?

$\mathrm{V}$ : I think the external pressure was more than my internal pressure which led to my performance anxiety. For example, there were so many competitors for me, or 
interviewers looked very serious. But I have less anxiety from myself, like practicing and skills.

L: What strategies did you use for overcoming music performance anxiety?

V: Talking with others before my performance and letting time fly faster, or if leave me alone before my performance, I would like to recall my piece before my performance.

L: How about your anxiety during your performance?

V: At the beginning, I normally felt nervous, but during the middle or close to the end, my anxiety would be reduced. I had a sense of excitement when my performance was close to the end.

L: Is it positive or negative for your performance? Why?

V: Neither, I think it is a normal psychological and physical reaction. Because it is always there, but when I was very young, it was more serious than now.

L: Have you ever experienced flow during your music performance? How is it?

V: Sometimes. It normally happened at the middle or end of my performance. At the beginning of my performance, I normally had anxiety, so no flow.

L: How often?

V: It depends, not every time, but I experienced flow in about $70 \%$ of my performances.

L: What factors do you think lead to your flow experience?

V: Focus on the music and performance.

L: Is it positive or negative for your performance? Why?

V: Positive. When I experienced flow, at least, I have no anxiety, and it was a 
happy process.

L: Do you think flow and anxiety are related? What relation?

V: I didn't think about this question before and I didn't pay attention on these two topics too.

L: That's fine, you can think about that slowly.

V: Maybe I think the more anxiety you experienced, the less frequently you experience flow. If you had serious anxiety, like sweating, it would influence your flow experience.

L: Like you said, you had serious anxiety when you were very young. Did you experience flow when you were very young?

V: Never. I just wanted to leave the stage early when I was very, very young.

L: What component(s) of flow here is/are related with anxiety?

1) Clarity of goals and immediate feedback

2) A high level of concentration on a limited field

3) Balance between skills and challenge

4) The feeling of control

5) Effortlessness

6) An altered perception of time

7) The melting together of action and consciousness

8) The autotelic quality of flow-experience

V: "Clear goals" like "I must be the top one". I think if it was too strong, it might increase your anxiety. Other factors will not lead to anxiety.

L: The picture below describes the effects of the skill/challenge balance discussed 
in Csikszentmihalyi's Flow Theory, which includes flow and anxiety. What do you think about this figure?

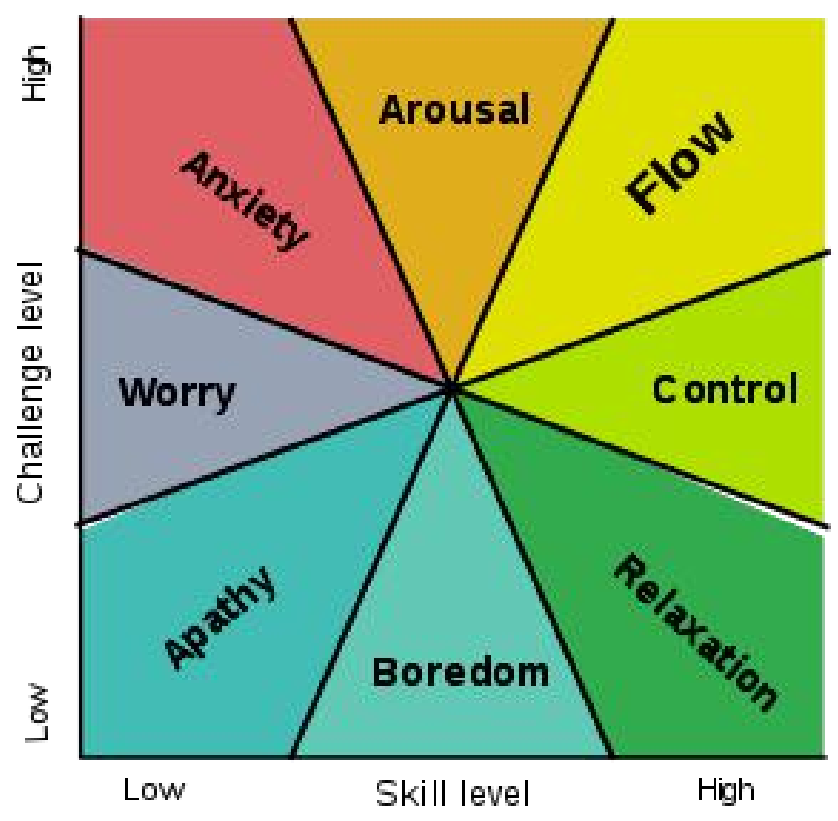

Mental state in terms of challenge level and skill level, according to Csikszentmihalyi's flow model

V: I agree with that, but when skill was high, challenge was not very high. Maybe we can experience flow then, too.

L: Do you think we can use flow theory or flow experience to reduce or overcome music performance anxiety? How?

$\mathrm{V}$ : Yes, the prerequisite for achieving flow is that a performer should have sufficient skills before going on the stage. If their skills are too low, it's impossible to experience flow.

L: Which aspect of flow can we use?

V: Skill and challenge balance, I think. 
L: Do you think these questions are related to my research topic? Do you have any suggestions for this study?

V: Yes. 
Originally from Zibo, ShanDong, China, Li Li earned a Bachelor of Music in Musicology from Hankou University and a Master of Music Education in Music and Dance from Central China Normal University. Ms. Li is an educator and clinician, having worked with students of different ages in the Wuhan of China. As a member of the International Society for Music Education and National Association for Music Education, Ms. Li participated in the Missouri Music Educators Annual In-Service Conferences and presented her study posters three times. She has published several papers in China, including for the Central China Normal University Journal of Postgraduates, China Times, Time and Space in Music, XiJiangyue, and Reading, Writing and ArithmeticQuality Education Forum. Ms. Li won the Chinese Government Scholarship for her Ph.D. study based on her GPA, research, and other performances. 